\title{
Design and structural optimization of dual FXR/PPARס activators
}

Simone Schierle, Sebastian Neumann, Pascal Heitel, Sabine Willems, Astrid Kaiser, Julius Pollinger, Daniel Merk

Goethe University Frankfurt, Institute of Pharmaceutical Chemistry, Max-von-Laue-Str. 9, D-60438 Frankfurt, Germany

- SUPPORTING INFORMATION -

\section{Table of Contents}

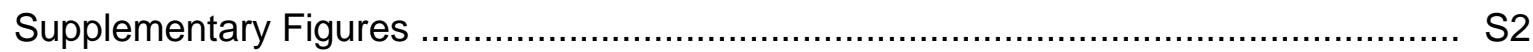

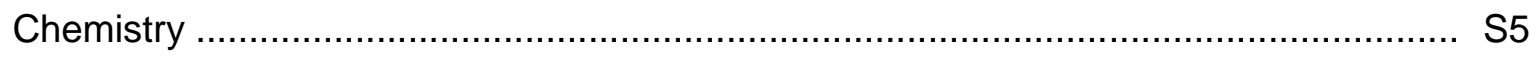

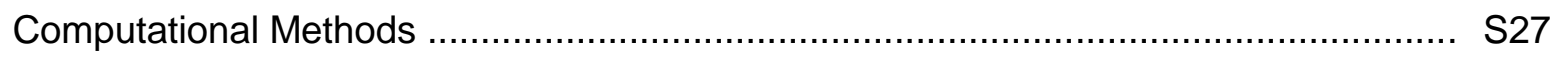

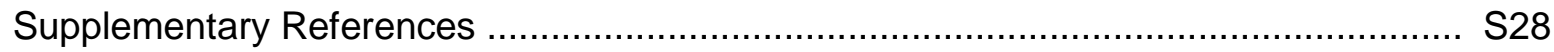




\section{Supplementary Figures}

FXR
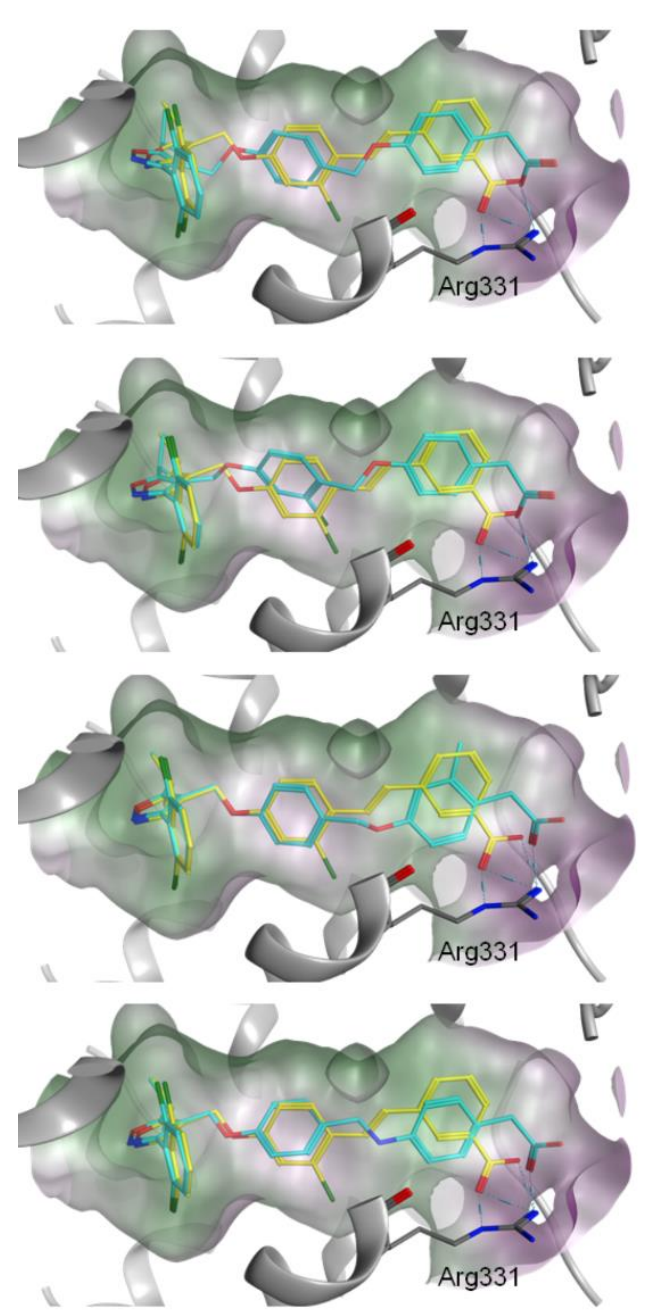

PPARס

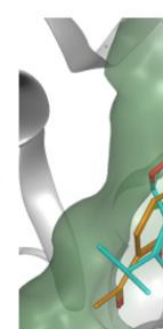

structure

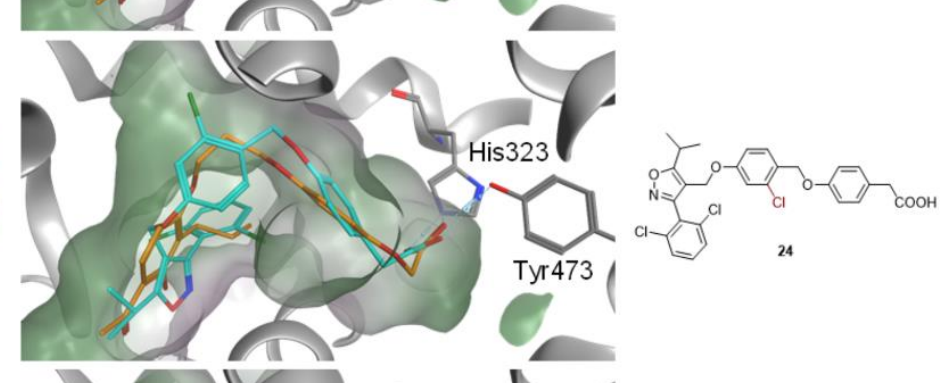

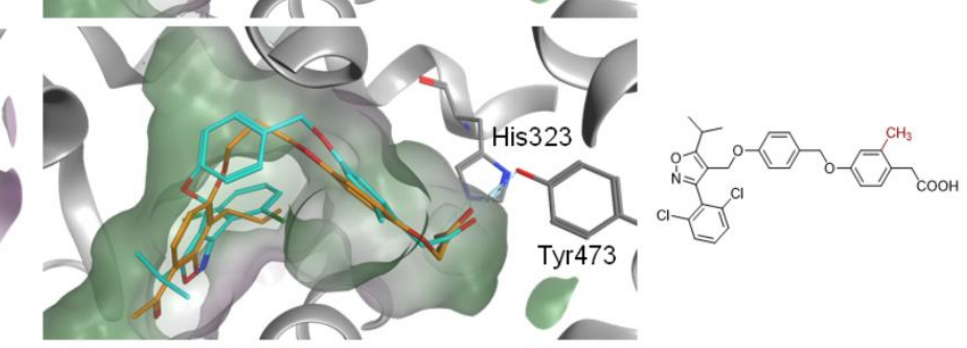

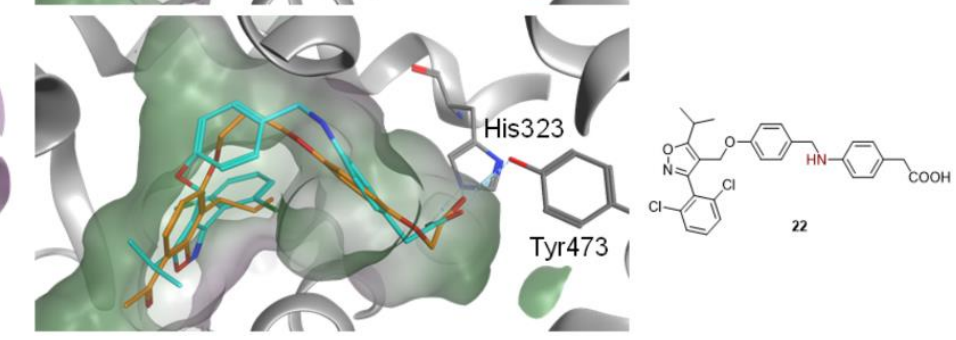

Figure S1. Molecular docking study for structural refinement of dual FXR/PPARס activator 21. Docking was performed for selected analogues (cyan) of $\mathbf{2 1}$ to the ligand binding sites of FXR (PDB-ID: 3DCT ${ }^{1}$ ) and PPARס (PDB-ID: 3D5F). Co-crystallized ligands (FXR: GW4064, 3, yellow; PPARס: L165,041, orange) are shown for comparison. Docking was performed and visualized in MOE. 

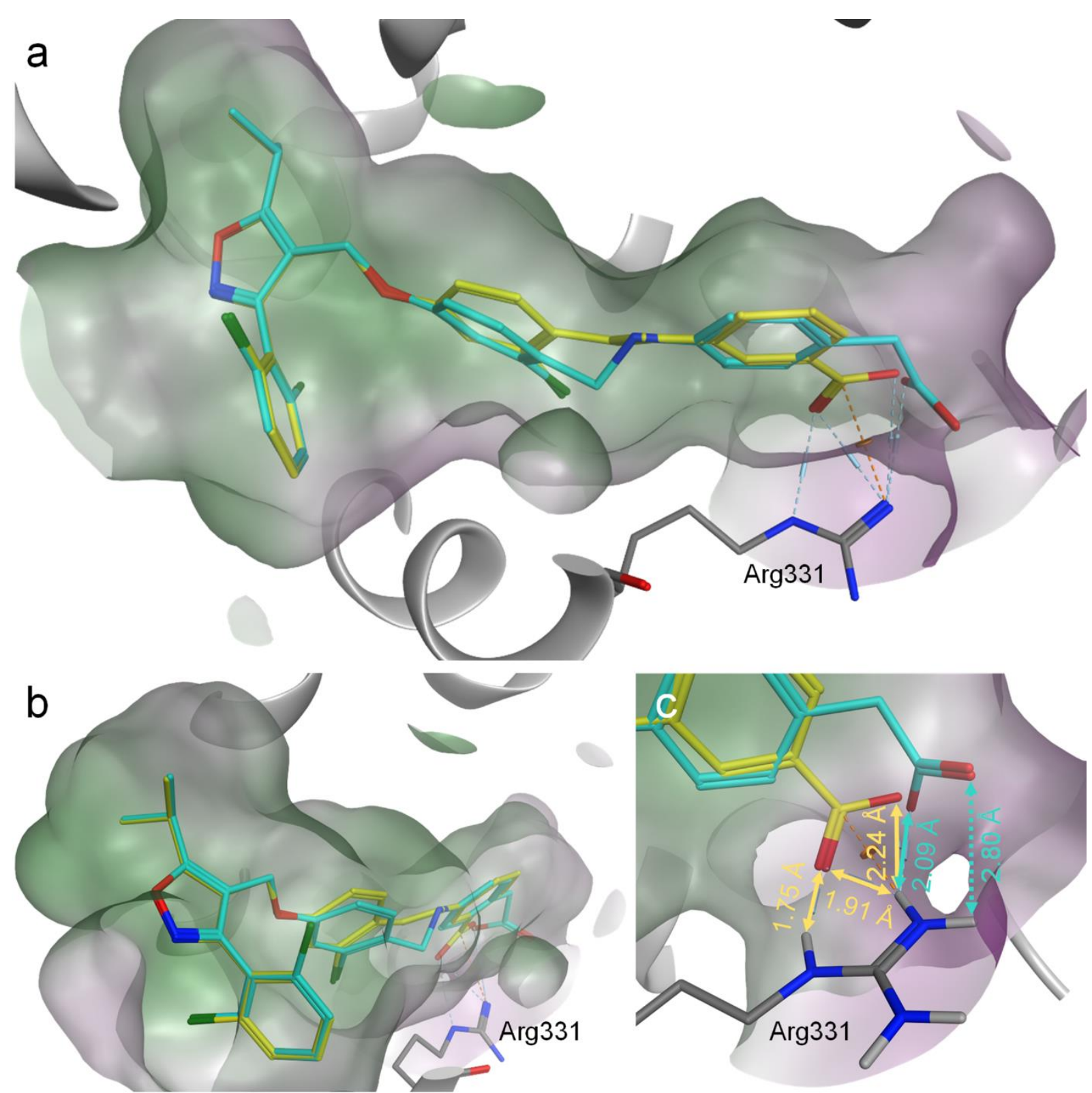

Figure S2. Molecular docking of the dual agonist 25 (cyan) to the FXR ligand binding site (PDB-ID: 3DCT ${ }^{1}$ ). Co-crystalized ligand GW4064 (yellow) for comparison. (a) The extended structure and linear substitution pattern of 25 affect angle and distance between the carboxylate motif and Arg331 likely weakening this key interaction with the FXR ligand binding site. Additionally, 25 adopts a slightly bent conformation to enable contacts with Arg331 despite its extended geometry. (b) The 3-(2,6-dichlorophenyl)-5-isopropylisoxazole moieties of 25 and GW4064 align very well in the predicted binding mode. (c) Distances between the carboxylic acid residues of GW4064 or 25 and Arg331. 

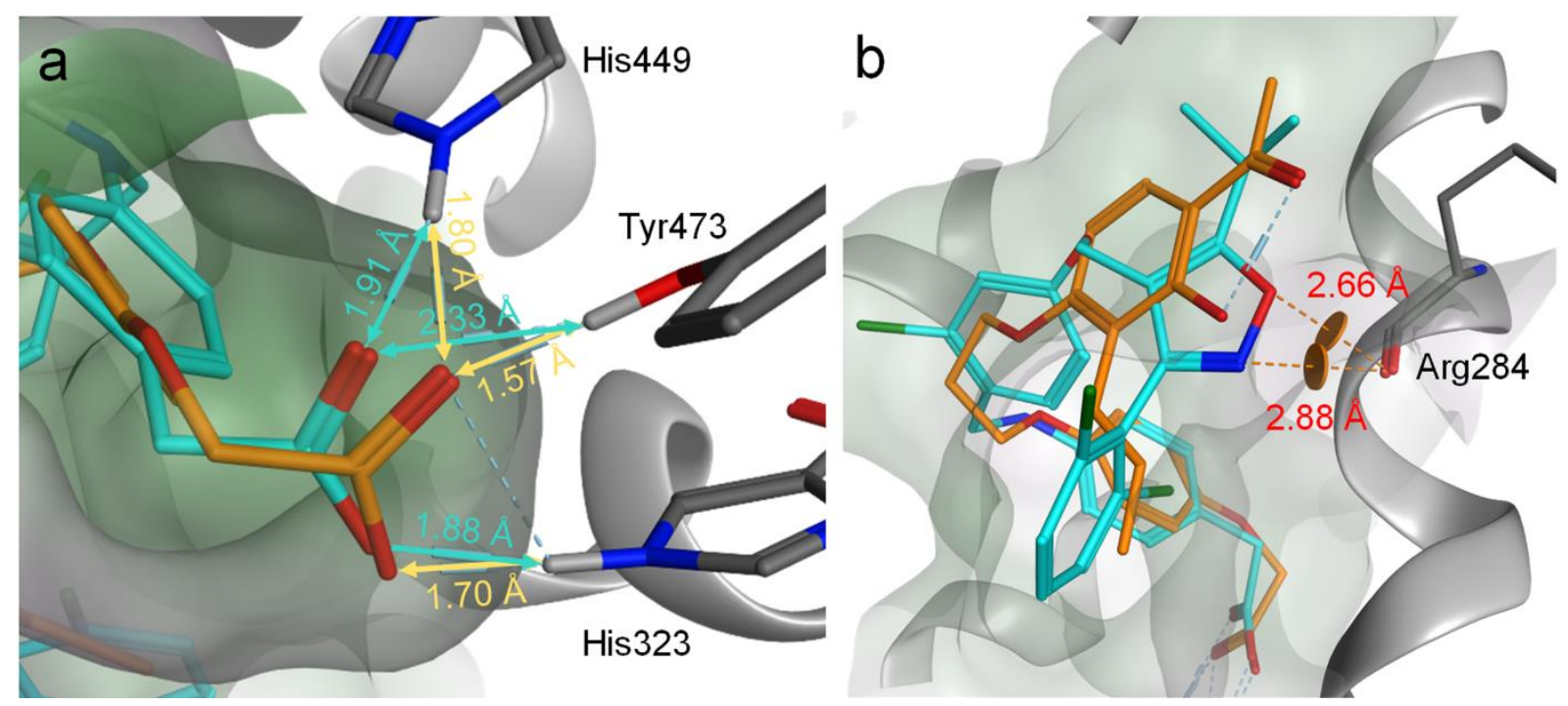

Figure S3. Molecular docking of the dual agonist 25 to the PPARס ligand binding site (PDBID: 3D5F). Co-crystalized ligand L165,041 (orange) for comparison. (a) The carboxylate motif of 25 is favorably positioned to engage polar contacts with the activation triad of His323, His449 and Tyr473. (b) The isoxazole heteroatoms of $\mathbf{2 5}$ form unfavorable contacts with the backbone oxygen of Arg284. 


\section{Chemistry}

General. All chemicals and solvents were of reagent grade and used without further purification unless otherwise specified. All reactions were conducted in oven-dried glassware under argon atmosphere and in absolute solvents. NMR spectra were recorded on a Bruker AV 500, Bruker AV 300 or a Bruker am250xp spectrometer (Bruker Corporation, Billerica, MA, USA). Chemical shifts $(\delta)$ are reported in ppm relative to tetramethylsilane (TMS) as reference. Multiplicity is reported: $s$, singlet; $d$, doublet; $d d$, doublet of doublets; $t$, triplet; hept, heptet; $m$, multiplet. Approximate coupling constants $(\mathcal{J})$ are given in hertz $(\mathrm{Hz})$. Mass spectra were obtained on a VG Platform II (Thermo Fischer Scientific, Inc., Waltham, MA, USA) using electrospray ionization (ESI). High-resolution mass spectra were recorded on a MALDI LTQ ORBITRAP XL instrument (Thermo Fisher Scientific). Compounds were purified by preparative HPLC using a Shimadzu preparative LC-20A Prominence (Shimadzu, Kyoto, Japan) with the following conditions: column, Luna $(10 \mu \mathrm{C} 18(2) 100 \AA \AA$; 250x21.2 mm; Phenomenex, Torrance, CA, U.S.A.); mobile phase, isocratic 50:50 acetonitrile/ $\mathrm{H}_{2} \mathrm{O}+0.1$ formic acid for $30 \mathrm{~min}$ at a flow rate of $21 \mathrm{~mL} / \mathrm{min}$ and UV-detection at $245 \mathrm{~nm}$ and $280 \mathrm{~nm}$. Compound purity was analyzed on a Waters 600 Controller HPLC (Waters, Milford, MA, U.S.A.) equipped with a Waters 2487 Dual Absorbance Detector and a Waters 717 plus Autosampler or on a VWR Chromaster (VWR, Radnor, PA, U.S.A.) equipped with a 5160 pump system, a DAD 5430, a 5260 Autosampler, and a MultoHigh100 RP18-5 $\mu$ 250x4 mm column (CS-Chromatographie Service $\mathrm{GmbH}$, Langerwehe, Germany) using a gradient $\left(\mathrm{H}_{2} \mathrm{O}+0.1 \%\right.$ formic acid/MeOH 80:20 isocratic for $5 \mathrm{~min}$ to $\mathrm{MeOH}$ after additional $45 \mathrm{~min}$ and $\mathrm{MeOH}$ for additional $10 \mathrm{~min}$ ) at a flow rate of 1 $\mathrm{mL} / \mathrm{min}$ or a gradient $\left(\mathrm{H}_{2} \mathrm{O}+0.1 \%\right.$ formic acid/MeOH 60:40 isocratic for 5 min to $\mathrm{MeOH}$ after additional $25 \mathrm{~min}$ and $\mathrm{MeOH}$ for additional $10 \mathrm{~min}$ ) at a flow rate of $1 \mathrm{~mL} / \mathrm{min}$ with UV-detection at $245 \mathrm{~nm}$ and $280 \mathrm{~nm}$. Only compounds with a purity $\geq 95 \%$ according to the AUC at UV 245 $\mathrm{nm}$ and $280 \mathrm{~nm}$ detection were used for biological testing.

\section{$\underline{\text { General procedures }}$}

General procedure A for the synthesis of benzaldehyde oximes 31-35

The respective benzaldehyde (26-30, 1.00 equiv.) was dissolved in ethanol $(0.65 \mathrm{M})$. Hydroxylamine hydrochloride ( 1.15 equiv.) and sodium hydroxide (1.15 equiv.) were dissolved in water $(1.45 \mathrm{M})$. Subsequently, both solutions were combined and stirred at $90^{\circ} \mathrm{C}$ for $12 \mathrm{~h}$. The volume of the reaction mixture was then reduced in vacuo, which induced the precipitation of the product. The product was filtered off, washed with water and dried in vacuo.

General procedure B for the synthesis of phenylhydroximic chlorides $\mathbf{3 6 - 4 0}$

The respective benzaldehyde oxime (31-35, 1 equiv.) was dissolved in DMF (0.35 M). NChlorosuccinimide ( 1 equiv.) was added and the reaction mixture was stirred at $\mathrm{rt}$ for $12 \mathrm{~h}$. Water was then added, and the product was extracted with ethyl acetate $(3 \times 30 \mathrm{~mL})$. The combined organic layers were dried over $\mathrm{MgSO}_{4}$ and the solvents were evaporated in vacuo.

General procedure $\mathbf{C}$ for esterification (67-78)

The respective benzoic acid (55-66, 1 equiv.) was dissolved in ethanol $(0.4 \mathrm{M})$ and concentrated sulfuric acid $(0.25-2.0 \mathrm{~mL})$ was added. The reaction mixture was refluxed for 4$12 \mathrm{~h}$. After cooling to room temperature, ethanol was evaporated in vacuo. Water $(30 \mathrm{~mL})$ was 
added and the product was extracted with methylene chloride (3x $50 \mathrm{~mL})$. The combined organic layers were dried over $\mathrm{MgSO}_{4}$ and the solvent was evaporated in vacuo. Further purification was performed by column chromatography.

General procedure D for the synthesis of isoxazoles 43-48

Methyl isobutyrylacetate (41) or methyl acetoacetate (42) (1 equiv.) was dissolved in THF $(0.4$ M) and was treated under stirring with a solution of sodium methoxide (1.01 equiv., in methanol) followed by a solution of the respective phenylhydroximic chloride (36-40, 1 equiv.) dissolved in THF (0.4 M). The reaction mixture was stirred at rt for $12 \mathrm{~h}$. Water was then added, and the product was extracted with ethyl acetate $(3 \times 30 \mathrm{~mL})$. The combined organic layers were dried over $\mathrm{MgSO}_{4}$ and the solvents were evaporated in vacuo. Further purification was performed by column chromatography.

General procedure $\mathbf{E}$ for reduction of carboxylates to methanol derivatives (49-54, 92-95)

The respective carboxylate $\left(\mathbf{4 3 - 4 8 , 8 8 - 9 1 )}\right.$ was dissolved in THF $(0.2 \mathrm{M})$ and cooled to $0^{\circ} \mathrm{C}$. A solution of diisobutylaluminium hydride (2.1-3.1 equiv., $1 \mathrm{M}$ in toluene) was slowly added. The reaction mixture was allowed to warm to $\mathrm{rt}$ and stirred for $24 \mathrm{~h}$. The reaction mixture was then cooled to $0^{\circ} \mathrm{C}$ again and quenched with methanol $(5 \mathrm{~mL})$ and aqueous sodium hydroxide solution ( $2 \mathrm{M}, 20 \mathrm{~mL}$ ). The suspension was filtered through celite and the filtrate was extracted with ethyl acetate $(3 \times 20 \mathrm{~mL})$. The combined organic layers were washed with saturated sodium chloride solution, dried over $\mathrm{MgSO}_{4}$ and the solvents were evaporated in vacuo. Further purification was performed by column chromatography.

General procedure F for Mitsunobu Reactions (79-91, 96-104, 107-108)

The respective phenol (67-73, 75-78, 1 equiv.), the respective alcohol (49-54, 92-95, 1 equiv.) and triphenylphosphine ( 1 equiv.) were dissolved in methylene chloride $(0.05 \mathrm{M})$. Diisopropylazodicarboxylate ( 1 equiv.) was added dropwise. The reaction mixture was stirred at $\mathrm{rt}$ for $4 \mathrm{~h}$. The solvent was evaporated in vacuo, and the product was purified by column chromatography.

General procedure $\mathbf{G}$ for ester hydrolysis with $\mathrm{LiOH}(\mathbf{5}-25)$

The respective ester $(\mathbf{7 9 - 8 7}, \mathbf{9 6 - 1 0 4}, \mathbf{1 1 0 - 1 1 2}, 1$ equiv.) was dissolved in a mixture of THF $(0.02 \mathrm{M})$ and ethanol $(0.05 \mathrm{M}) . \mathrm{LiOH} \cdot \mathrm{H}_{2} \mathrm{O}$ (5 equiv.) was dissolved in water. Subsequently, both solutions were combined and stirred at $\mathrm{rt}$ for $12 \mathrm{~h}$. The solvents were evaporated in vacuo. Hydrochloric acid (10-20 mL, $10 \%)$ was then added and the aqueous layer was extracted with ethyl acetate $(3 \times 30 \mathrm{~mL})$. The combined organic layers were dried over $\mathrm{MgSO}_{4}$ and the solvents were evaporated in vacuo. Further purification was performed by column chromatography.

\section{Synthesis and analytical characterization of 5-25 and intermediates}

4-(4-((5-Isopropyl-3-phenylisoxazol-4-yl)methoxy)phenyl)butanoic acid (5):

Preparation according to general procedure $\mathrm{G}$ using ethyl 4-(4-((5-isopropyl-3-phenylisoxazol4-yl)methoxy)phenyl)butanoate $\left(79,0.11 \mathrm{~g}, 0.26 \mathrm{mmol}, 1.0\right.$ equiv.) and $\mathrm{LiOH} \cdot \mathrm{H}_{2} \mathrm{O}(55 \mathrm{mg}, 1.3$ mmol, 5.0 equiv.) to yield 5 as a yellow solid (97 mg, 98\%). ${ }^{1} \mathrm{H} \mathrm{NMR}\left(500 \mathrm{MHz}, \mathrm{CDCl}_{3}\right) \delta=7.75$ - $7.69(\mathrm{~m}, 2 \mathrm{H}), 7.46-7.41(\mathrm{~m}, 3 \mathrm{H}), 7.15-7.10(\mathrm{~m}, 2 \mathrm{H}), 6.91-6.86(\mathrm{~m}, 2 \mathrm{H}), 4.82(\mathrm{~s}, 2 \mathrm{H})$, 
3.25 (hept, $J=7.0 \mathrm{~Hz} ; 1 \mathrm{H}$ ), 2.64 (t, $J=7.6 \mathrm{~Hz}, 2 \mathrm{H}$ ), 2.38 (t, $J=7.4 \mathrm{~Hz}, 2 \mathrm{H}), 1.99-1.91$ (m, $2 \mathrm{H}), 1.37(\mathrm{~d}, J=7.0 \mathrm{~Hz}, 6 \mathrm{H}) .{ }^{13} \mathrm{C} \mathrm{NMR}\left(126 \mathrm{MHz}, \mathrm{CDCl}_{3}\right) \delta=178.57,177.57,163.00,156.74$, $134.41,129.80,129.69,129.13,129.01,128.55,115.28,107.89,59.42,34.24,33.16,26.96$, 26.57, 21.03. MS $\left(\mathrm{ESI}^{+}\right): \mathrm{m} / \mathrm{z} 380.21\left([\mathrm{M}+\mathrm{H}]^{+}\right)$. HRMS $\left(\mathrm{MALDI}^{+}\right): \mathrm{m} / z$ calc. for $\mathrm{C}_{23} \mathrm{H}_{26} \mathrm{NO}_{4}$ 380.18563 , found $380.18567\left([\mathrm{M}+\mathrm{H}]^{+}\right)$.

5-(4-((5-Isopropyl-3-phenylisoxazol-4-yl)methoxy)phenyl)pentanoic acid (6):

Preparation according to general procedure $\mathrm{G}$ using ethyl 5-(4-((5-isopropyl-3-phenylisoxazol4-yl)methoxy)phenyl)pentanoate (80, $0.17 \mathrm{~g}, 0.41 \mathrm{mmol}, 1.0$ equiv.) and $\mathrm{LiOH} \cdot \mathrm{H}_{2} \mathrm{O}$ (86 mg, $2.0 \mathrm{mmol}, 5.0$ equiv.) to yield 6 as a yellow solid $(0.15 \mathrm{~g}, 91 \%) .{ }^{1} \mathrm{H} \mathrm{NMR}\left(500 \mathrm{MHz}, \mathrm{CDCl}_{3}\right) \delta$ $=7.74-7.70(\mathrm{~m}, 2 \mathrm{H}), 7.45-7.41(\mathrm{~m}, 3 \mathrm{H}), 7.11(\mathrm{~d}, J=8.5 \mathrm{~Hz}, 2 \mathrm{H}), 6.88(\mathrm{~d}, J=8.5 \mathrm{~Hz}, 2 \mathrm{H})$, $4.82(\mathrm{~s}, 2 \mathrm{H}), 3.31-3.20(\mathrm{~m}, 1 \mathrm{H}), 2.60(\mathrm{t}, J=7.0 \mathrm{~Hz}, 2 \mathrm{H}), 2.39(\mathrm{t}, J=6.9 \mathrm{~Hz}, 2 \mathrm{H}), 1.71-1.63$ $(\mathrm{m}, 4 \mathrm{H}), 1.37(\mathrm{~d}, J=7.0 \mathrm{~Hz}, 6 \mathrm{H}) .{ }^{13} \mathrm{C} \mathrm{NMR}\left(126 \mathrm{MHz}, \mathrm{CDCl}_{3}\right) \delta=178.47,177.57,163.00$, 156.57, 135.23, 129.79, 129.56, 129.15, 129.01, 128.56, 115.21, 107.92, 59.41, 34.79, 33.76, 31.12, 26.96, 24.37, 21.03. MS (ESI): $m / z 392.32$ ([M-H] $)^{-}$. HRMS (MALDI $\left.{ }^{+}\right): m / z$ calc. for $\mathrm{C}_{24} \mathrm{H}_{28} \mathrm{NO}_{4}$ 394.20128, found $394.20132\left([\mathrm{M}+\mathrm{H}]^{+}\right)$.

6-(4-((5-Isopropyl-3-phenylisoxazol-4-yl)methoxy)phenyl)hexanoic acid (7):

Preparation according to general procedure $\mathrm{G}$ using ethyl 6-(4-((5-isopropyl-3-phenylisoxazol4-yl)methoxy)phenyl)hexanoate (81, $0.15 \mathrm{~g}, 0.35 \mathrm{mmol}, 1.0$ equiv.) and $\mathrm{LiOH} \cdot \mathrm{H}_{2} \mathrm{O}$ (73 mg, 1.7 mmol, 5.0 equiv.) to yield 7 as a brown solid (125 mg, 87\%). ${ }^{1} \mathrm{H} \mathrm{NMR}\left(500 \mathrm{MHz}, \mathrm{CDCl}_{3}\right) \delta=$ $7.74-7.70(\mathrm{~m}, 2 \mathrm{H}), 7.45-7.41(\mathrm{~m}, 3 \mathrm{H}), 7.11(\mathrm{~d}, J=8.5 \mathrm{~Hz}, 2 \mathrm{H}), 6.90-6.86(\mathrm{~m}, 2 \mathrm{H}), 4.82$ (s, 2H), $3.29-3.20(\mathrm{~m}, 1 \mathrm{H}), 2.60-2.55(\mathrm{~m}, 2 \mathrm{H}), 2.36(\mathrm{t}, J=7.5 \mathrm{~Hz}, 2 \mathrm{H}), 1.71-1.59(\mathrm{~m}, 4 \mathrm{H})$, $1.43-1.35(\mathrm{~m}, 8 \mathrm{H}) .{ }^{13} \mathrm{C} \mathrm{NMR}\left(126 \mathrm{MHz}, \mathrm{CDCl}_{3}\right) \delta=179.06,177.56,163.00,156.48,135.70$, 129.79, 129.54, 129.14, 129.01, 128.56, 115.18, 107.94, 59.42, 34.94, 33.93, 31.44, 28.77, 26.95, 24.66, 21.03. MS (ESI $): m / z 406.35\left([\mathrm{M}-\mathrm{H}]^{-}\right)$. HRMS (MALDI $\left.{ }^{+}\right): m / z$ calc. for $\mathrm{C}_{25} \mathrm{H}_{30} \mathrm{NO}_{4}$ 408.21693, found $408.21717\left([\mathrm{M}+\mathrm{H}]^{+}\right)$.

4-(4-((5-Isopropyl-3-phenylisoxazol-4-yl)methoxy)phenoxy)benzoic acid (8):

Preparation according to general procedure $\mathrm{G}$ using ethyl 4-(4-((5-isopropyl-3-phenylisoxazol4-yl)methoxy)phenoxy)benzoate (82, $0.23 \mathrm{~g}, 0.51 \mathrm{mmol}, 1.0$ equiv.) and $\mathrm{LiOH} \cdot \mathrm{H}_{2} \mathrm{O}(0.11 \mathrm{~g}, 2.6$ mmol, 5.0 equiv.) to yield 8 as a yellow solid $(0.20 \mathrm{~g}, 90 \%) .{ }^{1} \mathrm{H} \mathrm{NMR}\left(500 \mathrm{MHz}, \mathrm{CDCl}_{3}\right) \delta=$ $8.06(\mathrm{~d}, J=8.8 \mathrm{~Hz}, 2 \mathrm{H}), 7.74-7.70(\mathrm{~m}, 2 \mathrm{H}), 7.48-7.43(\mathrm{~m}, 3 \mathrm{H}), 7.08-7.02(\mathrm{~m}, 2 \mathrm{H}), 7.01-$ 6.95 (m, 4H), 4.86 (s, 2H), 3.29 (hept, $J=7.0 \mathrm{~Hz}, 1 \mathrm{H}), 1.41$ (d, $J=7.0 \mathrm{~Hz}, 6 \mathrm{H}) .{ }^{13} \mathrm{C}$ NMR $(126$ $\mathrm{MHz}$, DMSO) $\delta=177.16,166.80,162.22,161.88,154.93,148.70,131.63,129.96,129.08$, 128.61, 127.99, 124.74, 121.67, 116.79, 116.31, 107.81, 59.35, 25.82, 20.74. MS (ESI) : $\mathrm{m} / \mathrm{z}$ $428.33\left([\mathrm{M}-\mathrm{H}]^{-}\right)$. HRMS (MALDI $\left.{ }^{+}\right): \mathrm{m} / z$ calc. for $\mathrm{C}_{26} \mathrm{H}_{24} \mathrm{NO}_{5} 430.16490$, found 430.16532 $\left([\mathrm{M}+\mathrm{H}]^{+}\right)$.

4-((4-((5-Isopropyl-3-phenylisoxazol-4-yl)methoxy)benzyl)oxy)benzoic acid (9):

Preparation according to general procedure G using ethyl 4-((4-((5-isopropyl-3phenylisoxazol-4-yl)methoxy)benzyl)oxy)benzoate (96, $0.11 \mathrm{~g}, 0.23 \mathrm{mmol}, 1.0$ equiv.) and $\mathrm{LiOH} \cdot \mathrm{H}_{2} \mathrm{O}$ (58 mg, $1.4 \mathrm{mmol}, 6.0$ equiv.) to yield 9 as a colorless solid $(0.10 \mathrm{~g}, 98 \%) .{ }^{1} \mathrm{H} \mathrm{NMR}$ $\left(500 \mathrm{MHz}, \mathrm{CDCl}_{3}\right) \delta=8.07(\mathrm{~d}, J=8.7 \mathrm{~Hz}, 2 \mathrm{H}), 7.73-7.68(\mathrm{~m}, 2 \mathrm{H}), 7.46-7.37(\mathrm{~m}, 5 \mathrm{H}), 7.04$ - $6.97(\mathrm{~m}, 4 \mathrm{H}), 5.08(\mathrm{~s}, 2 \mathrm{H}), 4.86(\mathrm{~s}, 2 \mathrm{H}), 3.27$ (hept, $J=7.0 \mathrm{~Hz}, 1 \mathrm{H}), 1.39(\mathrm{~d}, J=7.0 \mathrm{~Hz}, 6 \mathrm{H})$. ${ }^{13} \mathrm{C}$ NMR $\left(126 \mathrm{MHz}, \mathrm{CDCl}_{3}\right) \delta=177.66,171.16,163.31,163.00,158.43,132.53,129.86$, 
129.58, 129.18, 129.07, 129.05, 128.53, 121.93, 115.34, 114.72, 107.67, 70.01, 59.37, 27.01, 21.04. MS (ESI $\left.{ }^{+}\right): m / z 466.25\left([\mathrm{M}+\mathrm{Na}]^{+}\right)$. HRMS $\left(\mathrm{MALDI}^{+}\right): \mathrm{m} / z$ calc. for $\mathrm{C}_{27} \mathrm{H}_{26} \mathrm{NO}_{5} 444.18055$, found $444.17846\left([\mathrm{M}+\mathrm{H}]^{+}\right)$.

2-(4-((4-((5-Isopropyl-3-phenylisoxazol-4-yl)methoxy)benzyl)oxy)phenyl)acetic acid (10):

Preparation according to general procedure $G$ using ethyl 2-(4-((4-((5-isopropyl-3phenylisoxazol-4-yl)methoxy)benzyl)oxy)phenyl)acetate (97, $75 \mathrm{mg}, 0.15 \mathrm{mmol}, 1.0$ equiv.) and $\mathrm{LiOH} \cdot \mathrm{H}_{2} \mathrm{O}$ (31 mg, $0.75 \mathrm{mmol}, 5.0$ equiv.) to yield 10 as a yellow solid $(68 \mathrm{mg}, 94 \%) .{ }^{1} \mathrm{H}$ $\operatorname{NMR}\left(500 \mathrm{MHz}, \mathrm{CDCl}_{3}\right) \delta=7.73-7.67(\mathrm{~m}, 2 \mathrm{H}), 7.47-7.35(\mathrm{~m}, 5 \mathrm{H}), 7.21(\mathrm{~d}, J=8.6 \mathrm{~Hz}, 2 \mathrm{H})$, $6.99-6.92(\mathrm{~m}, 4 \mathrm{H}), 4.99(\mathrm{~s}, 2 \mathrm{H}), 4.85(\mathrm{~s}, 2 \mathrm{H}), 3.60(\mathrm{~s}, 2 \mathrm{H}), 3.26$ (hept, $J=7.0 \mathrm{~Hz}, 1 \mathrm{H}), 1.38$ $(\mathrm{d}, J=7.0 \mathrm{~Hz}, 6 \mathrm{H}) .{ }^{13} \mathrm{C} \mathrm{NMR}\left(126 \mathrm{MHz}, \mathrm{CDCl}_{3}\right) \delta=177.65,176.97,163.00,158.24,158.23$, 130.59, 130.01, 129.85, 129.48, 129.07, 129.04, 128.53, 125.76, 115.26, 115.13, 107.73, 69.83, 59.35, 40.11, 27.00, 21.03. MS (ESI $\left.{ }^{+}\right): m / z 480.10\left(\left[\mathrm{M}+\mathrm{Na}^{+}\right)\right.$. HRMS (MALDI $\left.{ }^{+}\right): \mathrm{m} / \mathrm{z}$ calc. for $\mathrm{C}_{28} \mathrm{H}_{27} \mathrm{NO}_{5} \mathrm{Na} 480.17814$, found $480.17830\left([\mathrm{M}+\mathrm{Na}]^{+}\right)$.

3-(4-((4-((5-Isopropyl-3-phenylisoxazol-4-yl)methoxy)benzyl)oxy)phenyl)propanoic acid (11): Preparation according to general procedure $G$ using ethyl 3-(4-((4-((5-isopropyl-3phenylisoxazol-4-yl)methoxy)benzyl)oxy)phenyl)propanoate $(98,0.11 \mathrm{~g}, 0.21 \mathrm{mmol}, 1.0$ equiv.) and $\mathrm{LiOH} \cdot \mathrm{H}_{2} \mathrm{O}(44 \mathrm{mg}, 1.1 \mathrm{mmol}, 5.0$ equiv.). The crude product was purified by column chromatography using EtOAc/hexane $(4: 1+2 \% \mathrm{HOAc})$ to obtain 11 as a colorless solid $(20 \mathrm{mg}$, 20\%). ${ }^{1} \mathrm{H}$ NMR $\left(500 \mathrm{MHz}, \mathrm{CDCl}_{3}\right) \delta=7.73-7.68(\mathrm{~m}, 2 \mathrm{H}), 7.47-7.41(\mathrm{~m}, 3 \mathrm{H}), 7.38(\mathrm{~d}, J=8.6$ $\mathrm{Hz}, 2 \mathrm{H}), 7.14(\mathrm{~d}, J=8.6 \mathrm{~Hz}, 2 \mathrm{H}), 6.99-6.95(\mathrm{~m}, 2 \mathrm{H}), 6.93-6.89(\mathrm{~m}, 2 \mathrm{H}), 4.98(\mathrm{~s}, 2 \mathrm{H}), 4.85$ $(\mathrm{s}, 2 \mathrm{H}), 3.31-3.22(\mathrm{~m}, 1 \mathrm{H}), 2.91(\mathrm{t}, J=7.7 \mathrm{~Hz}, 2 \mathrm{H}), 2.66(\mathrm{t}, J=7.8 \mathrm{~Hz}, 2 \mathrm{H}), 1.39(\mathrm{~d}, J=7.0$ $\mathrm{Hz}, 6 \mathrm{H}) .{ }^{13} \mathrm{C} \mathrm{NMR}\left(126 \mathrm{MHz}, \mathrm{CDCl}_{3}\right) \delta=178.15,177.64,163.00,158.21,157.51,132.68$, 130.16, 129.85, 129.48, 129.42, 129.07, 129.04, 128.53, 115.25, 115.02, 107.74, 69.83, 59.34, 35.86, 29.93, 27.00, 21.03. MS (ESI $\left.{ }^{+}\right): m / z 494.22\left([\mathrm{M}+\mathrm{Na}]^{+}\right)$. HRMS (MALDI $\left.{ }^{+}\right): m / z$ calc. for $\mathrm{C}_{29} \mathrm{H}_{29} \mathrm{NO}_{5} \mathrm{Na}$ 494.19379, found $494.19378\left([\mathrm{M}+\mathrm{Na}]^{+}\right)$.

3-((4-((5-Isopropyl-3-phenylisoxazol-4-yl)methoxy)benzyl)oxy)benzoic acid (12):

Preparation according to general procedure $G$ using ethyl 3-((4-((5-isopropyl-3phenylisoxazol-4-yl)methoxy)benzyl)oxy)benzoate (99, $54 \mathrm{mg}, 0.11 \mathrm{mmol}, 1.0$ equiv.) and $\mathrm{LiOH} \cdot \mathrm{H}_{2} \mathrm{O}$ (23 mg, $0.55 \mathrm{mmol}, 5.0$ equiv.) to yield 12 as a yellow solid (48 mg, 98\%). ${ }^{1} \mathrm{H} \mathrm{NMR}$ $\left(500 \mathrm{MHz}, \mathrm{CDCl}_{3}\right) \delta=7.74-7.68(\mathrm{~m}, 4 \mathrm{H}), 7.46-7.37(\mathrm{~m}, 6 \mathrm{H}), 7.24-7.21(\mathrm{~m}, 1 \mathrm{H}), 7.00-$ 6.97 (m, 2H), 5.07 (s, 2H), 4.86 (s, 2H), 3.27 (hept, $J=7.0 \mathrm{~Hz}, 1 \mathrm{H}$ ), 1.39 (d, $J=7.0 \mathrm{~Hz}, 6 \mathrm{H}$ ). ${ }^{13} \mathrm{C}$ NMR $\left(126 \mathrm{MHz}, \mathrm{CDCl}_{3}\right) \delta=177.66,171.11,163.01,158.91,158.36,130.63,129.86$, 129.76, 129.61, 129.53, 129.07, 129.05, 128.53, 123.05, 121.35, 115.52, 115.31, 107.71, 70.03, 59.37, 27.00, 21.03. MS (ESI $\left.{ }^{+}\right): m / z 466.19\left([\mathrm{M}+\mathrm{Naa}]^{+}\right)$. HRMS (MALDI $\left.{ }^{+}\right): m / z$ calc. for $\mathrm{C}_{27} \mathrm{H}_{26} \mathrm{NO}_{5} 444.18055$, found $444.17965\left([\mathrm{M}+\mathrm{H}]^{+}\right)$.

4-(4-((5-Methyl-3-phenylisoxazol-4-yl)methoxy)phenyl)butanoic acid (13):

Preparation according to general procedure $\mathrm{G}$ using ethyl 4-(4-((5-methyl-3-phenylisoxazol-4yl)methoxy)phenyl)butanoate $\left(83,0.23 \mathrm{~g}, 0.61 \mathrm{mmol}, 1.0\right.$ equiv.) and $\mathrm{LiOH} \cdot \mathrm{H}_{2} \mathrm{O}(0.13 \mathrm{~g}, 3.1$ $\mathrm{mmol}, 5.0$ equiv.). The crude product was purified by column chromatography using EtOAc/hexane $(3: 1+2 \% \mathrm{HOAc})$ as mobile phase to obtain 13 as a yellow solid $(33 \mathrm{mg}, 15 \%)$. ${ }^{1} \mathrm{H} \mathrm{NMR}\left(500 \mathrm{MHz}, \mathrm{CDCl}_{3}\right) \delta=7.75-7.70(\mathrm{~m}, 2 \mathrm{H}), 7.46-7.41(\mathrm{~m}, 3 \mathrm{H}), 7.13(\mathrm{~d}, J=8.5 \mathrm{~Hz}$, 2H), $6.91-6.86(\mathrm{~m}, 2 \mathrm{H}), 4.83(\mathrm{~s}, 2 \mathrm{H}), 2.64(\mathrm{t}, J=7.6 \mathrm{~Hz}, 2 \mathrm{H}), 2.49(\mathrm{~s}, 3 \mathrm{H}), 2.38(\mathrm{t}, J=7.4 \mathrm{~Hz}$, 
$2 \mathrm{H}), 2.00-1.91(\mathrm{~m}, 2 \mathrm{H}) .{ }^{13} \mathrm{C}$ NMR $\left(126 \mathrm{MHz}, \mathrm{CDCl}_{3}\right) \delta=178.49,169.79,162.92,156.70$, 134.47, 129.88, 129.72, 129.08, 129.05, 128.45, 115.25, 109.78, 59.75, 34.24, 33.14, 26.56, 11.51. MS $\left(\mathrm{ESI}^{+}\right): \mathrm{m} / z 374.13\left([\mathrm{M}+\mathrm{Na}]^{+}\right)$. HRMS $\left(\mathrm{MALDI}^{+}\right): \mathrm{m} / z$ calc. for $\mathrm{C}_{21} \mathrm{H}_{22} \mathrm{NO}_{4} 352.15433$, found $352.15451\left([\mathrm{M}+\mathrm{H}]^{+}\right)$.

4-(4-((3-(2-Chlorophenyl)-5-isopropylisoxazol-4-yl)methoxy)phenyl)butanoic acid (14):

Preparation according to general procedure G using ethyl 4-(4-((3-(2-chlorophenyl)-5isopropylisoxazol-4-yl)methoxy)phenyl)butanoate $(\mathbf{8 4}, 0.12 \mathrm{~g}, 0.27 \mathrm{mmol}, 1.0$ equiv.) and $\mathrm{LiOH} \cdot \mathrm{H}_{2} \mathrm{O}$ (57 mg, $1.4 \mathrm{mmol}, 5.0$ equiv.) to yield 14 as a yellow oil $(0.11 \mathrm{~g}, 98 \%) .{ }^{1} \mathrm{H}$ NMR (500 $\left.\mathrm{MHz}, \mathrm{CDCl}_{3}\right) \delta=7.50-7.44(\mathrm{~m}, 2 \mathrm{H}), 7.39(\mathrm{td}, J=7.7,1.8 \mathrm{~Hz}, 1 \mathrm{H}), 7.33(\mathrm{td}, J=7.5,1.2 \mathrm{~Hz}$, $1 \mathrm{H}), 7.03(\mathrm{~d}, J=8.6 \mathrm{~Hz}, 2 \mathrm{H}), 6.73-6.68(\mathrm{~m}, 2 \mathrm{H}), 4.75(\mathrm{~s}, 2 \mathrm{H}), 3.31$ (hept, $J=7.0 \mathrm{~Hz}, 1 \mathrm{H}$ ), $2.58(\mathrm{t}, J=7.6 \mathrm{~Hz}, 2 \mathrm{H}), 2.34(\mathrm{t}, J=7.4 \mathrm{~Hz}, 2 \mathrm{H}), 1.95-1.86(\mathrm{~m}, 2 \mathrm{H}), 1.40(\mathrm{~d}, J=7.0 \mathrm{~Hz}, 6 \mathrm{H})$. ${ }^{13} \mathrm{C}$ NMR $\left(126 \mathrm{MHz}, \mathrm{CDCl}_{3}\right) \delta=179.33,176.77,161.39,156.66,134.11,133.66,131.99$, 131.04, 129.98, 129.52, 128.51, 127.05, 114.98, 109.61, 59.75, 34.18, 33.25, 27.21, 26.52, 20.88. MS $\left(\mathrm{ESI}^{+}\right): \mathrm{m} / \mathrm{z} 436.17\left([\mathrm{M}+\mathrm{Na}]^{+}\right)$. HRMS $\left(\mathrm{MALDI}^{+}\right): \mathrm{m} / z$ calc. for $\mathrm{C}_{23} \mathrm{H}_{24} \mathrm{CINO}_{4} \mathrm{~K}$ 452.10254, found $452.10232\left([\mathrm{M}+\mathrm{K}]^{+}\right)$.

4-(4-((5-Isopropyl-3-(2-(trifluoromethyl)phenyl)isoxazol-4-yl)methoxy)phenyl)butanoic acid (15):

Preparation according to general procedure $G$ using ethyl 4-(4-((5-isopropyl-3-(2(trifluoromethyl)phenyl)isoxazol-4-yl)methoxy)phenyl)butanoate $(85,0.14 \mathrm{~g}, 0.30 \mathrm{mmol}, 1.0$ equiv.) and $\mathrm{LiOH} \cdot \mathrm{H}_{2} \mathrm{O}(63 \mathrm{mg}, 1.5 \mathrm{mmol}, 5.0$ equiv.) to yield 15 as a yellow oil $(0.13 \mathrm{~g}, 97 \%)$. ${ }^{1} \mathrm{H} \mathrm{NMR}\left(500 \mathrm{MHz}, \mathrm{CDCl}_{3}\right) \delta=7.80-7.76(\mathrm{~m}, 1 \mathrm{H}), 7.61-7.54(\mathrm{~m}, 2 \mathrm{H}), 7.50-7.46(\mathrm{~m}, 1 \mathrm{H})$, $7.04(\mathrm{~d}, J=8.6 \mathrm{~Hz}, 2 \mathrm{H}), 6.73-6.69(\mathrm{~m}, 2 \mathrm{H}), 4.62(\mathrm{~s}, 2 \mathrm{H}), 3.36-3.23(\mathrm{~m}, 1 \mathrm{H}), 2.58(\mathrm{t}, J=7.6$ $\mathrm{Hz}, 2 \mathrm{H}), 2.34(\mathrm{t}, J=7.4 \mathrm{~Hz}, 2 \mathrm{H}), 1.96-1.85(\mathrm{~m}, 2 \mathrm{H}), 1.40(\mathrm{~d}, J=7.0 \mathrm{~Hz}, 6 \mathrm{H}) .{ }^{13} \mathrm{C}$ NMR $(126$ $\left.\mathrm{MHz}, \mathrm{CDCl}_{3}\right) \delta=179.07,176.48,161.46,156.69,134.18,132.21,131.71,129.98,129.80$, 129.54, 127.52, 126.60, 123.73, 114.95, 109.72, 59.22, 34.17, 33.20, 27.11, 26.53, 20.93. MS $\left(\mathrm{ESI}^{+}\right): \mathrm{m} / z 470.20\left([\mathrm{M}+\mathrm{Na}]^{+}\right)$. HRMS (MALDI $\left.{ }^{+}\right): \mathrm{m} / z$ calc. for $\mathrm{C}_{24} \mathrm{H}_{25} \mathrm{~F}_{3} \mathrm{NO}_{4} 448.17302$, found $448.17272\left([\mathrm{M}+\mathrm{H}]^{+}\right)$.

4-(4-((3-(2,6-Dichlorophenyl)-5-isopropylisoxazol-4-yl)methoxy)phenyl)butanoic acid (16):

Preparation according to general procedure G using ethyl 4-(4-((3-(2,6-dichlorophenyl)-5isopropylisoxazol-4-yl)methoxy)phenyl)butanoate $(86,0.15 \mathrm{~g}, 0.31 \mathrm{mmol}, 1.0$ equiv.) and $\mathrm{LiOH} \cdot \mathrm{H}_{2} \mathrm{O}$ (67 mg, $1.6 \mathrm{mmol}, 5.0$ equiv.) to yield 16 as a yellow oil $(0.12 \mathrm{~g}, 86 \%) .{ }^{1} \mathrm{H}$ NMR (500 $\left.\mathrm{MHz}, \mathrm{CDCl}_{3}\right) \delta=7.41-7.38(\mathrm{~m}, 2 \mathrm{H}), 7.34-7.29(\mathrm{~m}, 1 \mathrm{H}), 7.02(\mathrm{~d}, J=8.5 \mathrm{~Hz}, 2 \mathrm{H}), 6.70(\mathrm{~d}, J$ $=8.5 \mathrm{~Hz}, 2 \mathrm{H}), 4.69(\mathrm{~s}, 2 \mathrm{H}), 3.37-3.26(\mathrm{~m}, 1 \mathrm{H}), 2.58(\mathrm{t}, J=7.6 \mathrm{~Hz}, 2 \mathrm{H}), 2.33(\mathrm{t}, J=7.4 \mathrm{~Hz}$, $2 \mathrm{H}), 1.94-1.85(\mathrm{~m}, 2 \mathrm{H}), 1.40(\mathrm{~d}, J=7.0 \mathrm{~Hz}, 6 \mathrm{H}) .{ }^{13} \mathrm{C} \mathrm{NMR}\left(126 \mathrm{MHz}, \mathrm{CDCl}_{3}\right) \delta=179.02$, $176.50,159.28,156.73,135.97,134.09,131.32,129.48,128.22,128.06,114.97,109.67$, 59.54, 34.18, 33.20, 27.22, 26.54, 20.92. MS (ESI) : $\mathrm{m} / \mathrm{z} 446.26\left([\mathrm{M}-\mathrm{H}]^{-}\right)$. HRMS (MALDI $\left.{ }^{+}\right): \mathrm{m} / \mathrm{z}$ calc. for $\mathrm{C}_{23} \mathrm{H}_{24} \mathrm{Cl}_{2} \mathrm{NO}_{4} 448.10769$, found $448.10593\left([\mathrm{M}+\mathrm{H}]^{+}\right)$.

4-(4-((3-(2,6-Dimethylphenyl)-5-isopropylisoxazol-4-yl)methoxy)phenyl)butanoic acid (17):

Preparation according to general procedure $G$ using ethyl 4-(4-((3-(2,6-dimethylphenyl)-5isopropylisoxazol-4-yl)methoxy)phenyl)butanoate (87, $84 \mathrm{mg}, 0.19 \mathrm{mmol}, 1.0$ equiv.) and $\mathrm{LiOH} \cdot \mathrm{H}_{2} \mathrm{O}$ (40 mg, $0.95 \mathrm{mmol}, 5.0$ equiv.) to yield 17 as a yellow oil (72 mg, 94\%). ${ }^{1} \mathrm{H} \mathrm{NMR}$ $\left(500 \mathrm{MHz}, \mathrm{CDCl}_{3}\right) \delta=7.20(\mathrm{t}, J=7.6 \mathrm{~Hz}, 1 \mathrm{H}), 7.07(\mathrm{~d}, J=7.6 \mathrm{~Hz}, 2 \mathrm{H}), 7.02(\mathrm{~d}, J=8.5 \mathrm{~Hz}$, 
$2 \mathrm{H}), 6.69(\mathrm{~d}, J=8.5 \mathrm{~Hz}, 2 \mathrm{H}), 4.53(\mathrm{~s}, 2 \mathrm{H}), 3.36-3.26(\mathrm{~m}, 1 \mathrm{H}), 2.57(\mathrm{t}, J=7.5 \mathrm{~Hz}, 2 \mathrm{H}), 2.33$ (t, $J=7.4 \mathrm{~Hz}, 2 \mathrm{H}), 2.12(\mathrm{~s}, 6 \mathrm{H}), 1.93-1.85(\mathrm{~m}, 2 \mathrm{H}), 1.41(\mathrm{~d}, J=7.0 \mathrm{~Hz}, 6 \mathrm{H}) .{ }^{13} \mathrm{C}$ NMR $(126$ $\left.\mathrm{MHz}, \mathrm{CDCl}_{3}\right) \delta=178.41,176.95,162.66,156.87,137.85,134.03,129.50,129.27,128.09$, $\left.127.50,114.84,109.06,59.28,34.18,33.15,27.29,26.58,20.97,20.18 . \mathrm{MS}_{(\mathrm{ESI}}{ }^{+}\right): \mathrm{m} / \mathrm{z}$ $430.25\left([\mathrm{M}+\mathrm{Na}]^{+}\right)$. HRMS (MALDI $\left.{ }^{+}\right): \mathrm{m} / z$ calc. for $\mathrm{C}_{25} \mathrm{H}_{30} \mathrm{NO}_{4} 408.21693$, found 408.21702 $\left([\mathrm{M}+\mathrm{H}]^{+}\right)$.

2-(4-((4-((3-(2-Chlorophenyl)-5-isopropylisoxazol-4-yl)methoxy)benzyl)oxy)phenyl)acetic acid (18):

Preparation according to general procedure G using ethyl 2-(4-((4-((3-(2-chlorophenyl)-5isopropylisoxazol-4-yl)methoxy)benzyl)oxy)phenyl)acetate (100, $41 \mathrm{mg}, 0.08 \mathrm{mmol}, 1.0$ equiv.) and $\mathrm{LiOH} \cdot \mathrm{H}_{2} \mathrm{O}(17 \mathrm{mg}, 0.40 \mathrm{mmol}, 5.0$ equiv.). Purification was performed by preparative HPLC to obtain 18 as a yellow oil $(14 \mathrm{mg}, 36 \%) .{ }^{1} \mathrm{H}$ NMR $\left(500 \mathrm{MHz}\right.$, acetone- $\left.d_{6}\right)$ $\delta=7.59-7.56(\mathrm{~m}, 1 \mathrm{H}), 7.54-7.48(\mathrm{~m}, 2 \mathrm{H}), 7.47-7.43(\mathrm{~m}, 1 \mathrm{H}), 7.35-7.31(\mathrm{~m}, 2 \mathrm{H}), 7.24-$ $7.19(\mathrm{~m}, 2 \mathrm{H}), 6.95-6.91(\mathrm{~m}, 2 \mathrm{H}), 6.87-6.83(\mathrm{~m}, 2 \mathrm{H}), 4.99(\mathrm{~s}, 2 \mathrm{H}), 4.92(\mathrm{~s}, 2 \mathrm{H}), 3.54(\mathrm{~s}, 2 \mathrm{H})$, $3.50-3.41(\mathrm{~m}, 1 \mathrm{H}), 1.38(\mathrm{~d}, J=7.0 \mathrm{~Hz}, 6 \mathrm{H}) .{ }^{13} \mathrm{C}$ NMR $\left(126 \mathrm{MHz}\right.$, acetone- $\left.d_{6}\right) \delta=177.09$, $172.97,162.05,158.97,158.73$, 133.99, 132.71, 132.08, 131.21, 131.06, 130.66, 130.04, 129.56, 128.05, 128.00, 115.70, 115.51, 110.55, 70.06, 60.26, 40.37, 27.48, 21.06. MS (ESI+): $\mathrm{m} / \mathrm{z} 514.13\left([\mathrm{M}+\mathrm{Na}]^{+}\right)$. HRMS $\left(\mathrm{MALDI}^{+}\right): \mathrm{m} / \mathrm{z}$ calc. for $\mathrm{C}_{28} \mathrm{H}_{27} \mathrm{CINO}_{5}$ 492.15723, found $492.15608\left([\mathrm{M}+\mathrm{H}]^{+}\right)$.

2-(4-((4-((3-(2-Chlorophenyl)-5-isopropylisoxazol-4-yl)methoxy)benzyl)oxy)phenoxy)acetic acid (19):

Preparation according to general procedure G using ethyl 2-(4-((4-((3-(2-chlorophenyl)-5isopropylisoxazol-4-yl)methoxy)benzyl)oxy)phenoxy)acetate (101, $52 \mathrm{mg}, 0.10 \mathrm{mmol}, 1.0$ equiv.) and $\mathrm{LiOH} \cdot \mathrm{H}_{2} \mathrm{O}(21 \mathrm{mg}, 0.50 \mathrm{mmol}, 5.0$ equiv.). The crude product was purified by column chromatography using EtOAc/hexane $(3: 1+2 \% \mathrm{HOAc})$ as mobile phase to obtain 19 as a yellow solid (24 mg, 47\%). ${ }^{1} \mathrm{H}$ NMR $\left(500 \mathrm{MHz}\right.$, acetone- $\left.d_{6}\right) \delta=7.58(\mathrm{dd}, J=8.0,0.9 \mathrm{~Hz}$, $1 \mathrm{H}), 7.55-7.48(\mathrm{~m}, 2 \mathrm{H}), 7.48-7.43(\mathrm{~m}, 1 \mathrm{H}), 7.34-7.30(\mathrm{~m}, 2 \mathrm{H}), 6.93-6.82(\mathrm{~m}, 6 \mathrm{H}), 4.95$ $(\mathrm{s}, 2 \mathrm{H}), 4.92(\mathrm{~s}, 2 \mathrm{H}), 4.63(\mathrm{~s}, 2 \mathrm{H}), 3.50-3.41(\mathrm{~m}, 1 \mathrm{H}), 1.38(\mathrm{~d}, J=7.0 \mathrm{~Hz}, 6 \mathrm{H}) .{ }^{13} \mathrm{C} \mathrm{NMR}(126$ $\mathrm{MHz}$, acetone- $\left.d_{6}\right) \delta=177.08,170.47,162.04,158.92,154.38,153.33,133.98,132.71,132.08$, 131.20, 130.65, 130.01, 129.55, 128.04, 116.50, 116.38, 115.66, 110.55, 70.56, 66.07, 60.24, 27.48, 21.06. MS $\left(\mathrm{ESI}^{+}\right): \mathrm{m} / \mathrm{z} 530.15\left([\mathrm{M}+\mathrm{Na}]^{+}\right)$. HRMS $\left(\mathrm{MALDI}^{+}\right): \mathrm{m} / z$ calc. for $\mathrm{C}_{28} \mathrm{H}_{27} \mathrm{CINO}_{6}$ 508.15214 , found $508.15127\left([\mathrm{M}+\mathrm{H}]^{+}\right)$.

2-(4-((4-((3-(2-Chlorophenyl)-5-isopropylisoxazol-4-yl)methoxy)benzyl)oxy)phenyl)-2methylpropanoic acid (20):

Preparation according to general procedure G using ethyl 2-(4-((4-((3-(2-chlorophenyl)-5isopropylisoxazol-4-yl)methoxy)benzyl)oxy)phenyl)-2-methylpropanoate (102, $35.0 \mathrm{mg}, 0.064$ mmol, 1.00 equiv.) and $\mathrm{LiOH} \cdot \mathrm{H}_{2} \mathrm{O}(20 \mathrm{mg}, 0.48 \mathrm{mmol}, 5.0$ equiv.). The crude product was purified by column chromatography using EtOAc/hexane $(3: 1+2 \% \mathrm{HOAc})$ as mobile phase to obtain 20 as a yellow oil ( $8 \mathrm{mg}, 24 \%) .{ }^{1} \mathrm{H}$ NMR $\left(500 \mathrm{MHz}\right.$, acetone- $\left.d_{6}\right) \delta=7.57(\mathrm{dd}, J=8.0$, $0.9 \mathrm{~Hz}, 1 \mathrm{H}), 7.54-7.47(\mathrm{~m}, 2 \mathrm{H}), 7.47-7.42(\mathrm{~m}, 1 \mathrm{H}), 7.36-7.29(\mathrm{~m}, 4 \mathrm{H}), 6.95-6.91(\mathrm{~m}$, $2 \mathrm{H}), 6.87-6.83(\mathrm{~m}, 2 \mathrm{H}), 4.99(\mathrm{~s}, 2 \mathrm{H}), 4.92(\mathrm{~s}, 2 \mathrm{H}), 3.50-3.41(\mathrm{~m}, 1 \mathrm{H}), 1.52(\mathrm{~s}, 6 \mathrm{H}), 1.38(\mathrm{~d}$, $J=7.0 \mathrm{~Hz}, 6 \mathrm{H}) .{ }^{13} \mathrm{C}$ NMR $\left(126 \mathrm{MHz}\right.$, acetone- $\left.d_{6}\right) \delta=178.14,177.08,162.04,158.96,158.37$, $138.24,133.98,132.71,132.08,131.06,130.65,130.03,129.55,128.04,127.63,115.70$, 
115.28, 110.54, 70.02, 60.24, 46.08, 27.47, 27.06, 21.06. MS (ESI $\left.{ }^{+}\right): m / z 542.14\left(\left[\mathrm{M}+\mathrm{Na}^{+}\right)\right.$. HRMS (MALDI $\left.{ }^{+}\right): m / z$ calc. for $\mathrm{C}_{30} \mathrm{H}_{31} \mathrm{CINO}_{5} 520.18853$, found $520.18683\left([\mathrm{M}+\mathrm{H}]^{+}\right)$.

\section{2-(4-((4-((3-(2,6-Dichlorophenyl)-5-isopropylisoxazol-4-yl)methoxy)benzyl)oxy)phenyl)acetic} acid (21):

Preparation according to general procedure G using ethyl 2-(4-((4-((3-(2,6-dichlorophenyl)-5isopropylisoxazol-4-yl)methoxy)benzyl)oxy)phenyl)acetate (103, $21 \mathrm{mg}, 0.04 \mathrm{mmol}, 1.0$ equiv.) and $\mathrm{LiOH} \cdot \mathrm{H}_{2} \mathrm{O}(8.4 \mathrm{mg}, 0.2 \mathrm{mmol}, 5.0$ equiv.) to yield 21 as a yellow oil (15 mg, 75\%). ${ }^{1} \mathrm{H}$ NMR $\left(500 \mathrm{MHz}\right.$, acetone- $\left.d_{6}\right) \delta=7.57-7.48(\mathrm{~m}, 3 \mathrm{H}), 7.32(\mathrm{~d}, J=8.6 \mathrm{~Hz}, 2 \mathrm{H}), 7.21(\mathrm{~d}, J=$ $8.6 \mathrm{~Hz}, 2 \mathrm{H}), 6.91$ (d, J = 8.6 Hz, 2H), $6.86-6.81(\mathrm{~m}, 2 \mathrm{H}), 4.98(\mathrm{~s}, 2 \mathrm{H}), 4.88(\mathrm{~s}, 2 \mathrm{H}), 3.53-$ $3.44(\mathrm{~m}, 3 \mathrm{H}), 1.39(\mathrm{~d}, J=7.0 \mathrm{~Hz}, 6 \mathrm{H}) .{ }^{13} \mathrm{C} \mathrm{NMR}\left(126 \mathrm{MHz}\right.$, acetone- $\left.d_{6}\right) \delta=176.88,173.83$, $159.94,159.03$, 158.66, 136.23, 132.80, 131.20, 131.02, 129.98, 129.18, 128.98, 128.30, 115.52, 115.48, 110.70, 70.05, 60.07, 40.80, 27.48, 21.10. MS (ESI+): $\mathrm{m} / z$ 548.16 ([M+Na $\left.]^{+}\right)$. HRMS (MALDI $\left.{ }^{+}\right): m / z$ calc. for $\mathrm{C}_{28} \mathrm{H}_{26} \mathrm{Cl}_{2} \mathrm{NO}_{5} 526.11825$, found $526.11699\left([\mathrm{M}+\mathrm{H}]^{+}\right)$.

\section{2-(4-((4-((3-(2,6-Dichlorophenyl)-5-isopropylisoxazol-4-yl)methoxy)benzyl)amino)phenyl) acetic acid (22):}

Preparation according to general procedure G using ethyl 2-(4-((4-((3-(2,6-dichlorophenyl)-5isopropylisoxazol-4-yl)methoxy)benzyl)amino)phenyl)acetate (110, $67 \mathrm{mg}, 0.12 \mathrm{mmol}, 1.0$ equiv.) and $\mathrm{LiOH} \cdot \mathrm{H}_{2} \mathrm{O}$ (24 mg, $0.60 \mathrm{mmol}, 5.0$ equiv.). Purification was performed by preparative HPLC to obtain 22 as a yellow solid (21 mg, 33\%). ${ }^{1} \mathrm{H} \mathrm{NMR}\left(500 \mathrm{MHz}, \mathrm{CDCl}_{3}\right) \delta=$ $7.40-7.37(\mathrm{~m}, 2 \mathrm{H}), 7.32-7.28(\mathrm{~m}, 1 \mathrm{H}), 7.20(\mathrm{~d}, J=8.6,2 \mathrm{H}), 7.06(\mathrm{~d}, J=8.4,2 \mathrm{H}), 6.74(\mathrm{~d}$, $J=8.6,2 \mathrm{H}), 6.56(\mathrm{~d}, J=8.5,2 \mathrm{H}), 4.71(\mathrm{~s}, 2 \mathrm{H}), 4.20(\mathrm{~s}, 2 \mathrm{H}), 3.51(\mathrm{~s}, 2 \mathrm{H}), 3.38-3.26(\mathrm{~m}, 1 \mathrm{H})$, $1.41(\mathrm{~d}, J=7.0,6 \mathrm{H}) .{ }^{13} \mathrm{C}$ NMR $\left(126 \mathrm{MHz}, \mathrm{CDCl}_{3}\right) \delta=176.94,176.50,159.26,157.64,147.46$, $135.97,132.16,131.34,130.31,128.81,128.24,128.06,122.33,115.11,113.12,109.58$, 59.58, 47.88, 40.18, 27.24, 20.93. MS $\left(\mathrm{ESI}^{+}\right): \mathrm{m} / \mathrm{z} 547.12\left([\mathrm{M}+\mathrm{Na}]^{+}\right)$. HRMS $\left(\mathrm{MALDI}^{+}\right): \mathrm{m} / \mathrm{z}$ calc. for $\mathrm{C}_{28} \mathrm{H}_{26} \mathrm{Cl}_{2} \mathrm{~N}_{2} \mathrm{O}_{4} \mathrm{Na} 547.11618$, found $547.11521\left([\mathrm{M}+\mathrm{Na}]^{+}\right)$.

2-(4-((4-((3-(2,6-Dichlorophenyl)-5-isopropylisoxazol-4-yl)methoxy)benzyl)amino)-2-

methylphenyl)acetic acid (23): Preparation according to general procedure G using ethyl 2-(4((4-((3-(2,6-dichlorophenyl)-5-isopropylisoxazol-4-yl)methoxy)benzyl)amino)-2-

methylphenyl)acetate $(\mathbf{1 1 1}, 0.11 \mathrm{~g}, 0.19 \mathrm{mmol}, 1.0$ equiv. $)$ and $\mathrm{LiOH} \cdot \mathrm{H}_{2} \mathrm{O}(40 \mathrm{mg}, 0.95 \mathrm{mmol}$, 5.0 equiv.). Purification was performed by preparative HPLC to obtain $\mathbf{2 3}$ as a yellow solid (95 $\mathrm{mg}, 95 \%) .{ }^{1} \mathrm{H}$ NMR $\left(500 \mathrm{MHz}, \mathrm{CDCl}_{3}\right) \delta=7.29-7.25(\mathrm{~m}, 2 \mathrm{H}), 7.21-7.17(\mathrm{~m}, 1 \mathrm{H}), 7.08(\mathrm{~d}$, $J=8.6,2 \mathrm{H}), 6.86(\mathrm{~d}, \mathrm{~J}=8.2,1 \mathrm{H}), 6.63-6.60(\mathrm{~m}, 2 \mathrm{H}), 6.39-6.31(\mathrm{~m}, 2 \mathrm{H}), 4.60(\mathrm{~s}, 2 \mathrm{H}), 4.08(\mathrm{~s}$, $2 \mathrm{H}), 3.42(\mathrm{~s}, 2 \mathrm{H}), 3.25-3.16(\mathrm{~m}, 1 \mathrm{H}), 2.10(\mathrm{~s}, 3 \mathrm{H}), 1.29(\mathrm{~d}, \mathrm{~J}=7.0,6 \mathrm{H}) .{ }^{13} \mathrm{C} \mathrm{NMR}(126 \mathrm{MHz}$, $\left.\mathrm{CDCl}_{3}\right) \delta=177.84,176.48,159.24,157.68,146.91,138.02,135.94,131.68,131.34,131.32$, 129.04, 128.22, 128.02, 115.64, 115.07, 111.25, 109.56, 59.55, 48.29, 38.13, 27.22, 20.91, 19.96. MS $\left(\mathrm{ESI}^{+}\right): \mathrm{m} / z 539.24\left([\mathrm{M}+\mathrm{H}]^{+}\right)$. HRMS (MALDI $\left.{ }^{+}\right): \mathrm{m} / z$ calc. for $\mathrm{C}_{29} \mathrm{H}_{28} \mathrm{Cl}_{2} \mathrm{~N}_{2} \mathrm{O}_{4} \mathrm{Na}$ 561.13183, found $561.13106\left([\mathrm{M}+\mathrm{Na}]^{+}\right)$.

2-(4-((2-Chloro-4-((3-(2,6-dichlorophenyl)-5-isopropylisoxazol-4-

yl)methoxy)benzyl)oxy)phenyl)acetic acid (24): Preparation according to general procedure $G$ using ethyl 2-(4-((2-chloro-4-((3-(2,6-dichlorophenyl)-5-isopropylisoxazol-4yl)methoxy)benzyl)oxy)phenyl)acetate (104, $0.28 \mathrm{~g}, 0.48 \mathrm{mmol}, 1.0$ equiv.) and $\mathrm{LiOH} \cdot \mathrm{H}_{2} \mathrm{O}$ $(0.10 \mathrm{~g}, 2.4 \mathrm{mmol}, 5.0$ equiv.). Purification was performed by preparative HPLC to obtain 24 
as a yellow solid $(0.21 \mathrm{~g}, 78 \%) .{ }^{1} \mathrm{H}$ NMR $\left(500 \mathrm{MHz}, \mathrm{CDCl}_{3}\right) \delta=7.28-7.25(\mathrm{~m}, 2 \mathrm{H}), 7.24-7.17$ $(\mathrm{m}, 2 \mathrm{H}), 7.09-7.05(\mathrm{~m}, 2 \mathrm{H}), 6.81-6.77(\mathrm{~m}, 2 \mathrm{H}), 6.69(\mathrm{~d}, \mathrm{~J}=2.5,1 \mathrm{H}), 6.56(\mathrm{dd}, \mathrm{J}=8.6,2.5$, $1 \mathrm{H}), 4.91(\mathrm{~s}, 2 \mathrm{H}), 4.59(\mathrm{~s}, 2 \mathrm{H}), 3.46(\mathrm{~s}, 2 \mathrm{H}), 3.19$ (hept, $\mathrm{J}=7.0,1 \mathrm{H}), 1.30(\mathrm{~d}, J=7.0,6 \mathrm{H}) .{ }^{13} \mathrm{C}$ $\operatorname{NMR}\left(126 \mathrm{MHz}, \mathrm{CDCl}_{3}\right) \delta=176.66,176.48,159.22,158.57,158.00,135.93,133.78,131.46$, 130.62, 130.28, 128.28, 127.88, 127.39, 126.01, 115.84, 115.69, 115.17, 113.86, 109.12, 67.05, 59.80, 40.07, 27.27, 20.95. MS (ESI $\left.{ }^{+}\right): m / z 582.05\left([\mathrm{M}+\mathrm{Na}]^{+}\right)$. HRMS (MALDI $): \mathrm{m} / \mathrm{z}$ calc. for $\mathrm{C}_{28} \mathrm{H}_{25} \mathrm{Cl}_{3} \mathrm{NO}_{5} 560.07928$, found $560.07754\left([\mathrm{M}+\mathrm{H}]^{+}\right)$.

\section{2,6-Dichlorobenzaldehyde oxime (31):}

Preparation according to general procedure A using 2,6-dichlorobenzaldehyde $(\mathbf{2 6}, 5.00 \mathrm{~g}$, $28.6 \mathrm{mmol}, 1.00$ equiv.), hydroxylamine hydrochloride $(2.29 \mathrm{~g}, 32.9 \mathrm{mmol}, 1.15$ equiv.) and $\mathrm{NaOH}$ (1.32 g, 32.9 mmol, 1.15 equiv.) to yield 31 as a colorless solid (5.0 g, 93\%) which was used without further purification. ${ }^{1} \mathrm{H}$ NMR $\left(500 \mathrm{MHz}, \mathrm{DMSO}-d_{6}\right) \delta=11.80(\mathrm{~s}, 1 \mathrm{H}), 8.22(\mathrm{~s}, 1 \mathrm{H})$, $7.55(\mathrm{~d}, J=8.1 \mathrm{~Hz}, 2 \mathrm{H}), 7.45-7.40(\mathrm{~m}, 1 \mathrm{H}) .{ }^{13} \mathrm{C} \mathrm{NMR}\left(126 \mathrm{MHz}, \mathrm{DMSO}-d_{6}\right) \delta=143.82$, 133.92, 131.03, 129.41, 128.95. MS $\left(\mathrm{ESI}^{+}\right): \mathrm{m} / \mathrm{z} 190.07\left([\mathrm{M}+\mathrm{H}]^{+}\right)$.

2-Chlorobenzaldehyde oxime (32):

Preparation according to general procedure A using 2-chlorobenzaldehyde $(\mathbf{2 7}, 5.00 \mathrm{~g}, 35.6$ mmol, 1.00 equiv.), hydroxylamine hydrochloride ( $2.84 \mathrm{~g}, 40.9 \mathrm{mmol}, 1.15$ equiv.) and $\mathrm{NaOH}$ (1.64 g, 40.9 mmol, 1.15 equiv.) to yield 32 as a yellow solid (5.5 g, 99\%) which was used without further purification. ${ }^{1} \mathrm{H}$ NMR $\left(500 \mathrm{MHz}, \mathrm{DMSO}-d_{6}\right) \delta=11.69(\mathrm{~s}, 1 \mathrm{H}), 8.36(\mathrm{~s}, 1 \mathrm{H}), 7.81$ (dd, $J=7.6,1.8 \mathrm{~Hz}, 1 \mathrm{H}), 7.49$ (dd, $J=7.9,1.2 \mathrm{~Hz}, 1 \mathrm{H}), 7.44-7.34(\mathrm{~m}, 2 \mathrm{H}) .{ }^{13} \mathrm{C}$ NMR $(126$ $\left.\mathrm{MHz}, \mathrm{DMSO}-d_{6}\right) \delta=144.58,132.23,130.96,130.32,129.86,127.57,126.82 . \mathrm{MS}\left(\mathrm{ESI}^{+}\right): \mathrm{m} / \mathrm{z}$ $156.03\left([\mathrm{M}+\mathrm{H}]^{+}\right)$.

2-(Trifluoromethyl)benzaldehyde oxime (33):

Preparation according to general procedure A using 2-(trifluoromethyl)benzaldehyde (28, 6.98 $\mathrm{g}, 40.1 \mathrm{mmol}, 1.00$ equiv.), hydroxylamine hydrochloride ( $3.20 \mathrm{~g}, 46.1 \mathrm{mmol}, 1.15$ equiv.) and $\mathrm{NaOH}(1.84 \mathrm{~g}, 46.1 \mathrm{mmol}, 1.15$ equiv.) to yield 33 as a yellow solid $(7.3 \mathrm{~g}, 96 \%)$ which was used without further purification. ${ }^{1} \mathrm{H}$ NMR $\left(500 \mathrm{MHz}\right.$, DMSO- $\left.d_{6}\right) \delta=11.87(\mathrm{~s}, 1 \mathrm{H}), 8.32-8.28$ $(\mathrm{m}, 1 \mathrm{H}), 8.00(\mathrm{~d}, J=7.8 \mathrm{~Hz}, 1 \mathrm{H}), 7.78(\mathrm{~d}, J=7.8 \mathrm{~Hz}, 1 \mathrm{H}), 7.71(\mathrm{t}, J=7.6 \mathrm{~Hz}, 1 \mathrm{H}), 7.61(\mathrm{t}, J=$ $7.7 \mathrm{~Hz}, 1 \mathrm{H}) .{ }^{13} \mathrm{C}$ NMR $\left(126 \mathrm{MHz}\right.$, DMSO- $\left.d_{6}\right) \delta=144.08,132.87,130.71,129.71,126.94$, 126.22, 125.97, 124.11. MS (ESI+): no molecular ion.

\section{2,6-Dimethylbenzaldehyde oxime (34):}

Preparation according to general procedure A using 2,6-dimethylbenzaldehyde $(\mathbf{2 9}, 4.30 \mathrm{~g}$, $32.1 \mathrm{mmol}, 1.00$ equiv.), hydroxylamine hydrochloride (2.56 g, $36.9 \mathrm{mmol}, 1.15$ equiv.) and $\mathrm{NaOH}$ (1.47 g, 36.9 mmol, 1.15 equiv.) to yield 34 as a colorless solid (4.3 g, 90\%) which was used without further purification. ${ }^{1} \mathrm{H}$ NMR $\left(500 \mathrm{MHz}, \mathrm{DMSO}-d_{6}\right) \delta=11.22(\mathrm{~s}, 1 \mathrm{H}), 8.33(\mathrm{~s}, 1 \mathrm{H})$, $7.16-7.12(\mathrm{~m}, 1 \mathrm{H}), 7.07(\mathrm{~d}, J=7.5 \mathrm{~Hz}, 2 \mathrm{H}), 2.33(\mathrm{~s}, 6 \mathrm{H}) .{ }^{13} \mathrm{C} \mathrm{NMR}\left(126 \mathrm{MHz}, \mathrm{DMSO}-d_{6}\right) \delta=$ 147.56, 136.68, 130.22, 128.27, 128.26, 20.86. MS (ESI+): $\mathrm{m} / \mathrm{z} 150.09\left([\mathrm{M}+\mathrm{H}]^{+}\right)$.

Benzaldehyde oxime (35):

Preparation according to general procedure A using benzaldehyde $(\mathbf{3 0}, 5.00 \mathrm{~g}, 47.1 \mathrm{mmol}$, 1.00 equiv.), hydroxylamine hydrochloride ( $3.77 \mathrm{~g}, 54.2 \mathrm{mmol}, 1.15$ equiv.) and $\mathrm{NaOH}(2.17 \mathrm{~g}$, $54.2 \mathrm{mmol}, 1.15$ equiv.) to yield 35 as a colorless solid $(5.0 \mathrm{~g}, 88 \%)$ which was used without 
further purification. ${ }^{1} \mathrm{H}$ NMR $\left(500 \mathrm{MHz}\right.$, DMSO- $\left.d_{6}\right) \delta=11.24(\mathrm{~s}, 1 \mathrm{H}), 8.14(\mathrm{~s}, 1 \mathrm{H}), 7.61-7.57$ $(\mathrm{m}, 2 \mathrm{H}), 7.42-7.35(\mathrm{~m}, 3 \mathrm{H}) .{ }^{13} \mathrm{C}$ NMR $\left(126 \mathrm{MHz}\right.$, DMSO- $\left.d_{6}\right) \delta=135.45,132.65,130.42$, 128.79, 126.61. MS (ESI+): no molecular ion.

$\mathrm{N}$-Hydroxy-2,6-dichlorobenzimidoyl chloride (36):

Preparation according to general procedure B using 2,6-dichlorobenzaldehyde oxime $(\mathbf{3 1}, 5.43$ g, $28.6 \mathrm{mmol}, 1.00$ equiv.) and $\mathrm{N}$-chlorosuccinimide ( $3.82 \mathrm{~g}, 28.6 \mathrm{mmol}, 1.00$ equiv.) to yield 36 as a yellow solid $(6.2 \mathrm{~g}, 96 \%)$ which was used without further purification. ${ }^{1} \mathrm{H}$ NMR (500 $\left.\mathrm{MHz}, \mathrm{DMSO}-d_{6}\right) \delta=12.68(\mathrm{~s}, 1 \mathrm{H}), 7.67-7.54(\mathrm{~m}, 3 \mathrm{H}) \cdot{ }^{13} \mathrm{C} \mathrm{NMR}\left(126 \mathrm{MHz}, \mathrm{DMSO}-d_{6}\right) \delta=$ $\left.134.38,132.86,131.81,128.79,128.72 . \mathrm{MS}_{(\mathrm{ESI}}{ }^{+}\right)$: no molecular ion.

$N$-Hydroxy-2-chlorobenzimidoyl chloride (37):

Preparation according to general procedure B using 2-chlorobenzaldehyde oxime $(32,5.50 \mathrm{~g}$, $35.4 \mathrm{mmol}, 1.00$ equiv.) and $\mathrm{N}$-chlorosuccinimide ( $4.72 \mathrm{~g}, 35.4 \mathrm{mmol}, 1.00$ equiv.) to yield 37 as an orange oil $(6.0 \mathrm{~g}, 89 \%)$ which was used without further purification. ${ }^{1} \mathrm{H}$ NMR $(500 \mathrm{MHz}$, DMSO- $\left.d_{6}\right) \delta=12.55(\mathrm{~s}, 1 \mathrm{H}), 7.61-7.50(\mathrm{~m}, 3 \mathrm{H}), 7.47-7.43(\mathrm{~m}, 1 \mathrm{H}) .{ }^{13} \mathrm{C} \mathrm{NMR}(126 \mathrm{MHz}$, DMSO- $\left.d_{6}\right) \delta=132.94,132.03,131.89,131.77,131.45,130.10,127.65 . M S\left(E S I^{+}\right)$: no molecular ion.

$\mathrm{N}$-Hydroxy-2-(trifluormethyl)benzimidoyl chloride (38):

Preparation according to general procedure B using 2-(trifluoromethyl)benzaldehyde oxime (33, $7.29 \mathrm{~g}, 38.6 \mathrm{mmol}, 1.00$ equiv.) and $\mathrm{N}$-chlorosuccinimide (5.14 g, $38.6 \mathrm{mmol}, 1.00$ equiv.) to yield 38 as a yellow solid $(7.9 \mathrm{~g}, 92 \%)$ which was used without further purification. ${ }^{1} \mathrm{H}$ NMR $\left(500 \mathrm{MHz}, \mathrm{DMSO}-d_{6}\right) \delta=12.60(\mathrm{~s}, 1 \mathrm{H}), 7.86(\mathrm{~d}, J=7.8 \mathrm{~Hz}, 1 \mathrm{H}), 7.79(\mathrm{~d}, J=7.6 \mathrm{~Hz}, 1 \mathrm{H}), 7.76$ $-7.68(\mathrm{~m}, 2 \mathrm{H}) .{ }^{13} \mathrm{C}$ NMR $\left(126 \mathrm{MHz}\right.$, DMSO- $\left.d_{6}\right) \delta=133.03,132.24,131.54,130.88,130.85$, 127.20, 126.69, 123.57. MS $\left(\mathrm{ESI}^{+}\right)$: no molecular ion.

$\mathrm{N}$-Hydroxy-2,6-dimethylbenzimidoyl chloride (39):

Preparation according to general procedure B using 2,6-dimethylbenzaldehyde oxime (34, $4.28 \mathrm{~g}, 28.7 \mathrm{mmol}, 1.00$ equiv.) and $\mathrm{N}$-chlorosuccinimide ( $3.83 \mathrm{~g}, 28.7 \mathrm{mmol}, 1.00$ equiv.) to yield 39 as a yellow solid $(5.0 \mathrm{~g}, 94 \%)$ which was used without further purification. ${ }^{1} \mathrm{H}$ NMR $\left(500 \mathrm{MHz}, \mathrm{DMSO}-d_{6}\right) \delta=12.22(\mathrm{~s}, 1 \mathrm{H}), 7.26(\mathrm{t}, J=7.6 \mathrm{~Hz}, 1 \mathrm{H}), 7.13(\mathrm{~d}, J=7.6 \mathrm{~Hz}, 2 \mathrm{H}), 2.23$ $(\mathrm{s}, 6 \mathrm{H}) .{ }^{13} \mathrm{C}$ NMR $\left(126 \mathrm{MHz}\right.$, DMSO- $\left.d_{6}\right) \delta=136.65,133.63,132.35,129.74,127.61,19.03$. $\mathrm{MS}\left(\mathrm{ESI}^{+}\right)$: no molecular ion.

a-Chlorobenzaldoxime (40):

Preparation according to general procedure B using benzaldehyde oxime (35, $5.03 \mathrm{~g}, 41.5$ mmol, 1.00 equiv.) and $\mathrm{N}$-chlorosuccinimide ( $5.54 \mathrm{~g}, 41.5 \mathrm{mmol}, 1.00$ equiv.) to yield $\mathbf{4 0}$ as an orange oil $(5.2 \mathrm{~g}, 81 \%)$ which was used without further purification. ${ }^{1} \mathrm{H}$ NMR $(500 \mathrm{MHz}$, DMSO$\left.d_{6}\right) \delta=12.41(\mathrm{~s}, 1 \mathrm{H}), 7.82-7.76(\mathrm{~m}, 2 \mathrm{H}), 7.51-7.44(\mathrm{~m}, 3 \mathrm{H}) .{ }^{13} \mathrm{C}$ NMR $\left(126 \mathrm{MHz}\right.$, DMSO- $\left.d_{6}\right)$ $\delta=135.45,132.65,130.42,128.79,126.61 . \mathrm{MS}\left(\mathrm{ESI}^{+}\right)$: no molecular ion.

Methyl 3-(2,6-dichlorophenyl)-5-isopropylisoxazole-4-carboxylate (43):

Preparation according to general procedure D using methyl isobutyrylacetate $(41,823 \mathrm{mg}$, $5.71 \mathrm{mmol}, 1.00$ equiv.), sodium methoxide (1.25 g, $5.77 \mathrm{mmol}, 1.01$ equiv.) and $N$-hydroxy2,6-dichloro benzimidoylchloride (36, $1.28 \mathrm{~g}, 5.71 \mathrm{mmol}, 1.00$ equiv.). The product was purified 
by column chromatography using hexane/EtOAc (15:1) to obtain $\mathbf{4 3}$ as a yellow solid $(0.27 \mathrm{~g}$, 15\%). ${ }^{1} \mathrm{H}$ NMR $\left(500 \mathrm{MHz}, \mathrm{CDCl}_{3}\right) \delta=7.41-7.39(\mathrm{~m}, 2 \mathrm{H}), 7.35-7.31(\mathrm{~m}, 1 \mathrm{H}), 3.91-3.82(\mathrm{~m}$, $1 \mathrm{H}), 3.66(\mathrm{~s}, 3 \mathrm{H}), 1.43(\mathrm{~d}, J=7.0 \mathrm{~Hz}, 6 \mathrm{H}) .{ }^{13} \mathrm{C} \mathrm{NMR}\left(126 \mathrm{MHz}, \mathrm{CDCl}_{3}\right) \delta=183.34,161.73$,

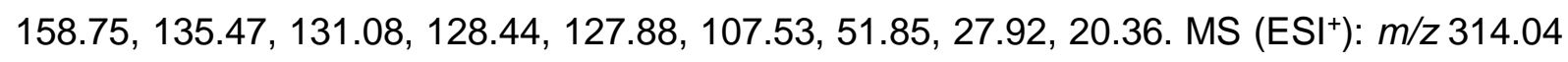
$\left([\mathrm{M}+\mathrm{H}]^{+}\right)$.

Methyl 3-(2-chlorophenyl)-5-isopropylisoxazole-4-carboxylate (44):

Preparation according to general procedure $D$ using methyl isobutyrylacetate $(41,4.55 \mathrm{~g}, 31.6$ mmol, 1.00 equiv.), sodium methoxide (6.89 g, $31.9 \mathrm{mmol}, 1.01$ equiv.), $N$-hydroxy-2-chloro benzimidoylchloride $(37,6.00 \mathrm{~g}, 31.6 \mathrm{mmol}, 1.00$ equiv. $)$. The product was purified by column chromatography using hexane/EtOAc $(15: 1)$ to yield 44 as a yellow solid $(2.43 \mathrm{~g}, 28 \%) .{ }^{1} \mathrm{H}$ $\operatorname{NMR}\left(500 \mathrm{MHz}, \mathrm{CDCl}_{3}\right) \delta=7.48-7.45(\mathrm{~m}, 1 \mathrm{H}), 7.44-7.39(\mathrm{~m}, 2 \mathrm{H}), 7.37-7.33(\mathrm{~m}, 1 \mathrm{H}), 3.88$ $-3.79(\mathrm{~m}, 1 \mathrm{H}), 3.67(\mathrm{~s}, 3 \mathrm{H}), 1.42(\mathrm{~d}, J=7.0 \mathrm{~Hz}, 6 \mathrm{H}) .{ }^{13} \mathrm{C} \mathrm{NMR}\left(126 \mathrm{MHz}, \mathrm{CDCl}_{3}\right) \delta=182.79$, 162.25, 160.89, 134.09, 131.09, 130.91, 129.53, 128.82, 126.71, 107.94, 51.78, 27.76, 20.41. MS $\left(\mathrm{ESI}^{+}\right): \mathrm{m} / \mathrm{z} 280.11\left([\mathrm{M}+\mathrm{H}]^{+}\right)$.

Methyl 5-isopropyl-3-(2-(trifluoromethyl)phenyl)isoxazole-4-carboxylate (45):

Preparation according to general procedure $D$ using methyl isobutyrylacetate $(41,2.98 \mathrm{~g}, 20.7$ mmol, 1.00 equiv.), sodium methoxide $(4.51 \mathrm{~g}, 20.9 \mathrm{mmol}, 1.01$ equiv.) and $\mathrm{N}$-hydroxy-2(trifluormethyl) benzimidoylchloride $(38,4.62 \mathrm{~g}, 20.7 \mathrm{mmol}, 1.00$ equiv.). The product was purified by column chromatography using hexane/EtOAc (15:1) to obtain $\mathbf{4 1}$ as a yellow oil (2.4 g, 38\%). ${ }^{1} \mathrm{H}$ NMR $\left(500 \mathrm{MHz}, \mathrm{CDCl}_{3}\right) \delta=7.78-7.74(\mathrm{~m}, 1 \mathrm{H}), 7.64-7.55(\mathrm{~m}, 2 \mathrm{H}), 7.40(\mathrm{~d}, \mathrm{~J}=$ $6.9 \mathrm{~Hz}, 1 \mathrm{H}), 3.88-3.79(\mathrm{~m}, 1 \mathrm{H}), 3.59(\mathrm{~s}, 3 \mathrm{H}), 1.41(\mathrm{~d}, J=7.0 \mathrm{~Hz}, 6 \mathrm{H}) .{ }^{13} \mathrm{C} \mathrm{NMR}(126 \mathrm{MHz}$, $\left.\mathrm{CDCl}_{3}\right) \delta=182.66,161.92,160.92,131.37,131.35,129.65,129.52,127.86,126.37,123.78$, 108.10, 51.55, 27.72, 20.29. MS (ESI $\left.{ }^{+}\right): m / z 314.06\left([\mathrm{M}+\mathrm{H}]^{+}\right)$.

Methyl 3-(2,6-dimethylphenyl)-5-isopropylisoxazole-4-carboxylate (46):

Preparation according to general procedure $D$ using methyl isobutyrylacetate $(\mathbf{4 1}, 3.53 \mathrm{~g}, 24.5$ mmol, 1.00 equiv.), sodium methoxide (5.35 g, $24.8 \mathrm{mmol}, 1.01$ equiv.) and $N$-hydroxy-2,6dimethylbenzimidoyl chloride (39, $4.50 \mathrm{~g}, 24.5 \mathrm{mmol}, 1.00$ equiv.). The product was purified by column chromatography using hexane/EtOAc (15:1) to obtain $\mathbf{4 6}$ as a yellow oil (3.3 g, 49\%). ${ }^{1} \mathrm{H}$ NMR $\left(500 \mathrm{MHz}, \mathrm{CDCl}_{3}\right) \delta=7.22(\mathrm{t}, J=7.6 \mathrm{~Hz}, 1 \mathrm{H}), 7.08(\mathrm{~d}, J=7.6 \mathrm{~Hz}, 2 \mathrm{H}), 3.86$ (hept, $J$ $=7.0 \mathrm{~Hz}, 1 \mathrm{H}), 3.62(\mathrm{~s}, 3 \mathrm{H}), 2.08(\mathrm{~s}, 6 \mathrm{H}), 1.43(\mathrm{~d}, J=7.0 \mathrm{~Hz}, 6 \mathrm{H}) \cdot{ }^{13} \mathrm{C} \mathrm{NMR}\left(126 \mathrm{MHz}, \mathrm{CDCl}_{3}\right)$ $\delta=183.33,162.30,161.88,137.14,129.06,128.63,127.22,107.25,51.70,27.96,20.45$, 20.16. $\mathrm{MS}\left(\mathrm{ESI}^{+}\right): \mathrm{m} / \mathrm{z} 296.12\left([\mathrm{M}+\mathrm{Na}]^{+}\right)$.

Methyl 5-isopropyl-3-phenylisoxazole-4-carboxylate (47):

Preparation according to general procedure D using methyl isobutyrylacetate $(\mathbf{4 1}, 2.42 \mathrm{~g}, 16.8$ mmol, 1.00 equiv.), sodium methoxide (3.67 g, $17.0 \mathrm{mmol}, 1.01$ equiv.) and $\alpha-$ chlorobenzaldoxime (40, $2.62 \mathrm{~g}, 16.8 \mathrm{mmol}, 1.00$ equiv.). The product was purified by column chromatography using hexane/EtOAc $(15: 1)$ to obtain 47 as a yellow oil $(0.71 \mathrm{~g}, 17 \%)$. ${ }^{1} \mathrm{H}$ NMR $\left(500 \mathrm{MHz}, \mathrm{CDCl}_{3}\right) \delta=7.61-7.58(\mathrm{~m}, 2 \mathrm{H}), 7.47-7.43(\mathrm{~m}, 3 \mathrm{H}), 3.81$ (hept, $J=7.0 \mathrm{~Hz}, 1 \mathrm{H}$ ), $3.75(\mathrm{~s}, 3 \mathrm{H}), 1.41$ (d, $J=7.0 \mathrm{~Hz}, 6 \mathrm{H}) .{ }^{13} \mathrm{C} \mathrm{NMR}\left(126 \mathrm{MHz}, \mathrm{CDCl}_{3}\right) \delta=183.31,162.64,162.63$, 129.82, 129.42, 128.78, 128.17, 106.63, 51.72, 27.91, 20.44. MS (ESI+): $m / z 246.13\left([\mathrm{M}+\mathrm{H}]^{+}\right)$. 
Methyl 5-methyl-3-phenylisoxazole-4-carboxylate (48):

Preparation according to general procedure D using methyl acetoacetate $(\mathbf{4 2}, 1.95 \mathrm{~g}, 16.8$ mmol, 1.00 equiv.), sodium methoxide (3.67 g, $17.0 \mathrm{mmol}, 1.01$ equiv.) and $\alpha-$ chlorobenzaldoxime $(\mathbf{4 0}, 2.62 \mathrm{~g}, 16.8 \mathrm{mmol}, 1.00$ equiv.). The product was purified by column chromatography using hexane/EtOAc (15:1) to obtain 48 as a yellow oil (1.4 g, 38\%). ${ }^{1} \mathrm{H}$ NMR $\left(500 \mathrm{MHz}, \mathrm{CDCl}_{3}\right) \delta=7.64-7.60(\mathrm{~m}, 2 \mathrm{H}), 7.49-7.42(\mathrm{~m}, 3 \mathrm{H}), 3.77(\mathrm{~s}, 3 \mathrm{H}), 2.73(\mathrm{~s}, 3 \mathrm{H}) .{ }^{13} \mathrm{C}$ $\operatorname{NMR}\left(126 \mathrm{MHz}, \mathrm{CDCl}_{3}\right) \delta=176.03,162.67,162.54,129.89,129.41,128.51,128.16,108.36$, 51.74, 13.72. MS (ESI+): no molecular ion.

(3-(2,6-Dichlorophenyl)-5-isopropylisoxazol-4-yl)methanol (49):

Preparation according to general procedure $E$ using methyl 3-(2,6-dichlorophenyl)-5isopropylisoxazole-4-carboxylate $(43,0.27 \mathrm{~g}, 0.85 \mathrm{mmol}, 1.0$ equiv.) and diisobutylaluminium hydride (1.8 $\mathrm{mL}, 1.8 \mathrm{mmol}, 2.1$ equiv.). The product was purified by column chromatography using hexane/EtOAc (3:1) to obtain 49 as a colorless solid $(0.14 \mathrm{~g}, 58 \%)$. ${ }^{1} \mathrm{H}$ NMR $(500 \mathrm{MHz}$, $\left.\mathrm{CDCl}_{3}\right) \delta=7.46-7.41(\mathrm{~m}, 2 \mathrm{H}), 7.39-7.34(\mathrm{~m}, 1 \mathrm{H}), 4.35-4.34(\mathrm{~m}, 2 \mathrm{H}), 3.41-3.27(\mathrm{~m}, 1 \mathrm{H})$, $1.44(\mathrm{~d}, J=7.0 \mathrm{~Hz}, 6 \mathrm{H}) .{ }^{13} \mathrm{C} \mathrm{NMR}\left(126 \mathrm{MHz}, \mathrm{CDCl}_{3}\right) \delta=176.47,159.23,135.84,131.48$,

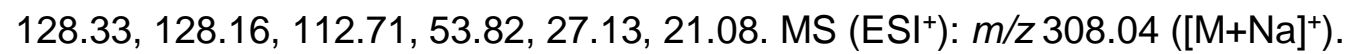

(3-(2-Chlorophenyl)-5-isopropylisoxazol-4-yl)methanol (50):

Preparation according to general procedure $\mathrm{E}$ using methyl 3-(2-chlorophenyl)-5isopropylisoxazole-4-carboxylate $(44,0.92 \mathrm{~g}, 3.3 \mathrm{mmol}, 1.0$ equiv.) and diisobutylaluminium hydride ( $8.2 \mathrm{~mL}, 8.2 \mathrm{mmol}, 2.5$ equiv.) to yield 50 as a yellow oil $(0.81 \mathrm{~g}, 98 \%)$ which used without further purification. ${ }^{1} \mathrm{H}$ NMR $\left(500 \mathrm{MHz}, \mathrm{CDCl}_{3}\right) \delta=7.52-7.48(\mathrm{~m}, 1 \mathrm{H}), 7.46-7.39(\mathrm{~m}$, 2H), $7.39-7.33(\mathrm{~m}, 1 \mathrm{H}), 4.40(\mathrm{~s}, 2 \mathrm{H}), 3.33$ (hept, $J=7.0 \mathrm{~Hz}, 1 \mathrm{H}), 1.41(\mathrm{~d}, J=7.0 \mathrm{~Hz}, 6 \mathrm{H}) .{ }^{13} \mathrm{C}$ $\operatorname{NMR}\left(126 \mathrm{MHz}, \mathrm{CDCl}_{3}\right) \delta=176.23,161.19,133.49,131.95,131.06,129.94,128.66,127.14$, 112.87, 53.97, 27.00, 21.01. MS (ESI+): $m / z 252.10\left([\mathrm{M}+\mathrm{H}]^{+}\right)$.

(5-Isopropyl-3-(2-(trifluoromethyl)phenyl)isoxazol-4-yl)methanol (51):

Preparation according to general procedure $\mathrm{E}$ using methyl 5-isopropyl-3-(2(trifluoromethyl)phenyl)isoxazole-4-carboxylate $(45,1.5 \mathrm{~g}, 4.8 \mathrm{mmol}, 1.0$ equiv.) and diisobutylaluminium hydride ( $12 \mathrm{~mL}, 12 \mathrm{mmol}, 2.5$ equiv.). The product was purified by column chromatography using hexane/EtOAc (3:1) to obtain 51 as a colorless oil (1.0 g, 74\%). ${ }^{1} \mathrm{H} \mathrm{NMR}$ $\left(500 \mathrm{MHz}, \mathrm{CDCl}_{3}\right) \delta=7.82-7.77(\mathrm{~m}, 1 \mathrm{H}), 7.66-7.57(\mathrm{~m}, 2 \mathrm{H}), 7.46(\mathrm{~d}, J=6.9 \mathrm{~Hz}, 1 \mathrm{H}), 4.32$ (s, 2H), 3.30 (hept, $J=7.0 \mathrm{~Hz}, 1 \mathrm{H}$ ), 1.41 (d, $J=7.0 \mathrm{~Hz}, 6 \mathrm{H}) \cdot{ }^{13} \mathrm{C}$ NMR $\left(126 \mathrm{MHz}, \mathrm{CDCl}_{3}\right) \delta=$ 175.82, 161.24, 132.08, 131.77, 129.93, 129.81, 127.73, 126.66, 123.74, 112.97, 53.48, 26.93, 21.05. MS $\left(\mathrm{ESI}^{+}\right): \mathrm{m} / \mathrm{z} 286.13\left([\mathrm{M}+\mathrm{H}]^{+}\right)$.

(3-(2,6-Dimethylphenyl)-5-isopropylisoxazol-4-yl)methanol (52):

Preparation according to general procedure E using methyl 3-(2,6-dimethylphenyl)-5isopropylisoxazole-4-carboxylate $(46,1.30 \mathrm{~g}, 4.76 \mathrm{mmol}, 1.00$ equiv.) and diisobutylaluminium hydride (10 mL, $10 \mathrm{mmol}, 2.1$ equiv.). The product was purified by column chromatography using hexane/EtOAc (3:1) to obtain 52 as a colorless oil $(0.68 \mathrm{~g}, 58 \%)$. ${ }^{1} \mathrm{H}$ NMR $(500 \mathrm{MHz}$, $\left.\mathrm{CDCl}_{3}\right) \delta=7.23(\mathrm{t}, J=7.6 \mathrm{~Hz}, 1 \mathrm{H}), 7.10(\mathrm{~d}, J=7.6 \mathrm{~Hz}, 2 \mathrm{H}), 4.26-4.25(\mathrm{~m}, 2 \mathrm{H}), 3.31$ (hept, $J$ $=7.0 \mathrm{~Hz}, 1 \mathrm{H}), 2.11(\mathrm{~s}, 6 \mathrm{H}), 1.42(\mathrm{~d}, J=7.0 \mathrm{~Hz}, 6 \mathrm{H}) \cdot{ }^{13} \mathrm{C} \mathrm{NMR}\left(126 \mathrm{MHz}, \mathrm{CDCl}_{3}\right) \delta=175.88$, $\left.\left.162.44,137.67,129.30,128.34,127.55,112.15,53.67,27.03,21.15,20.18 . \mathrm{MS}_{(\mathrm{ESI}}\right)^{+}\right): \mathrm{m} / \mathrm{z}$ $246.20\left([\mathrm{M}+\mathrm{H}]^{+}\right)$. 
(5-Isopropyl-3-phenylisoxazol-4-yl)methanol (53):

Preparation according to general procedure $\mathrm{E}$ using methyl 5-isopropyl-3-phenylisoxazole-4carboxylate $(47,0.71 \mathrm{~g}, 2.88 \mathrm{mmol}, 1.00$ equiv.) and diisobutylaluminium hydride $(6.05 \mathrm{~mL}$, $6.05 \mathrm{mmol}, 2.1$ equiv.). The product was purified by column chromatography using hexane/EtOAc (2:1) to obtain 53 as a yellow oil $(0.47 \mathrm{~g}, 75 \%) .{ }^{1} \mathrm{H}$ NMR $\left(500 \mathrm{MHz}, \mathrm{CDCl}_{3}\right) \delta=$ $7.81-7.77(\mathrm{~m}, 2 \mathrm{H}), 7.50-7.45(\mathrm{~m}, 3 \mathrm{H}), 4.58-4.57(\mathrm{~m}, 2 \mathrm{H}), 3.29$ (hept, $J=7.0 \mathrm{~Hz}, 1 \mathrm{H}), 1.40$ $(\mathrm{d}, J=7.0 \mathrm{~Hz}, 6 \mathrm{H}) .{ }^{13} \mathrm{C}$ NMR $\left(126 \mathrm{MHz}, \mathrm{CDCl}_{3}\right) \delta=176.52,162.69,129.82,129.31,128.99$, 128.51, 111.14, 53.63, 26.78, 21.23. MS (ESI $): m / z 218.22\left([\mathrm{M}+\mathrm{H}]^{+}\right)$.

(5-Methyl-3-phenylisoxazol-4-yl)methanol (54):

Preparation according to general procedure E using methyl 5-methyl-3-phenylisoxazole-4carboxylate (48, $0.83 \mathrm{~g}, 3.8 \mathrm{mmol}, 1.0$ equiv.) and diisobutylaluminium hydride $(8.1 \mathrm{~mL}, 8.1$ mmol, 2.1 equiv.) to yield 54 as a yellow oil $(0.70 \mathrm{~g}, 96 \%)$ which was used without further purification. ${ }^{1} \mathrm{H}$ NMR $\left(500 \mathrm{MHz}, \mathrm{CDCl}_{3}\right) \delta=7.82-7.77(\mathrm{~m}, 2 \mathrm{H}), 7.50-7.43(\mathrm{~m}, 3 \mathrm{H}), 4.57(\mathrm{~s}$, $2 \mathrm{H}), 2.49$ (s, 3H). ${ }^{13} \mathrm{C}$ NMR (126 MHz, $\left.\mathrm{CDCl}_{3}\right) \delta=168.68,162.58,129.88,129.24,129.02$, 128.41, 113.02, 53.99, 11.32. MS (ESI $\left.{ }^{+}\right): m / z 190.21\left([\mathrm{M}+\mathrm{H}]^{+}\right)$.

Ethyl 4-hydroxybenzoate (67):

Preparation according to general procedure $\mathrm{C}$ using 4-hydroxybenzoic acid (55, $5.00 \mathrm{~g}, 36.2$ mmol, 1.00 equiv.) and $\mathrm{H}_{2} \mathrm{SO}_{4}(1.65 \mathrm{~mL})$. The product was purified by column chromatography using hexane/EtOAc (3:1) to obtain 67 as a colorless solid $(5.4 \mathrm{~g}, 90 \%)$. ${ }^{1} \mathrm{H}$ NMR $(500 \mathrm{MHz}$, $\left.\mathrm{CDCl}_{3}\right) \delta=7.99-7.94(\mathrm{~m}, 2 \mathrm{H}), 6.89-6.84(\mathrm{~m}, 2 \mathrm{H}), 5.65(\mathrm{~s}, 1 \mathrm{H}), 4.35(\mathrm{q}, J=7.1 \mathrm{~Hz}, 2 \mathrm{H})$, $1.38(\mathrm{t}, J=7.1 \mathrm{~Hz}, 3 \mathrm{H}) .{ }^{13} \mathrm{C} \mathrm{NMR}\left(126 \mathrm{MHz}, \mathrm{CDCl}_{3}\right) \delta=166.74,159.90,132.03,123.16$, 115.30, 60.97, 14.50. MS (ESI): $m / z 165.25\left([\mathrm{M}-\mathrm{H}]^{-}\right)$.

Ethyl 2-(4-hydroxyphenyl)acetate (68):

Preparation according to general procedure $\mathrm{C}$ using 2-(4-hydroxyphenyl)acetic acid (56, 2.00 g, $13.1 \mathrm{mmol}, 1.00$ equiv.) and $\mathrm{H}_{2} \mathrm{SO}_{4}(0.75 \mathrm{~mL})$ to yield 68 as a yellow oil $(2.1 \mathrm{~g}, 89 \%)$ which was used without further purification. ${ }^{1} \mathrm{H}$ NMR $\left(500 \mathrm{MHz}, \mathrm{CDCl}_{3}\right) \delta=7.14-7.09(\mathrm{~m}, 2 \mathrm{H}), 6.76$ - $6.72(\mathrm{~m}, 2 \mathrm{H}), 5.50(\mathrm{~s}, 1 \mathrm{H}), 4.15(\mathrm{q}, J=7.1 \mathrm{~Hz}, 2 \mathrm{H}), 3.54(\mathrm{~s}, 2 \mathrm{H}), 1.26(\mathrm{t}, J=7.1 \mathrm{~Hz}, 3 \mathrm{H}) .{ }^{13} \mathrm{C}$ $\operatorname{NMR}\left(126 \mathrm{MHz}, \mathrm{CDCl}_{3}\right) \delta=172.70,154.97,130.56,126.08,115.63,61.16,40.65,14.29$. MS $\left(\mathrm{ESI}^{+}\right): \mathrm{m} / z 203.12\left([\mathrm{M}+\mathrm{Na}]^{+}\right)$.

Ethyl 3-(4-hydroxyphenyl)propanoate (69):

Preparation according to general procedure $\mathrm{C}$ using 3-(4-hydroxyphenyl)propanoic acid (57, $4.00 \mathrm{~g}, 24.1 \mathrm{mmol}, 1.00$ equiv.) and $\mathrm{H}_{2} \mathrm{SO}_{4}(0.90 \mathrm{~mL})$ to yield 69 as a yellow oil $(4.6 \mathrm{~g}, 99 \%)$ which was used without further purification. ${ }^{1} \mathrm{H} \mathrm{NMR}\left(500 \mathrm{MHz}, \mathrm{CDCl}_{3}\right) \delta=7.05(\mathrm{~d}, J=8.5 \mathrm{~Hz}$, 2H), $6.77-6.72(\mathrm{~m}, 2 \mathrm{H}), 5.29(\mathrm{~s}, 1 \mathrm{H}), 4.12(\mathrm{q}, J=7.1 \mathrm{~Hz}, 2 \mathrm{H}), 2.88(\mathrm{t}, J=7.7 \mathrm{~Hz}, 2 \mathrm{H}), 2.59$ (t, $J=7.7 \mathrm{~Hz}, 2 \mathrm{H}), 1.23(\mathrm{t}, J=7.1 \mathrm{~Hz}, 3 \mathrm{H}) .{ }^{13} \mathrm{C} \mathrm{NMR}\left(126 \mathrm{MHz}, \mathrm{CDCl}_{3}\right) \delta=173.52,154.23$, $132.65,129.55,115.44,60.69,36.42,30.25,14.32 . \mathrm{MS}\left(\mathrm{ESI}^{+}\right): \mathrm{m} / z 217.06\left([\mathrm{M}+\mathrm{Na}]^{+}\right)$.

Ethyl 4-(4-hydroxyphenyl)butanoate (70):

Preparation according to general procedure $\mathrm{C}$ using 4-(4-Hydroxyphenyl)butanoic acid (58, $1.00 \mathrm{~g}, 5.55 \mathrm{mmol}, 1.00$ equiv.) and $\mathrm{H}_{2} \mathrm{SO}_{4}(0.25 \mathrm{~mL})$ to yield 70 as a yellow oil $(0.91 \mathrm{~g}, 78 \%)$ which was used without further purification. ${ }^{1} \mathrm{H} \mathrm{NMR}\left(500 \mathrm{MHz}, \mathrm{CDCl}_{3}\right) \delta=7.03(\mathrm{~d}, J=8.3 \mathrm{~Hz}$, $2 \mathrm{H}), 6.76(\mathrm{~d}, J=8.4 \mathrm{~Hz}, 2 \mathrm{H}), 5.17(\mathrm{~s}, 1 \mathrm{H}), 4.13(\mathrm{q}, J=7.1 \mathrm{~Hz}, 2 \mathrm{H}), 2.57(\mathrm{t}, J=7.6 \mathrm{~Hz}, 2 \mathrm{H})$, 
2.31 (t, $J=7.5 \mathrm{~Hz}, 2 \mathrm{H}), 1.96-1.87(\mathrm{~m}, 2 \mathrm{H}), 1.25$ (t, $J=7.1 \mathrm{~Hz}, 3 \mathrm{H}) .{ }^{13} \mathrm{C} \mathrm{NMR}(126 \mathrm{MHz}$, $\left.\mathrm{CDCl}_{3}\right) \delta=174.09,154.01,133.59,129.69,115.34,60.56,34.36,33.80,26.90,14.36 . \mathrm{MS}$ $\left(\mathrm{ESI}^{+}\right): \mathrm{m} / \mathrm{z} 231.15\left([\mathrm{M}+\mathrm{Na}]^{+}\right)$.

Ethyl 5-(4-hydroxyphenyl)pentanoate (71):

Preparation according to general procedure $\mathrm{C}$ using 5-(4-hydroxyphenyl)pentanoic acid (59, $1.00 \mathrm{~g}, 5.15 \mathrm{mmol}, 1.00$ equiv.) and $\mathrm{H}_{2} \mathrm{SO}_{4}(0.25 \mathrm{~mL})$ to yield 71 as a yellow oil $(1.1 \mathrm{~g}, 95 \%)$ which was used without further purification. ${ }^{1} \mathrm{H}$ NMR $\left(500 \mathrm{MHz}, \mathrm{CDCl}_{3}\right) \delta=7.05-7.01(\mathrm{~m}$, $2 \mathrm{H}), 6.79-6.71(\mathrm{~m}, 2 \mathrm{H}), 4.88(\mathrm{~s}, 1 \mathrm{H}), 4.12(\mathrm{q}, J=7.1 \mathrm{~Hz}, 2 \mathrm{H}), 2.55(\mathrm{t}, J=7.3 \mathrm{~Hz}, 2 \mathrm{H}), 2.32$ (t, $J=7.2 \mathrm{~Hz}, 2 \mathrm{H}), 1.69-1.58(\mathrm{~m}, 4 \mathrm{H}), 1.25(\mathrm{t}, J=7.1 \mathrm{~Hz}, 3 \mathrm{H}) .{ }^{13} \mathrm{C} \mathrm{NMR}\left(126 \mathrm{MHz}, \mathrm{CDCl}_{3}\right) \delta$

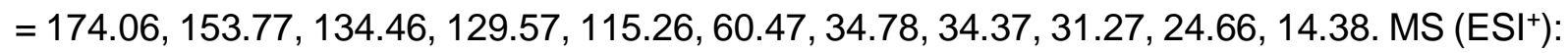
$\mathrm{m} / \mathrm{z} 245.15\left([\mathrm{M}+\mathrm{Na}]^{+}\right)$.

Ethyl 6-(4-hydroxyphenyl)hexanoate (72):

Preparation according to general procedure $\mathrm{C}$ using 6-(4-hydroxyphenyl)hexanoic acid (60, $0.25 \mathrm{~g}, 1.2 \mathrm{mmol}, 1.00$ equiv.) and $\mathrm{H}_{2} \mathrm{SO}_{4}(0.10 \mathrm{~mL})$ to yield 72 as a yellow oil $(0.27 \mathrm{~g}, 96 \%)$ which was used without further purification. ${ }^{1} \mathrm{H}$ NMR $\left(500 \mathrm{MHz}, \mathrm{CDCl}_{3}\right) \delta=7.08-6.99(\mathrm{~m}$, 2H), $6.81-6.69(\mathrm{~m}, 2 \mathrm{H}), 4.75(\mathrm{~s}, 1 \mathrm{H}), 4.12(\mathrm{q}, J=7.1 \mathrm{~Hz}, 2 \mathrm{H}), 2.53(\mathrm{t}, J=7.6 \mathrm{~Hz}, 2 \mathrm{H}), 2.29$ (t, $J=7.5 \mathrm{~Hz}, 2 \mathrm{H}), 1.69-1.55(\mathrm{~m}, 4 \mathrm{H}), 1.39-1.31(\mathrm{~m}, 2 \mathrm{H}), 1.25(\mathrm{t}, J=7.1 \mathrm{~Hz}, 3 \mathrm{H}) .{ }^{13} \mathrm{C}$ NMR $\left(126 \mathrm{MHz}, \mathrm{CDCl}_{3}\right) \delta=174.12,153.66,134.87,129.56,115.21,60.41,34.92,34.45,31.45$, 28.80, 24.97, 14.38. MS (ESI $)^{-}: m / z 235.36\left(\left[\mathrm{M}-\mathrm{H}^{-}\right]^{-}\right)$.

Ethyl 2-chloro-4-hydroxybenzoate (73): Preparation according to general procedure $\mathrm{C}$ using 2-Chloro-4-hydroxybenzoic acid $\left(61,0.50 \mathrm{~g}, 2.9 \mathrm{mmol}, 1.0\right.$ equiv.) and $\mathrm{H}_{2} \mathrm{SO}_{4}(0.13 \mathrm{~mL})$ to yield 73 as a yellow oil $(0.41 \mathrm{~g}, 71 \%)$ which was used without further purification. ${ }^{1} \mathrm{H}$ NMR (500 $\mathrm{MHz}, \mathrm{DMSO}) \delta=7.74(\mathrm{~d}, J=8.7 \mathrm{~Hz}, 1 \mathrm{H}), 6.89(\mathrm{~d}, J=2.4 \mathrm{~Hz}, 1 \mathrm{H}), 6.80(\mathrm{dd}, J=8.7,2.4 \mathrm{~Hz}$, $1 \mathrm{H}), 4.24(\mathrm{q}, J=7.1 \mathrm{~Hz}, 2 \mathrm{H}), 1.28(\mathrm{t}, J=7.1 \mathrm{~Hz}, 3 \mathrm{H}) .{ }^{13} \mathrm{C}$ NMR $(126 \mathrm{MHz}, \mathrm{DMSO}) \delta=164.62$, $161.41,134.23,133.58,119.91,117.63,114.55,60.86,14.25 . M S(E S I): ~ m / z ~ 198.85([M-H])$.

Ethyl 2-(4-amino-2-methylphenyl)acetate (74):

Preparation according to general procedure $\mathrm{C}$ using 2-(4-amino-2-methylphenyl)acetic acid (62, $0.50 \mathrm{~g}, 3.0 \mathrm{mmol}, 1.0$ equiv.) and $\mathrm{H}_{2} \mathrm{SO}_{4}(0.13 \mathrm{~mL})$ to yield 74 as a brown oil $(0.52 \mathrm{~g}, 91 \%)$ which was used without further purification. ${ }^{1} \mathrm{H} \mathrm{NMR}\left(500 \mathrm{MHz}, \mathrm{CDCl}_{3}\right) \delta=6.98(\mathrm{~d}, J=8.0$, $1 \mathrm{H}$ ), 6.54 (d, $J=2.2,1 \mathrm{H}$ ), 6.51 (dd, $J=8.0,2.4,1 \mathrm{H}$ ), 4.13 (q, $J=7.1,2 \mathrm{H}$ ), 3.51 (s, 2H), 2.23 $(\mathrm{s}, 3 \mathrm{H}), 1.24$ (t, $J=7.1,3 \mathrm{H}) .{ }^{13} \mathrm{C}$ NMR $\left(126 \mathrm{MHz}, \mathrm{CDCl}_{3}\right) \delta=172.22,145.21,137.98,131.20$, 123.40, 117.46, 113.17, 60.77, 38.59, 19.82, 14.33. MS $\left(\mathrm{ESI}^{+}\right): \mathrm{m} / \mathrm{z} 194.20\left([\mathrm{M}+\mathrm{H}]^{+}\right)$.

Ethyl 3-hydroxybenzoate (75):

Preparation according to general procedure $\mathrm{C}$ using 3-hydroxybenzoic acid $(63,2.00 \mathrm{~g}, 14.5$ mmol, 1.00 equiv.) and $\mathrm{H}_{2} \mathrm{SO}_{4}(1.25 \mathrm{~mL})$ to yield 75 as a yellow solid $(2.3 \mathrm{~g}, 95 \%)$ which was used without further purification. ${ }^{1} \mathrm{H}$ NMR $\left(500 \mathrm{MHz}, \mathrm{CDCl}_{3}\right) \delta=7.63-7.59(\mathrm{~m}, 2 \mathrm{H}), 7.33-$ $7.29(\mathrm{~m}, 1 \mathrm{H}), 7.09-7.05(\mathrm{~m}, 1 \mathrm{H}), 6.05(\mathrm{~s}, 1 \mathrm{H}), 4.38(\mathrm{q}, J=7.1 \mathrm{~Hz}, 2 \mathrm{H}), 1.39(\mathrm{t}, J=7.1 \mathrm{~Hz}$, $3 \mathrm{H}) .{ }^{13} \mathrm{C}$ NMR $\left(126 \mathrm{MHz}, \mathrm{CDCl}_{3}\right) \delta=167.01,156.05,131.81,129.82,121.95,120.36,116.47$, 61.46, 14.39. MS (ESI-): $m / z 165.20\left([\mathrm{M}-\mathrm{H}]^{-}\right)$. 
Ethyl 2-(4-hydroxyphenoxy)acetate (76):

Preparation according to general procedure $C$ using 2-(4-hydroxyphenoxy)acetic acid (64, 2.00 g, 11.9 mmol, 1.00 equiv.) and $\mathrm{H}_{2} \mathrm{SO}_{4}(0.75 \mathrm{~mL})$ to yield 76 as a yellow solid $(1.6 \mathrm{~g}, 67 \%)$ which was used without further purification. ${ }^{1} \mathrm{H}$ NMR $\left(500 \mathrm{MHz}, \mathrm{CDCl}_{3}\right) \delta=6.83-6.79(\mathrm{~m}, 2 \mathrm{H}), 6.77$ $-6.73(\mathrm{~m}, 2 \mathrm{H}), 4.73(\mathrm{~s}, 1 \mathrm{H}), 4.56(\mathrm{~s}, 2 \mathrm{H}), 4.27(\mathrm{q}, J=7.1 \mathrm{~Hz}, 2 \mathrm{H}), 1.29(\mathrm{t}, J=7.1 \mathrm{~Hz}, 3 \mathrm{H}) .{ }^{13} \mathrm{C}$ $\operatorname{NMR}\left(126 \mathrm{MHz}, \mathrm{CDCl}_{3}\right) \delta=169.48,152.19,150.49,116.24,116.20,66.52,61.52,14.31$. MS $\left(\mathrm{ESI}^{+}\right): \mathrm{m} / \mathrm{z} 219.09\left([\mathrm{M}+\mathrm{Na}]^{+}\right)$.

\section{Ethyl 4-(4-hydroxyphenoxy)benzoate (77):}

Preparation according to general procedure $\mathrm{C}$ using 4-(4-hydroxyphenoxy)benzoic acid (65, $1.00 \mathrm{~g}, 4.34 \mathrm{mmol}, 1.00$ equiv.) and $\mathrm{H}_{2} \mathrm{SO}_{4}(0.25 \mathrm{~mL})$. The product was purified by column chromatography using hexane/EtOAc $(3: 1)$ to obtain 77 as a colorless solid $(1.0 \mathrm{~g}, 92 \%) .{ }^{1} \mathrm{H}$ $\operatorname{NMR}\left(500 \mathrm{MHz}, \mathrm{CDCl}_{3}\right) \delta=8.02-7.95(\mathrm{~m}, 2 \mathrm{H}), 6.98-6.90(\mathrm{~m}, 4 \mathrm{H}), 6.89-6.84(\mathrm{~m}, 2 \mathrm{H}), 5.28$ $(\mathrm{s}, 1 \mathrm{H}), 4.36(\mathrm{q}, J=7.1 \mathrm{~Hz}, 2 \mathrm{H}), 1.38(\mathrm{t}, J=7.1 \mathrm{~Hz}, 3 \mathrm{H}) \cdot{ }^{13} \mathrm{C} \mathrm{NMR}\left(126 \mathrm{MHz}, \mathrm{CDCl}_{3}\right) \delta=$ $166.63,162.88,152.85,148.78,131.76,124.26,121.96,116.70,116.46,61.07,14.48$. MS $\left(\mathrm{ESI}^{-}\right): \mathrm{m} / \mathrm{z} 257.32\left([\mathrm{M}-\mathrm{H}]^{-}\right)$.

Ethyl 2-(4-hydroxyphenyl)-2-methylpropanoate (78):

Preparation according to general procedure $\mathrm{C}$ using 2-(4-hydroxyphenyl)-2-methylpropanoic acid (66, $0.25 \mathrm{~g}, 1.4 \mathrm{mmol}, 1.00$ equiv.) and $\mathrm{H}_{2} \mathrm{SO}_{4}(0.10 \mathrm{~mL})$ to yield 78 as a brown oil $(0.25$ $\mathrm{g}, 86 \%)$ which was used without further purification. ${ }^{1} \mathrm{H} \mathrm{NMR}\left(500 \mathrm{MHz}, \mathrm{CDCl}_{3}\right) \delta=7.23-7.19$ $(\mathrm{m}, 2 \mathrm{H}), 6.79-6.75(\mathrm{~m}, 2 \mathrm{H}), 5.03(\mathrm{~s}, 1 \mathrm{H}), 4.11(\mathrm{q}, J=7.1 \mathrm{~Hz}, 2 \mathrm{H}), 1.54(\mathrm{~s}, 6 \mathrm{H}), 1.18(\mathrm{t}, \mathrm{J}=$ $7.1 \mathrm{~Hz}, 3 \mathrm{H}) .{ }^{13} \mathrm{C}$ NMR $\left(126 \mathrm{MHz}, \mathrm{CDCl}_{3}\right) \delta=177.26,154.36,137.13,127.12,115.24,60.99$, 45.86, 26.72, 14.19. $\mathrm{MS}\left(\mathrm{ESI}^{+}\right): \mathrm{m} / \mathrm{z} 231.13\left([\mathrm{M}+\mathrm{Na}]^{+}\right)$.

Ethyl 4-(4-((5-isopropyl-3-phenylisoxazol-4-yl)methoxy)phenyl)butanoate (79):

Preparation according to general procedure $\mathrm{F}$ using (5-isopropyl-3-phenylisoxazol-4yl)methanol (53, $0.20 \mathrm{~g}, 0.92 \mathrm{mmol}, 1.0$ equiv.), ethyl 4-(4-hydroxyphenyl)butanoate (70, 0.19 g, $0.92 \mathrm{mmol}, 1.0$ equiv.), triphenylphosphine ( $0.24 \mathrm{~g}, 0.92 \mathrm{mmol}, 1.0$ equiv.) and diisopropyl azodicarboxylate $(0.18 \mathrm{~mL}, 0.92 \mathrm{mmol}, 1.0$ equiv.). The product was purified by column chromatography using hexane/EtOAc (5:1) to obtain 79 as a yellow oil $(0.11 \mathrm{~g}, 30 \%) .{ }^{1} \mathrm{H}$ NMR $\left(500 \mathrm{MHz}, \mathrm{CDCl}_{3}\right) \delta=7.74-7.69(\mathrm{~m}, 2 \mathrm{H}), 7.46-7.41(\mathrm{~m}, 3 \mathrm{H}), 7.14-7.10(\mathrm{~m}, 2 \mathrm{H}), 6.90-$ $6.86(\mathrm{~m}, 2 \mathrm{H}), 4.82(\mathrm{~s}, 2 \mathrm{H}), 4.13(\mathrm{q}, J=7.1 \mathrm{~Hz}, 2 \mathrm{H}), 3.25$ (hept, $J=7.0 \mathrm{~Hz}, 1 \mathrm{H}), 2.61$ (t, $J=7.6$ $\mathrm{Hz}, 2 \mathrm{H}), 2.32$ (t, $J=7.5 \mathrm{~Hz}, 2 \mathrm{H}), 1.99-1.89(\mathrm{~m}, 2 \mathrm{H}), 1.37(\mathrm{~d}, J=7.0 \mathrm{~Hz}, 6 \mathrm{H}), 1.26$ (t, $J=7.1$ $\mathrm{Hz}, 3 \mathrm{H}) .{ }^{13} \mathrm{C}$ NMR $\left(126 \mathrm{MHz}, \mathrm{CDCl}_{3}\right) \delta=177.57,173.69,163.00,156.68,134.68,129.79$, $129.69,129.15,129.01,128.55,115.23,107.90,60.44,59.41,34.41,33.78,26.96,26.91$, 21.03, 14.41. MS $\left(\mathrm{ESI}^{+}\right): \mathrm{m} / \mathrm{z} 408.25\left([\mathrm{M}+\mathrm{H}]^{+}\right)$.

Ethyl 5-(4-((5-isopropyl-3-phenylisoxazol-4-yl)methoxy)phenyl)pentanoate (80):

Preparation according to general procedure $F$ using (5-isopropyl-3-phenylisoxazol-4yl)methanol (53, $0.20 \mathrm{~g}, 0.92 \mathrm{mmol}, 1.0$ equiv.), ethyl 5-(4-hydroxyphenyl)pentanoate (71, 0.20 g, $0.92 \mathrm{mmol}, 1.0$ equiv.), triphenylphosphine ( $0.24 \mathrm{~g}, 0.92 \mathrm{mmol}, 1.0$ equiv.) and diisopropyl azodicarboxylate $(0.18 \mathrm{~mL}, 0.92 \mathrm{mmol}, 1.0$ equiv.). The product was purified by column chromatography using hexane/EtOAc (7:1) to obtain 80 as a yellow oil $(0.17 \mathrm{~g}, 44 \%)$. ${ }^{1} \mathrm{H}$ NMR $\left(500 \mathrm{MHz}, \mathrm{CDCl}_{3}\right) \delta=7.75-7.69(\mathrm{~m}, 2 \mathrm{H}), 7.46-7.40(\mathrm{~m}, 3 \mathrm{H}), 7.11(\mathrm{~d}, J=8.5 \mathrm{~Hz}, 2 \mathrm{H}), 6.90$ - $6.85(\mathrm{~m}, 2 \mathrm{H}), 4.81(\mathrm{~s}, 2 \mathrm{H}), 4.12(\mathrm{q}, J=7.1 \mathrm{~Hz}, 2 \mathrm{H}), 3.31-3.20(\mathrm{~m}, 1 \mathrm{H}), 2.59(\mathrm{t}, J=7.2 \mathrm{~Hz}$, 
2H), $2.32(\mathrm{t}, J=7.1 \mathrm{~Hz}, 2 \mathrm{H}), 1.71-1.59(\mathrm{~m}, 4 \mathrm{H}), 1.37(\mathrm{~d}, J=7.0 \mathrm{~Hz}, 6 \mathrm{H}), 1.25$ (t, $J=7.1 \mathrm{~Hz}$, $3 \mathrm{H}) .{ }^{13} \mathrm{C}$ NMR $\left(126 \mathrm{MHz}, \mathrm{CDCl}_{3}\right) \delta=177.56,173.82,163.00,156.53,135.41,129.78,129.55$, $129.16,129.01,128.55,115.18,107.92,60.39,59.40,34.83,34.35,31.25,26.95,24.68$, 21.03, 14.40. MS $\left(\mathrm{ESI}^{+}\right): \mathrm{m} / \mathrm{z} 444.27\left([\mathrm{M}+\mathrm{Na}]^{+}\right)$.

Ethyl 6-(4-((5-isopropyl-3-phenylisoxazol-4-yl)methoxy)phenyl)hexanoate (81):

Preparation according to general procedure $\mathrm{F}$ using (5-isopropyl-3-phenylisoxazol-4yl)methanol (53, $0.13 \mathrm{~g}, 0.60 \mathrm{mmol}, 1.0$ equiv.), ethyl 6-(4-hydroxyphenyl)hexanoate $(\mathbf{7 2}, 0.14$ g, $0.60 \mathrm{mmol}, 1.0$ equiv.), triphenylphosphine ( $0.16 \mathrm{~g}, 0.60 \mathrm{mmol}, 1.0$ equiv.) and diisopropyl azodicarboxylate $(0.12 \mathrm{~mL}, 0.60 \mathrm{mmol}, 1.0$ equiv.). The product was purified by column chromatography using hexane/EtOAc (8:1) to obtain 81 as a yellow oil $(0.15 \mathrm{~g}, 58 \%)$. ${ }^{1} \mathrm{H}$ NMR $\left(500 \mathrm{MHz}, \mathrm{CDCl}_{3}\right) \delta=7.75-7.70(\mathrm{~m}, 2 \mathrm{H}), 7.47-7.41(\mathrm{~m}, 3 \mathrm{H}), 7.11(\mathrm{~d}, J=8.5 \mathrm{~Hz}, 2 \mathrm{H}), 6.91$ $-6.85(\mathrm{~m}, 2 \mathrm{H}), 4.82(\mathrm{~s}, 2 \mathrm{H}), 4.12(\mathrm{q}, J=7.1 \mathrm{~Hz}, 2 \mathrm{H}), 3.30-3.20(\mathrm{~m}, 1 \mathrm{H}), 2.62-2.52(\mathrm{~m}, 2 \mathrm{H})$, $2.30(\mathrm{t}, J=7.5 \mathrm{~Hz}, 2 \mathrm{H}), 1.70-1.57(\mathrm{~m}, 4 \mathrm{H}), 1.45-1.33(\mathrm{~m}, 8 \mathrm{H}), 1.25(\mathrm{t}, J=7.1 \mathrm{~Hz}, 3 \mathrm{H}) .{ }^{13} \mathrm{C}$ $\operatorname{NMR}\left(126 \mathrm{MHz}, \mathrm{CDCl}_{3}\right) \delta=177.56,173.95,163.01,156.47,135.79,129.78,129.54,129.16$, 129.00, 128.56, 115.15, 107.94, 60.36, 59.41, 34.97, 34.44, 31.47, 28.85, 26.95, 24.97, 21.03, 14.40. $\mathrm{MS}\left(\mathrm{ESI}^{+}\right): \mathrm{m} / \mathrm{z} 458.30\left([\mathrm{M}+\mathrm{Na}]^{+}\right)$.

Ethyl 4-(4-((5-isopropyl-3-phenylisoxazol-4-yl)methoxy)phenoxy)benzoate (82):

Preparation according to general procedure $F$ using (5-isopropyl-3-phenylisoxazol-4yl)methanol (53, $0.20 \mathrm{~g}, 0.92 \mathrm{mmol}, 1.0$ equiv.), ethyl 4-(4-hydroxyphenoxy)benzoate (77, 0.24 g, $0.92 \mathrm{mmol}, 1.0$ equiv.), triphenylphosphine ( $0.24 \mathrm{~g}, 0.92 \mathrm{mmol}, 1.0$ equiv.) and diisopropyl azodicarboxylate $(0.18 \mathrm{~mL}, 0.92 \mathrm{mmol}, 1.0$ equiv.). The product was purified by column chromatography using hexane/EtOAc $(7: 1)$ to obtain 82 as a yellow oil $(0.23 \mathrm{~g}, 55 \%) .{ }^{1} \mathrm{H}$ NMR $\left(500 \mathrm{MHz}, \mathrm{CDCl}_{3}\right) \delta=8.02-7.97(\mathrm{~m}, 2 \mathrm{H}), 7.75-7.70(\mathrm{~m}, 2 \mathrm{H}), 7.49-7.43(\mathrm{~m}, 3 \mathrm{H}), 7.06-$ $7.00(\mathrm{~m}, 2 \mathrm{H}), 6.99-6.92(\mathrm{~m}, 4 \mathrm{H}), 4.85(\mathrm{~s}, 2 \mathrm{H}), 4.36(\mathrm{q}, J=7.1 \mathrm{~Hz}, 2 \mathrm{H}), 3.28$ (hept, $J=7.0$ $\mathrm{Hz}, 1 \mathrm{H}), 1.42-1.36(\mathrm{~m}, 9 \mathrm{H}) .{ }^{13} \mathrm{C}$ NMR $\left(126 \mathrm{MHz}, \mathrm{CDCl}_{3}\right) \delta=177.62,166.30,162.99,162.53$, 155.24, 149.66, 131.75, 129.87, 129.11, 129.04, 128.55, 124.63, 121.78, 116.64, 116.60, $\left.107.70,60.96,59.94,26.99,21.06,14.51 . \mathrm{MS}(\mathrm{ESI})^{+}\right): \mathrm{m} / \mathrm{z} 480.23\left([\mathrm{M}+\mathrm{Na}]^{+}\right)$.

Ethyl 4-(4-((5-methyl-3-phenylisoxazol-4-yl)methoxy)phenyl)butanoate (83):

Preparation according to general procedure $\mathrm{F}$ using (5-methyl-3-phenylisoxazol-4-yl)methanol (54, $0.20 \mathrm{~g}, 1.1 \mathrm{mmol}, 1.0$ equiv.), ethyl 4-(4-hydroxyphenyl)butanoate $(\mathbf{7 0}, 0.22 \mathrm{~g}, 1.1 \mathrm{mmol}$, 1.0 equiv.), triphenylphosphine ( $0.28 \mathrm{~g}, 1.1 \mathrm{mmol}, 1.0$ equiv.) and diisopropyl azodicarboxylate $(0.21 \mathrm{~mL}, 1.1 \mathrm{mmol}, 1.0$ equiv.). The product was purified by column chromatography using hexane/EtOAc (5:1) to obtain 83 as a yellow oil $(0.23 \mathrm{~g}, 58 \%) .{ }^{1} \mathrm{H} \mathrm{NMR}\left(500 \mathrm{MHz}, \mathrm{CDCl}_{3}\right) \delta=$ $7.76-7.70(\mathrm{~m}, 2 \mathrm{H}), 7.47-7.41(\mathrm{~m}, 3 \mathrm{H}), 7.15-7.10(\mathrm{~m}, 2 \mathrm{H}), 6.92-6.85(\mathrm{~m}, 2 \mathrm{H}), 4.83(\mathrm{~s}, 2 \mathrm{H})$, $4.13(\mathrm{q}, J=7.1 \mathrm{~Hz}, 2 \mathrm{H}), 2.64-2.60(\mathrm{~m}, 2 \mathrm{H}), 2.48(\mathrm{~s}, 3 \mathrm{H}), 2.32$ (t, $J=7.5 \mathrm{~Hz}, 2 \mathrm{H}), 1.98-1.89$ $(\mathrm{m}, 2 \mathrm{H}), 1.26(\mathrm{t}, J=7.1 \mathrm{~Hz}, 3 \mathrm{H}) .{ }^{13} \mathrm{C} N M R\left(126 \mathrm{MHz}, \mathrm{CDCl}_{3}\right) \delta=173.57,169.66,162.79$, 156.50, 134.62, 129.74, 129.59, 128.96, 128.92, 128.32, 115.07, 109.66, 60.32, 59.61, 34.28, 33.65, 26.77, 14.28, 11.38. MS (ESI $\left.{ }^{+}\right): m / z 402.14\left([\mathrm{M}+\mathrm{Na}]^{+}\right)$.

Ethyl 4-(4-((3-(2-chlorophenyl)-5-isopropylisoxazol-4-yl)methoxy)phenyl)butanoate (84):

Preparation according to general procedure F using (3-(2-chlorophenyl)-5-isopropylisoxazol4-yl)methanol (50, $0.13 \mathrm{~g}, 0.53 \mathrm{mmol}, 1.0$ equiv.), ethyl 4-(4-hydroxyphenyl)butanoate (70, 
$0.11 \mathrm{~g}, 0.53 \mathrm{mmol}, 1.0$ equiv.), triphenylphosphine $(0.14 \mathrm{~g}, 0.53 \mathrm{mmol}, 1.0$ equiv.) and diisopropyl azodicarboxylate $(0.10 \mathrm{~mL}, 0.53 \mathrm{mmol}, 1.0$ equiv.). The product was purified by column chromatography using hexane/EtOAc (8:1) to obtain 84 as a colorless oil $(0.12 \mathrm{~g}$, $52 \%) .{ }^{1} \mathrm{H}$ NMR $\left(500 \mathrm{MHz}, \mathrm{CDCl}_{3}\right) \delta=7.48(\mathrm{dd}, J=8.0,1.0 \mathrm{~Hz}, 1 \mathrm{H}), 7.46$ (dd, $J=7.5,1.7 \mathrm{~Hz}$, $1 \mathrm{H}), 7.40(\mathrm{td}, J=7.7,1.8 \mathrm{~Hz}, 1 \mathrm{H}), 7.33(\mathrm{td}, J=7.5,1.2 \mathrm{~Hz}, 1 \mathrm{H}), 7.03(\mathrm{~d}, J=8.6 \mathrm{~Hz}, 2 \mathrm{H}), 6.72$ $-6.68(\mathrm{~m}, 2 \mathrm{H}), 4.75(\mathrm{~s}, 2 \mathrm{H}), 4.11(\mathrm{q}, J=7.1 \mathrm{~Hz}, 2 \mathrm{H}), 3.38-3.25(\mathrm{~m}, 1 \mathrm{H}), 2.60-2.53(\mathrm{~m}, 2 \mathrm{H})$, $2.28(\mathrm{t}, J=7.5 \mathrm{~Hz}, 2 \mathrm{H}), 1.94-1.83(\mathrm{~m}, 2 \mathrm{H}), 1.40(\mathrm{~d}, J=7.0 \mathrm{~Hz}, 6 \mathrm{H}), 1.24(\mathrm{t}, J=7.1 \mathrm{~Hz}, 3 \mathrm{H})$. ${ }^{13} \mathrm{C}$ NMR $\left(126 \mathrm{MHz}, \mathrm{CDCl}_{3}\right) \delta=176.77,173.67,161.41,156.61,134.39,133.67,132.00$, 131.03, 129.98, 129.53, 128.54, 127.05, 114.94, 109.62, 60.42, 59.75, 34.36, 33.75, 27.21, 26.88, 20.89, 14.40. MS (ESI+): $\mathrm{m} / \mathrm{z} 464.21\left([\mathrm{M}+\mathrm{Na}]^{+}\right)$.

Ethyl 4-(4-((5-isopropyl-3-(2-(trifluoromethyl)phenyl)isoxazol-4-yl)methoxy)phenyl)butanoate (85):

Preparation according to general procedure $F$ using (5-isopropyl-3-(2(trifluoromethyl)phenyl)isoxazol-4-yl)methanol $(51,0.15 \mathrm{~g}, 0.53 \mathrm{mmol}, 1.0$ equiv.), ethyl 4-(4hydroxyphenyl)butanoate $(70,0.11 \mathrm{~g}, 0.53 \mathrm{mmol}, 1.0$ equiv. $)$, triphenylphosphine $(0.14 \mathrm{~g}, 0.53$ mmol, 1.0 equiv.) and diisopropyl azodicarboxylate $(0.10 \mathrm{~mL}, 0.53 \mathrm{mmol}, 1.0$ equiv.). The product was purified by column chromatography using hexane/EtOAc (8:1) to obtain 85 as a colorless oil $(0.14 \mathrm{~g}, 56 \%) .{ }^{1} \mathrm{H}$ NMR $\left(500 \mathrm{MHz}, \mathrm{CDCl}_{3}\right) \delta=7.80-7.76(\mathrm{~m}, 1 \mathrm{H}), 7.61-7.54(\mathrm{~m}$, $2 \mathrm{H}), 7.50-7.47(\mathrm{~m}, 1 \mathrm{H}), 7.04(\mathrm{~d}, J=8.6 \mathrm{~Hz}, 2 \mathrm{H}), 6.73-6.68(\mathrm{~m}, 2 \mathrm{H}), 4.62(\mathrm{~s}, 2 \mathrm{H}), 4.11(\mathrm{q}, J$ $=7.1 \mathrm{~Hz}, 2 \mathrm{H}$ ), 3.29 (hept, $J=7.0 \mathrm{~Hz}, 1 \mathrm{H}$ ), 2.56 (t, $J=7.6 \mathrm{~Hz}, 2 \mathrm{H}$ ), 2.28 (t, $J=7.5 \mathrm{~Hz}, 2 \mathrm{H}$ ), $1.94-1.84(\mathrm{~m}, 2 \mathrm{H}), 1.40(\mathrm{~d}, J=7.0 \mathrm{~Hz}, 6 \mathrm{H}), 1.24(\mathrm{t}, J=7.1 \mathrm{~Hz}, 3 \mathrm{H}) .{ }^{13} \mathrm{C}$ NMR $(126 \mathrm{MHz}$, $\left.\mathrm{CDCl}_{3}\right) \delta=176.47,173.66,161.46,156.62,134.46,132.21,131.70,129.98,129.79,129.54$, 127.54, 126.59, 123.73, 114.90, 109.73, 60.42, 59.21, 34.35, 33.74, 27.11, 26.88, 20.93, 14.39. $\mathrm{MS}\left(\mathrm{ESI}^{+}\right): \mathrm{m} / z 498.16\left([\mathrm{M}+\mathrm{Na}]^{+}\right)$.

Ethyl 4-(4-((3-(2,6-dichlorophenyl)-5-isopropylisoxazol-4-yl)methoxy)phenyl)butanoate (86):

Preparation according to general procedure $F$ using (3-(2,6-dichlorophenyl)-5isopropylisoxazol-4-yl)methanol $(49,0.14 \mathrm{~g}, \quad 0.48 \mathrm{mmol}, 1.0$ equiv.), ethyl 4-(4hydroxyphenyl)butanoate $(70,0.10 \mathrm{~g}, 0.48 \mathrm{mmol}, 1.0$ equiv. $)$, triphenylphosphine $(0.13 \mathrm{~g}, 0.48$ mmol, 1.0 equiv.) and diisopropyl azodicarboxylate ( $94 \mu \mathrm{L}, 0.48 \mathrm{mmol}, 1.0$ equiv.). The product was purified by column chromatography using hexane/EtOAc $(7: 1)$ to obtain $\mathbf{8 6}$ as a yellow oil $(0.15 \mathrm{~g}, 65 \%) .{ }^{1} \mathrm{H}$ NMR $\left(500 \mathrm{MHz}, \mathrm{CDCl}_{3}\right) \delta=7.41-7.38(\mathrm{~m}, 2 \mathrm{H}), 7.34-7.29(\mathrm{~m}, 1 \mathrm{H}), 7.02$ (d, $J=8.5 \mathrm{~Hz}, 2 \mathrm{H}), 6.72-6.68(\mathrm{~m}, 2 \mathrm{H}), 4.69(\mathrm{~s}, 2 \mathrm{H}), 4.11(\mathrm{q}, J=7.1 \mathrm{~Hz}, 2 \mathrm{H}), 3.37-3.27(\mathrm{~m}$, $1 \mathrm{H}), 2.55(\mathrm{t}, J=7.6 \mathrm{~Hz}, 2 \mathrm{H}), 2.28(\mathrm{t}, J=7.5 \mathrm{~Hz}, 2 \mathrm{H}), 1.94-1.83(\mathrm{~m}, 2 \mathrm{H}), 1.40(\mathrm{~d}, J=7.0 \mathrm{~Hz}$, $6 \mathrm{H}), 1.24(\mathrm{t}, J=7.1 \mathrm{~Hz}, 3 \mathrm{H}) .{ }^{13} \mathrm{C} \mathrm{NMR}\left(126 \mathrm{MHz}, \mathrm{CDCl}_{3}\right) \delta=176.50,173.68,159.29,156.68$, 135.97, 134.37, 131.32, 129.49, 128.22, 128.07, 114.92, 109.68, 60.41, 59.53, 34.35, 33.73, 27.22, 26.88, 20.92, 14.40. MS (ESI $\left.{ }^{+}\right): m / z 498.12\left([\mathrm{M}+\mathrm{Na}]^{+}\right)$.

Ethyl 4-(4-((3-(2,6-dimethylphenyl)-5-isopropylisoxazol-4-yl)methoxy)phenyl)butanoate (87): Preparation according to general procedure F using (3-(2,6-dimethylphenyl)-5isopropylisoxazol-4-yl)methanol $(\mathbf{5 2}, 0.12 \mathrm{~g}, \quad 0.49 \mathrm{mmol}, 1.0$ equiv.), ethyl 4-(4hydroxyphenyl)butanoate $(70,0.10 \mathrm{~g}, 0.49 \mathrm{mmol}, 1.0$ equiv. $)$, triphenylphosphine $(0.13 \mathrm{~g}, 0.49$ mmol, 1.0 equiv.) and diisopropyl azodicarboxylate ( $95 \mu \mathrm{L}, 0.49 \mathrm{mmol}, 1.0$ equiv.). The product was purified by column chromatography using hexane/EtOAc (8:1) to obtain 87 as a yellow oil $(84 \mathrm{mg}, 38 \%) .{ }^{1} \mathrm{H}$ NMR $\left(500 \mathrm{MHz}\right.$, methanol- $\left.d_{4}\right) \delta=7.26-7.21(\mathrm{~m}, 1 \mathrm{H}), 7.12(\mathrm{~d}, J=7.7 \mathrm{~Hz}$, 
2H), $7.01(\mathrm{~d}, J=8.6 \mathrm{~Hz}, 2 \mathrm{H}), 6.71-6.65(\mathrm{~m}, 2 \mathrm{H}), 4.61(\mathrm{~s}, 2 \mathrm{H}), 4.08(\mathrm{q}, J=7.1 \mathrm{~Hz}, 2 \mathrm{H}), 3.44$ - $3.35(\mathrm{~m}, 1 \mathrm{H}), 2.54(\mathrm{t}, J=7.5 \mathrm{~Hz}, 2 \mathrm{H}), 2.26(\mathrm{t}, J=7.4 \mathrm{~Hz}, 2 \mathrm{H}), 2.09(\mathrm{~s}, 6 \mathrm{H}), 1.91-1.79(\mathrm{~m}$, $2 \mathrm{H}), 1.41(\mathrm{~d}, J=7.0 \mathrm{~Hz}, 6 \mathrm{H}), 1.22(\mathrm{t}, J=7.1 \mathrm{~Hz}, 3 \mathrm{H}) .{ }^{13} \mathrm{C}$ NMR $\left(126 \mathrm{MHz}\right.$, methanol- $\left.d_{4}\right) \delta=$ 178.36, 175.36, 164.18, 158.11, 138.76, 135.58, 130.52, 130.46, 129.02, 128.48, 115.82, $110.99,61.41,60.15,35.13,34.32,28.21,27.98,21.14,20.10,14.52 . \mathrm{MS}_{\left(\mathrm{ESI}^{+}\right): \mathrm{m} / \mathrm{z} 458.21}$ $\left([\mathrm{M}+\mathrm{Na}]^{+}\right)$.

Ethyl 4-((5-isopropyl-3-phenylisoxazol-4-yl)methoxy)benzoate (88):

Preparation according to general procedure $F$ using (5-isopropyl-3-phenylisoxazol-4yl)methanol (53, $0.43 \mathrm{~g}, 2.0 \mathrm{mmol}, 1.0$ equiv.), ethyl 4-hydroxybenzoate $(67,0.33 \mathrm{~g}, 2.0 \mathrm{mmol}$, 1.0 equiv.), triphenylphosphine $(0.52 \mathrm{~g}, 2.0 \mathrm{mmol}, 1.0$ equiv.) and diisopropyl azodicarboxylate ( $0.39 \mathrm{~mL}, 2.0 \mathrm{mmol}, 1.0$ equiv.). The product was purified by column chromatography using hexane/EtOAc (8:1) to obtain 88 as a yellow oil $(0.49 \mathrm{~g}, 67 \%) .{ }^{1} \mathrm{H} \mathrm{NMR}\left(500 \mathrm{MHz}, \mathrm{CDCl}_{3}\right) \delta=$ $8.04-8.00(\mathrm{~m}, 2 \mathrm{H}), 7.68-7.64(\mathrm{~m}, 2 \mathrm{H}), 7.46-7.40(\mathrm{~m}, 3 \mathrm{H}), 6.99-6.94(\mathrm{~m}, 2 \mathrm{H}), 4.90(\mathrm{~s}$, $2 \mathrm{H}), 4.36(\mathrm{q}, J=7.1 \mathrm{~Hz}, 2 \mathrm{H}), 3.32-3.24(\mathrm{~m}, 1 \mathrm{H}), 1.42-1.36(\mathrm{~m}, 9 \mathrm{H}) .{ }^{13} \mathrm{C} N M R(126 \mathrm{MHz}$, $\left.\mathrm{CDCl}_{3}\right) \delta=177.75,166.37,162.99,161.93,131.80,129.91,129.07,128.97,128.49,123.86$, $114.51,107.35,60.91,59.40,27.02,21.03,14.53 . \mathrm{MS}\left(\mathrm{ESI}^{+}\right): \mathrm{m} / \mathrm{z} 388.18\left([\mathrm{M}+\mathrm{Na}]^{+}\right)$.

Ethyl 4-((3-(2-chlorophenyl)-5-isopropylisoxazol-4-yl)methoxy)benzoate (89):

Preparation according to general procedure $\mathrm{F}$ using (3-(2-chlorophenyl)-5-isopropylisoxazol4-yl)methanol (50, $0.67 \mathrm{~g}, 2.7 \mathrm{mmol}, 1.0$ equiv.), ethyl 4-hydroxybenzoate (67, $0.45 \mathrm{~g}, 2.7$ mmol, 1.0 equiv.), triphenylphosphine $(0.70 \mathrm{~g}, 2.7 \mathrm{mmol}, 1.0$ equiv.) and diisopropyl azodicarboxylate $(0.53 \mathrm{~mL}, 2.7 \mathrm{mmol}, 1.0$ equiv. $)$. The product was purified by column chromatography using hexane/EtOAc (8:1) to obtain 89 as a yellow oil $(0.86 \mathrm{~g}, 80 \%) .{ }^{1} \mathrm{H}$ NMR $\left(500 \mathrm{MHz}, \mathrm{CDCl}_{3}\right) \delta=7.95-7.90(\mathrm{~m}, 2 \mathrm{H}), 7.50-7.44(\mathrm{~m}, 2 \mathrm{H}), 7.41(\mathrm{td}, J=7.7,1.8 \mathrm{~Hz}, 1 \mathrm{H})$, 7.34 (td, $J=7.5,1.3 \mathrm{~Hz}, 1 \mathrm{H}), 6.79-6.75(\mathrm{~m}, 2 \mathrm{H}), 4.84(\mathrm{~s}, 2 \mathrm{H}), 4.33(\mathrm{q}, J=7.1 \mathrm{~Hz}, 2 \mathrm{H}), 3.32$ (hept, $J=7.0 \mathrm{~Hz}, 1 \mathrm{H}), 1.41(\mathrm{~d}, J=7.0 \mathrm{~Hz}, 6 \mathrm{H}), 1.36(\mathrm{t}, J=7.1 \mathrm{~Hz}, 3 \mathrm{H}) .{ }^{13} \mathrm{C}$ NMR $(126 \mathrm{MHz}$, $\left.\mathrm{CDCl}_{3}\right) \delta=176.85,166.35,161.86,161.32,133.62,131.93,131.63,131.18,130.03,128.38$,

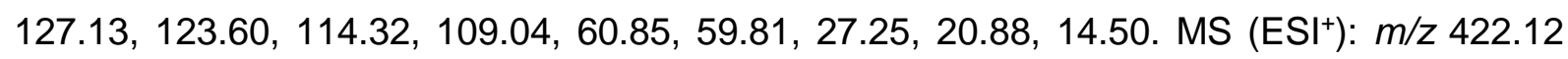
$\left([\mathrm{M}+\mathrm{Na}]^{+}\right)$.

Ethyl 4-((3-(2,6-dichlorophenyl)-5-isopropylisoxazol-4-yl)methoxy)benzoate (90):

Preparation according to general procedure $F$ using (3-(2,6-Dichlorophenyl)-5isopropylisoxazol-4-yl)methanol (49, $0.60 \mathrm{~g}, 2.1 \mathrm{mmol}, 1.0$ equiv.), ethyl 4-hydroxybenzoate (67, $0.35 \mathrm{~g}, 2.1 \mathrm{mmol}, 1.0$ equiv.), triphenylphosphine (0.55 g, $2.1 \mathrm{mmol}, 1.0$ equiv.) and diisopropyl azodicarboxylate $(0.41 \mathrm{~mL}, 2.1 \mathrm{mmol}, 1.0$ equiv.). The product was purified by column chromatography using hexane/EtOAc (6:1) to obtain 90 as a yellow oil $(0.61 \mathrm{~g}, 67 \%) .{ }^{1} \mathrm{H}$ $\operatorname{NMR}\left(500 \mathrm{MHz}, \mathrm{CDCl}_{3}\right) \delta=7.95-7.89(\mathrm{~m}, 2 \mathrm{H}), 7.42-7.38(\mathrm{~m}, 2 \mathrm{H}), 7.34-7.29(\mathrm{~m}, 1 \mathrm{H}), 6.80$ $-6.75(\mathrm{~m}, 2 \mathrm{H}), 4.78(\mathrm{~s}, 2 \mathrm{H}), 4.33(\mathrm{q}, J=7.1 \mathrm{~Hz}, 2 \mathrm{H}), 3.33$ (hept, $J=7.0 \mathrm{~Hz}, 1 \mathrm{H}), 1.42(\mathrm{~d}, J=$ $7.0 \mathrm{~Hz}, 6 \mathrm{H}), 1.36(\mathrm{t}, J=7.1 \mathrm{~Hz}, 3 \mathrm{H}) .{ }^{13} \mathrm{C} \mathrm{NMR}\left(126 \mathrm{MHz}, \mathrm{CDCl}_{3}\right) \delta=176.59,166.37,161.91$, $159.19,135.91,131.60,131.45,128.26,127.86,123.58,114.26,109.07,60.85,59.51,27.25$, 20.94, 14.50. MS $\left(\mathrm{ESI}^{+}\right): \mathrm{m} / \mathrm{z} 434.08\left([\mathrm{M}+\mathrm{H}]^{+}\right)$.

Ethyl 2-chloro-4-((3-(2,6-dichlorophenyl)-5-isopropylisoxazol-4-yl)methoxy)benzoate (91):

Preparation according to general procedure $F$ using (3-(2,6-dichlorophenyl)-5isopropylisoxazol-4-yl)methanol (49, $0.529 \mathrm{~g}, 1.85 \mathrm{mmol}, 1.00$ equiv.), ethyl 2-chloro-4- 
hydroxybenzoate $(73,0.371 \mathrm{~g}, 1.85 \mathrm{mmol}, 1.00$ equiv.), triphenylphosphine $(0.485 \mathrm{~g}, 1.85$ mmol, 1.00 equiv.) and diisopropyl azodicarboxylate ( $0.365 \mathrm{~mL}, 1.85 \mathrm{mmol}, 1.00$ equiv.). The product was purified by column chromatography using hexane/EtOAc (5:1) to obtain 91 as a yellow oil $(0.35 \mathrm{~g}, 41 \%) .{ }^{1} \mathrm{H}$ NMR $\left(500 \mathrm{MHz}, \mathrm{CDCl}_{3}\right) \delta=7.78(\mathrm{~d}, J=8.8,1 \mathrm{H}), 7.41-7.30(\mathrm{~m}$, $3 \mathrm{H}), 6.81(\mathrm{~d}, J=2.5,1 \mathrm{H}), 6.68(\mathrm{dd}, J=8.8,2.5,1 \mathrm{H}), 4.76(\mathrm{~s}, 2 \mathrm{H}), 4.34(\mathrm{q}, J=7.1,2 \mathrm{H}), 3.34-$ $3.27(\mathrm{~m}, 1 \mathrm{H}), 1.43(\mathrm{~d}, J=6.9,6 \mathrm{H}), 1.37(\mathrm{t}, J=7.1,3 \mathrm{H}) .{ }^{13} \mathrm{C} \mathrm{NMR}\left(126 \mathrm{MHz}, \mathrm{CDCl}_{3}\right) \delta=176.74$, $165.19,161.02,159.15,135.90,135.77,133.32,131.54,128.31,127.90,122.75,116.95$, 113.26, 108.71, 61.35, 59.83, 27.27, 20.96, 14.38. MS (ESI+): $m / z 490.00\left([\mathrm{M}+\mathrm{Na}]^{+}\right)$.

(4-((5-Isopropyl-3-phenylisoxazol-4-yl)methoxy)phenyl)methanol (92):

Preparation according to general procedure E using ethyl 4-((5-isopropyl-3-phenylisoxazol-4yl)methoxy)benzoate (88, $0.49 \mathrm{~g}, 1.3 \mathrm{mmol}, 1.0$ equiv.) and diisobutylaluminium hydride (4.0 $\mathrm{mL}, 4.0 \mathrm{mmol}, 3.0$ equiv.) to yield 92 as a yellow oil $(0.41 \mathrm{~g}, 95 \%)$ which was used without further purification. ${ }^{1} \mathrm{H}$ NMR $\left(500 \mathrm{MHz}, \mathrm{CDCl}_{3}\right) \delta=7.73-7.67(\mathrm{~m}, 2 \mathrm{H}), 7.46-7.40(\mathrm{~m}, 3 \mathrm{H})$, $7.32(\mathrm{~d}, J=8.6 \mathrm{~Hz}, 2 \mathrm{H}), 6.97-6.92(\mathrm{~m}, 2 \mathrm{H}), 4.85(\mathrm{~s}, 2 \mathrm{H}), 4.65(\mathrm{~s}, 2 \mathrm{H}), 3.33-3.21(\mathrm{~m}, 1 \mathrm{H})$, $1.39(\mathrm{~d}, J=7.0 \mathrm{~Hz}, 6 \mathrm{H}) .{ }^{13} \mathrm{C} \mathrm{NMR}\left(126 \mathrm{MHz}, \mathrm{CDCl}_{3}\right) \delta=177.60,163.00,157.97,134.13$, $129.83,129.09,129.02,128.88,128.53,115.22,107.76,65.10,59.36,26.99,21.02$. MS $\left(\mathrm{ESI}^{+}\right): \mathrm{m} / \mathrm{z} 346.09\left([\mathrm{M}+\mathrm{Na}]^{+}\right)$.

(4-((3-(2-Chlorophenyl)-5-isopropylisoxazol-4-yl)methoxy)phenyl)methanol (93):

Preparation according to general procedure E using ethyl 4-((3-(2-chlorophenyl)-5isopropylisoxazol-4-yl)methoxy)benzoate $(89,0.58 \mathrm{~g}, 1.4 \mathrm{mmol}, 1.0$ equiv.) and diisobutylaluminium hydride $(3.0 \mathrm{~mL}, 3.0 \mathrm{mmol}, 2.1$ equiv.) to yield 93 as a yellow oil $(0.50 \mathrm{~g}$, $96 \%)$ which was used without further purification. ${ }^{1} \mathrm{H} \mathrm{NMR}\left(500 \mathrm{MHz}, \mathrm{CDCl}_{3}\right) \delta=7.50-7.44$ (m, 2H), 7.40 (td, $J=7.7,1.8 \mathrm{~Hz}, 1 \mathrm{H}), 7.34(\mathrm{td}, J=7.5,1.3 \mathrm{~Hz}, 1 \mathrm{H}), 7.25-7.21(\mathrm{~m}, 2 \mathrm{H}), 6.79$ $-6.74(\mathrm{~m}, 2 \mathrm{H}), 4.78(\mathrm{~s}, 2 \mathrm{H}), 4.59(\mathrm{~s}, 2 \mathrm{H}), 3.32$ (hept, $J=7.0 \mathrm{~Hz}, 1 \mathrm{H}), 1.41(\mathrm{~d}, J=7.0 \mathrm{~Hz}, 6 \mathrm{H})$. ${ }^{13} \mathrm{C}$ NMR $\left(126 \mathrm{MHz}, \mathrm{CDCl}_{3}\right) \delta=176.77,161.38,157.90,133.87,133.66,131.98,131.07$, $\left.130.00,128.72,128.51,127.07,114.99,109.47,65.08,59.76,27.23,20.88 . \mathrm{MS}_{(\mathrm{ESI}}{ }^{+}\right): \mathrm{m} / \mathrm{z}$ $380.08\left([\mathrm{M}+\mathrm{Na}]^{+}\right)$.

(4-((3-(2,6-Dichlorophenyl)-5-isopropylisoxazol-4-yl)methoxy)phenyl)methanol (94):

Preparation according to general procedure E using ethyl 4-((3-(2,6-dichlorophenyl)-5isopropylisoxazol-4-yl)methoxy)benzoate $(90,0.61 \mathrm{~g}, 1.4 \mathrm{mmol}, 1.0$ equiv.) and diisobutylaluminium hydride $(3.9 \mathrm{~mL}, 3.9 \mathrm{mmol}, 2.8$ equiv.) to yield 94 as a yellow oil $(0.51 \mathrm{~g}$, $98 \%)$ which was used without further purification. ${ }^{1} \mathrm{H} \mathrm{NMR}\left(500 \mathrm{MHz}, \mathrm{CDCl}_{3}\right) \delta=7.42-7.38$ (m, 2H), $7.34-7.29(\mathrm{~m}, 1 \mathrm{H}), 7.22(\mathrm{~d}, J=8.5 \mathrm{~Hz}, 2 \mathrm{H}), 6.76(\mathrm{~d}, J=8.6 \mathrm{~Hz}, 2 \mathrm{H}), 4.72(\mathrm{~s}, 2 \mathrm{H})$, $4.59(\mathrm{~s}, 2 \mathrm{H}), 3.33$ (hept, $J=7.0 \mathrm{~Hz}, 1 \mathrm{H}), 1.41(\mathrm{~d}, J=7.0 \mathrm{~Hz}, 6 \mathrm{H}) \cdot{ }^{13} \mathrm{C}$ NMR $\left(126 \mathrm{MHz}, \mathrm{CDCl}_{3}\right)$ $\delta=176.50,159.25,157.97,135.94,133.85,131.35,128.68,128.23,128.01,114.95,109.52$, 65.07, 59.53, 27.23, 20.92. MS $\left(\mathrm{ESI}^{+}\right): \mathrm{m} / \mathrm{z} 414.03\left([\mathrm{M}+\mathrm{Na}]^{+}\right)$.

(2-Chloro-4-((3-(2,6-dichlorophenyl)-5-isopropylisoxazol-4-yl)methoxy)phenyl)methanol (95): Preparation according to general procedure E using ethyl 2-chloro-4-((3-(2,6-dichlorophenyl)5-isopropylisoxazol-4-yl)methoxy)benzoate $(91,0.35 \mathrm{~g}, 0.75 \mathrm{mmol}, 1.00$ equiv.) and diisobutylaluminium hydride $(2.3 \mathrm{~mL}, 2.3 \mathrm{mmol}, 3.1$ equiv.) to yield 95 as colorless solid $(0.31$ $\mathrm{g}, 98 \%)$ which was used without further purification. ${ }^{1} \mathrm{H} \mathrm{NMR}\left(500 \mathrm{MHz}\right.$, DMSO- $\left.d_{6}\right) \delta=7.66-$ $7.50(\mathrm{~m}, 3 \mathrm{H}), 7.34(d, J=8.5 \mathrm{~Hz}, 1 \mathrm{H}), 6.83(\mathrm{~d}, J=2.5 \mathrm{~Hz}, 1 \mathrm{H}), 6.73(\mathrm{dd}, J=8.5,2.5 \mathrm{~Hz}, 1 \mathrm{H})$, 
$4.83(\mathrm{~s}, 2 \mathrm{H}), 4.43(\mathrm{~s}, 2 \mathrm{H}), 3.49-3.42(\mathrm{~m}, 1 \mathrm{H}), 1.32(\mathrm{~d}, J=7.0 \mathrm{~Hz}, 6 \mathrm{H}) .{ }^{13} \mathrm{C} \mathrm{NMR}(126 \mathrm{MHz}$, DMSO- $\left.d_{6}\right) \delta=176.57,158.85,157.93,136.67,136.24,131.78,130.32,128.73,128.32$, 127.86, 115.25, 108.98, 63.81, 59.33, 29.12, 19.87. MS (ESI+): $m / z 425.97\left([\mathrm{M}+\mathrm{H}]^{+}\right)$.

Ethyl 4-((4-((5-isopropyl-3-phenylisoxazol-4-yl)methoxy)benzyl)oxy)benzoate (96):

Preparation according to general procedure $\mathrm{F}$ using (4-((5-isopropyl-3-phenylisoxazol-4yl)methoxy)phenyl)methanol ( $92,0.20 \mathrm{~g}, 0.62 \mathrm{mmol}, 1.0$ equiv.), ethyl 4-hydroxybenzoate (67, $0.10 \mathrm{~g}, 0.62 \mathrm{mmol}, 1.0$ equiv.), triphenylphosphine $(0.16 \mathrm{~g}, 0.62 \mathrm{mmol}, 1.0$ equiv.) and diisopropyl azodicarboxylate $(0.12 \mathrm{~mL}, 0.62 \mathrm{mmol}, 1.0$ equiv.). The product was purified by column chromatography using hexane/EtOAc (7:1) to obtain 96 as a yellow oil $(0.11 \mathrm{~g}, 38 \%)$. ${ }^{1} \mathrm{H}$ NMR $\left(500 \mathrm{MHz}, \mathrm{CDCl}_{3}\right) \delta=8.03-7.98(\mathrm{~m}, 2 \mathrm{H}), 7.72-7.67(\mathrm{~m}, 2 \mathrm{H}), 7.46-7.37(\mathrm{~m}, 5 \mathrm{H})$, $7.00-6.95(\mathrm{~m}, 4 \mathrm{H}), 5.06(\mathrm{~s}, 2 \mathrm{H}), 4.85(\mathrm{~s}, 2 \mathrm{H}), 4.35(\mathrm{q}, J=7.1 \mathrm{~Hz}, 2 \mathrm{H}), 3.32-3.21(\mathrm{~m}, 1 \mathrm{H})$, $1.41-1.36(\mathrm{~m}, 9 \mathrm{H}) .{ }^{13} \mathrm{C} \mathrm{NMR}\left(126 \mathrm{MHz}, \mathrm{CDCl}_{3}\right) \delta=177.65,166.51,163.00,162.52,158.39$, $131.71,129.85,129.55,129.34,129.08,129.04,128.52,123.31,115.31,114.53,107.68$, 69.92, 60.82, 59.36, 27.00, 21.03, 14.53. MS (ESI $): m / z 494.30\left([\mathrm{M}+\mathrm{Na}]^{+}\right)$.

Ethyl 2-(4-((4-((5-isopropyl-3-phenylisoxazol-4-yl)methoxy)benzyl)oxy)phenyl)acetate (97):

Preparation according to general procedure F using (4-((5-isopropyl-3-phenylisoxazol-4yl)methoxy)phenyl)methanol (92, $0.15 \mathrm{~g}, \quad 0.46 \mathrm{mmol}, \quad 1.0$ equiv.), ethyl 2-(4hydroxyphenyl)acetate $(68,83 \mathrm{mg}, 0.46 \mathrm{mmol}, 1.0$ equiv.), triphenylphosphine $(0.12 \mathrm{~g}, 0.46$ mmol, 1.0 equiv.) and diisopropyl azodicarboxylate $(93 \mu \mathrm{L}, 0.46 \mathrm{mmol}, 1.0$ equiv.). The product was purified by column chromatography using hexane/EtOAc (8:1) to obtain 97 as a colorless oil (75 mg, 34\%). ${ }^{1} \mathrm{H} \mathrm{NMR}\left(500 \mathrm{MHz}, \mathrm{CDCl}_{3}\right) \delta=7.72-7.68(\mathrm{~m}, 2 \mathrm{H}), 7.46-7.41(\mathrm{~m}, 3 \mathrm{H}), 7.38$ (d, $J=8.6 \mathrm{~Hz}, 2 \mathrm{H}), 7.21(\mathrm{~d}, J=8.6 \mathrm{~Hz}, 2 \mathrm{H}), 6.99-6.91(\mathrm{~m}, 4 \mathrm{H}), 4.99(\mathrm{~s}, 2 \mathrm{H}), 4.85(\mathrm{~s}, 2 \mathrm{H})$, 4.15 (q, $J=7.1 \mathrm{~Hz}, 2 \mathrm{H}$ ), 3.55 (s, 2H), 3.26 (hept, $J=7.0 \mathrm{~Hz}, 1 \mathrm{H}$ ), 1.39 (d, $J=7.0 \mathrm{~Hz}, 6 \mathrm{H}$ ), 1.25 $(\mathrm{t}, J=7.1 \mathrm{~Hz}, 3 \mathrm{H}) .{ }^{13} \mathrm{C}$ NMR $\left(126 \mathrm{MHz}, \mathrm{CDCl}_{3}\right) \delta=177.64,172.09,163.01,158.23,158.01$, $130.45,130.09,129.84,129.48,129.09,129.04,128.53,126.67,115.24,115.03,107.73$, 69.82, 60.96, 59.35, 40.67, 27.00, 21.03, 14.34. MS (ESI $\left.{ }^{+}\right): m / z 508.26\left([\mathrm{M}+\mathrm{Na}]^{+}\right)$.

Ethyl 3-(4-((4-((5-isopropyl-3-phenylisoxazol-4-yl)methoxy)benzyl)oxy)phenyl)propanoate (98):

Preparation according to general procedure $\mathrm{F}$ using (4-((5-isopropyl-3-phenylisoxazol-4yl)methoxy)phenyl)methanol (92, $0.22 \mathrm{~g}, \quad 0.67 \mathrm{mmol}, \quad 1.0$ equiv.), ethyl 3-(4hydroxyphenyl)propanoate $(69,0.13 \mathrm{~g}, 0.67 \mathrm{mmol}, 1.0$ equiv.), triphenylphosphine $(0.18 \mathrm{~g}$, $0.67 \mathrm{mmol}, 1.0$ equiv.) and diisopropyl azodicarboxylate $(0.13 \mathrm{~mL}, 0.67 \mathrm{mmol}, 1.0$ equiv.). The product was purified by column chromatography using hexane/EtOAc (7:1) to obtain 98 as a yellow oil $(0.11 \mathrm{~g}, 33 \%) .{ }^{1} \mathrm{H}$ NMR $\left(500 \mathrm{MHz}, \mathrm{CDCl}_{3}\right) \delta=7.72-7.68(\mathrm{~m}, 2 \mathrm{H}), 7.45-7.41(\mathrm{~m}$, $3 \mathrm{H}), 7.40-7.36(\mathrm{~m}, 2 \mathrm{H}), 7.13(\mathrm{~d}, J=8.6 \mathrm{~Hz}, 2 \mathrm{H}), 6.99-6.95(\mathrm{~m}, 2 \mathrm{H}), 6.93-6.87(\mathrm{~m}, 2 \mathrm{H})$, $4.98(\mathrm{~s}, 2 \mathrm{H}), 4.85(\mathrm{~s}, 2 \mathrm{H}), 4.13(\mathrm{q}, J=7.1 \mathrm{~Hz}, 2 \mathrm{H}), 3.32-3.21(\mathrm{~m}, 1 \mathrm{H}), 2.90(\mathrm{t}, J=7.8 \mathrm{~Hz}$, 2H), $2.59(\mathrm{t}, J=7.8 \mathrm{~Hz}, 2 \mathrm{H}), 1.39(\mathrm{~d}, J=7.0 \mathrm{~Hz}, 6 \mathrm{H}), 1.24(\mathrm{t}, J=7.2 \mathrm{~Hz}, 3 \mathrm{H}) .{ }^{13} \mathrm{C}$ NMR $(126$ $\left.\mathrm{MHz}, \mathrm{CDCl}_{3}\right) \delta=177.63,173.14,163.01,158.20,157.41,133.12,130.21,129.84,129.47$, $129.44,129.09,129.04,128.53,115.23,114.94,107.73,69.83,60.54,59.35,36.37,30.28$, 27.00, 21.03, 14.37. MS (ESI $)^{+}: m / z 522.16\left([\mathrm{M}+\mathrm{Na}]^{+}\right)$.

Ethyl 3-((4-((5-isopropyl-3-phenylisoxazol-4-yl)methoxy)benzyl)oxy)benzoate (99): 
Preparation according to general procedure $\mathrm{F}$ using (4-((5-isopropyl-3-phenylisoxazol-4yl)methoxy)phenyl)methanol (92, $0.15 \mathrm{~g}, 0.46 \mathrm{mmol}, 1.0$ equiv.), ethyl 3-hydroxybenzoate (75, $76 \mathrm{mg}, 0.46 \mathrm{mmol}, 1.0$ equiv.), triphenylphosphine $(0.12 \mathrm{~g}, 0.46 \mathrm{mmol}, 1.0$ equiv.) and diisopropyl azodicarboxylate ( $93 \mu \mathrm{L}, 0.46 \mathrm{mmol}, 1.0$ equiv.). The product was purified by column chromatography using hexane/EtOAc (8:1) to obtain 99 as a colorless oil $(54 \mathrm{mg}$, 25\%). ${ }^{1} \mathrm{H}$ NMR $\left(500 \mathrm{MHz}, \mathrm{CDCl}_{3}\right) \delta=7.72-7.65(\mathrm{~m}, 4 \mathrm{H}), 7.46-7.33(\mathrm{~m}, 6 \mathrm{H}), 7.16$ (ddd, $J=$ 8.2, 2.5, $1.0 \mathrm{~Hz}, 1 \mathrm{H}), 7.00-6.96(\mathrm{~m}, 2 \mathrm{H}), 5.05(\mathrm{~s}, 2 \mathrm{H}), 4.85(\mathrm{~s}, 2 \mathrm{H}), 4.38(\mathrm{q}, J=7.1 \mathrm{~Hz}, 2 \mathrm{H})$, $3.31-3.22(\mathrm{~m}, 1 \mathrm{H}), 1.43-1.37(\mathrm{~m}, 9 \mathrm{H}) .{ }^{13} \mathrm{C} \mathrm{NMR}\left(126 \mathrm{MHz}, \mathrm{CDCl}_{3}\right) \delta=177.65,166.61$, $163.01,158.84,158.34,131.99,129.85,129.67,129.61,129.56,129.09,129.05,128.53$,

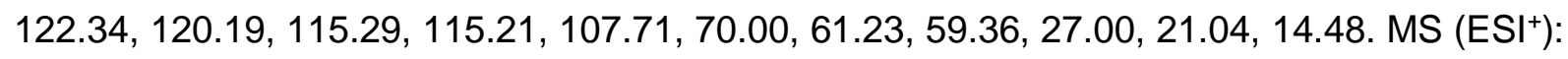
$\mathrm{m} / \mathrm{z} 494.25\left([\mathrm{M}+\mathrm{Na}]^{+}\right)$.

Ethyl 2-(4-((4-((3-(2-chlorophenyl)-5-isopropylisoxazol-4-

yl)methoxy)benzyl)oxy)phenyl)acetate (100):

Preparation according to general procedure $F$ using (4-((3-(2-chlorophenyl)-5isopropylisoxazol-4-yl)methoxy)phenyl)methanol $(93,0.10 \mathrm{~g}, 0.28 \mathrm{mmol}, 1.0$ equiv.), ethyl 2(4-hydroxyphenyl)acetate (68, $50 \mathrm{mg}, 0.28 \mathrm{mmol}, 1.0$ equiv.), triphenylphosphine ( $73 \mathrm{mg}, 0.28$ mmol, 1.0 equiv.) and diisopropyl azodicarboxylate ( $56 \mu \mathrm{L}, 0.28 \mathrm{mmol}, 1.0$ equiv.). The product was purified by column chromatography using hexane/EtOAc (8:1) to obtain 100 as a yellow oil (41 mg, 28\%). ${ }^{1} \mathrm{H}$ NMR (500 MHz, $\left.\mathrm{CDCl}_{3}\right) \delta=7.50-7.44(\mathrm{~m}, 2 \mathrm{H}), 7.40$ (td, $J=7.7,1.8 \mathrm{~Hz}$, $1 \mathrm{H}), 7.33$ (td, $J=7.5,1.2 \mathrm{~Hz}, 1 \mathrm{H}), 7.28(\mathrm{~d}, J=8.6 \mathrm{~Hz}, 2 \mathrm{H}), 7.19(\mathrm{~d}, J=8.6 \mathrm{~Hz}, 2 \mathrm{H}), 6.90$ (d, J $=8.6 \mathrm{~Hz}, 2 \mathrm{H}), 6.78(\mathrm{~d}, J=8.1 \mathrm{~Hz}, 2 \mathrm{H}), 4.94(\mathrm{~s}, 2 \mathrm{H}), 4.79(\mathrm{~s}, 2 \mathrm{H}), 4.14(\mathrm{q}, J=7.1 \mathrm{~Hz}, 2 \mathrm{H}), 3.54$ (s, 2H), $3.37-3.27(\mathrm{~m}, 1 \mathrm{H}), 1.41(\mathrm{~d}, J=7.0 \mathrm{~Hz}, 6 \mathrm{H}), 1.25(\mathrm{t}, J=7.1 \mathrm{~Hz}, 3 \mathrm{H}) .{ }^{13} \mathrm{C}$ NMR $(126$ $\left.\mathrm{MHz}, \mathrm{CDCl}_{3}\right) \delta=176.80,172.09,161.39,158.14,157.99,133.64,131.97,131.08,130.42$, $130.00,129.82$, 129.31, 128.47, 127.08, 126.62, 115.01, 115.00, 109.45, 69.78, 60.95, 59.74, 40.65, 27.23, 20.88, 14.33. MS $\left(\mathrm{ESI}^{+}\right): \mathrm{m} / z 542.23\left([\mathrm{M}+\mathrm{Na}]^{+}\right)$.

Ethyl 2-(4-((4-((3-(2-chlorophenyl)-5-isopropylisoxazol-4yl)methoxy)benzyl)oxy)phenoxy)acetate (101):

Preparation according to general procedure F using (4-((3-(2-chlorophenyl)-5isopropylisoxazol-4-yl)methoxy)phenyl)methanol $(93,0.10 \mathrm{~g}, 0.28 \mathrm{mmol}, 1.0$ equiv.), ethyl 2(4-hydroxyphenoxy)acetate (76, $55 \mathrm{mg}, 0.28 \mathrm{mmol}, 1.0$ equiv.), triphenylphosphine (73 mg, $0.28 \mathrm{mmol}, 1.0$ equiv.) and diisopropyl azodicarboxylate (56 $\mu \mathrm{L}, 0.28 \mathrm{mmol}, 1.0$ equiv.). The product was purified by column chromatography using hexane/EtOAc (7:1) to obtain 101 as a yellow oil (53 mg, 35\%). ${ }^{1} \mathrm{H}$ NMR $\left(500 \mathrm{MHz}, \mathrm{CDCl}_{3}\right) \delta=7.50-7.44(\mathrm{~m}, 2 \mathrm{H}), 7.40(\mathrm{td}, J=7.7$, $1.8 \mathrm{~Hz}, 1 \mathrm{H}), 7.33(\mathrm{td}, J=7.5,1.3 \mathrm{~Hz}, 1 \mathrm{H}), 7.29-7.26(\mathrm{~m}, 2 \mathrm{H}), 6.89-6.83(\mathrm{~m}, 4 \mathrm{H}), 6.80-$ $6.76(\mathrm{~m}, 2 \mathrm{H}), 4.90(\mathrm{~s}, 2 \mathrm{H}), 4.78(\mathrm{~s}, 2 \mathrm{H}), 4.56(\mathrm{~s}, 2 \mathrm{H}), 4.26(\mathrm{q}, J=7.1 \mathrm{~Hz}, 2 \mathrm{H}), 3.32$ (hept, $J=$ $7.0 \mathrm{~Hz}, 1 \mathrm{H}), 1.41(\mathrm{~d}, J=7.0 \mathrm{~Hz}, 6 \mathrm{H}), 1.29(\mathrm{t}, J=7.1 \mathrm{~Hz}, 3 \mathrm{H}) .{ }^{13} \mathrm{C} \mathrm{NMR}\left(126 \mathrm{MHz}, \mathrm{CDCl}_{3}\right) \delta=$ $176.80,169.34,161.40,158.13,153.84,152.35,133.65,131.98,131.09,130.00,129.95$, 129.32, 128.49, 127.09, 115.99, 115.91, 115.00, 109.45, 70.37, 66.46, 61.46, 59.74, 27.24, 20.89, 14.32. MS $\left(\mathrm{ESI}^{+}\right): \mathrm{m} / \mathrm{z} 558.22\left([\mathrm{M}+\mathrm{Na}]^{+}\right)$.

Ethyl 2-(4-((4-((3-(2-chlorophenyl)-5-isopropylisoxazol-4-yl)methoxy)benzyl)oxy)phenyl)-2methylpropanoate (102):

Preparation according to general procedure $F$ using (4-((3-(2-chlorophenyl)-5isopropylisoxazol-4-yl)methoxy)phenyl)methanol $(93,0.10 \mathrm{~g}, 0.28 \mathrm{mmol}, 1.0$ equiv.), ethyl 2- 
(4-hydroxyphenyl)-2-methylpropanoate (78, $58 \mathrm{mg}, 0.28 \mathrm{mmol}, 1.0$ equiv.), triphenylphosphine (73 mg, $0.28 \mathrm{mmol}, 1.0$ equiv.) and diisopropyl azodicarboxylate ( $56 \mu \mathrm{L}, 0.28 \mathrm{mmol}, 1.0$ equiv.). The product was purified by column chromatography using hexane/EtOAc (7:1) to obtain 102 as a yellow oil $(35 \mathrm{mg}, 26 \%) .{ }^{1} \mathrm{H}$ NMR $\left(500 \mathrm{MHz}\right.$, acentone- $\left.d_{6}\right) \delta=7.58(\mathrm{dd}, J=8.0,0.9 \mathrm{~Hz}$, $1 \mathrm{H}), 7.54-7.48(\mathrm{~m}, 2 \mathrm{H}), 7.47-7.43(\mathrm{~m}, 1 \mathrm{H}), 7.35-7.31(\mathrm{~m}, 2 \mathrm{H}), 7.28-7.24(\mathrm{~m}, 2 \mathrm{H}), 6.95$ - $6.91(\mathrm{~m}, 2 \mathrm{H}), 6.87-6.83(\mathrm{~m}, 2 \mathrm{H}), 4.99(\mathrm{~s}, 2 \mathrm{H}), 4.92(\mathrm{~s}, 2 \mathrm{H}), 4.06$ (q, J = 7.1 Hz, 2H), $3.50-$ $3.41(\mathrm{~m}, 1 \mathrm{H}), 1.50(\mathrm{~s}, 6 \mathrm{H}), 1.38(\mathrm{~d}, J=7.0 \mathrm{~Hz}, 6 \mathrm{H}), 1.14(\mathrm{t}, J=7.1 \mathrm{~Hz}, 3 \mathrm{H}) .{ }^{13} \mathrm{C}$ NMR $(126$ $\mathrm{MHz}$, acentone- $\left.d_{6}\right) \delta=177.10,176.82,162.05,158.99,158.41,138.08,133.99,132.72$, 132.10, 131.04, 130.67, 130.08, 129.57, 128.06, 127.53, 115.72, 115.32, 110.55, 70.03, 61.05, $\left.60.25,46.35,27.48,27.00,21.06,14.36 . \mathrm{MS}_{(\mathrm{ESI}}+\right): \mathrm{m} / z 570.15\left([\mathrm{M}+\mathrm{Na}]^{+}\right)$.

Ethyl 2-(4-((4-((3-(2,6-dichlorophenyl)-5-isopropylisoxazol-4-

yl)methoxy)benzyl)oxy)phenyl)acetate (103):

Preparation according to general procedure F using (4-((3-(2,6-dichlorophenyl)-5isopropylisoxazol-4-yl)methoxy)phenyl)methanol $(94,0.15 \mathrm{~g}, 0.38 \mathrm{mmol}, 1.0$ equiv.), ethyl 2(4-hydroxyphenyl)acetate (68, $68 \mathrm{mg}, 0.38 \mathrm{mmol}, 1.0$ equiv.), triphenylphosphine $(0.10 \mathrm{~g}, 0.38$ mmol, 1.0 equiv.) and diisopropyl azodicarboxylate $(75 \mu \mathrm{L}, 0.38 \mathrm{mmol}, 1.0$ equiv.). The product was purified by column chromatography using hexane/EtOAc (7:1) to obtain 103 as a yellow oil $(21 \mathrm{mg}, 10 \%)$. ${ }^{1} \mathrm{H}$ NMR $\left(500 \mathrm{MHz}\right.$, acentone- $\left.d_{6}\right) \delta=7.57-7.49(\mathrm{~m}, 3 \mathrm{H}), 7.34-7.31(\mathrm{~m}$, $2 \mathrm{H}), 7.21-7.18(\mathrm{~m}, 2 \mathrm{H}), 6.94-6.90(\mathrm{~m}, 2 \mathrm{H}), 6.86-6.82(\mathrm{~m}, 2 \mathrm{H}), 4.98(\mathrm{~s}, 2 \mathrm{H}), 4.88(\mathrm{~s}, 2 \mathrm{H})$, 4.08 (q, $J=7.1 \mathrm{~Hz}, 2 \mathrm{H}$ ), 3.54 (s, 2H), 3.48 (hept, $J=7.0 \mathrm{~Hz}, 1 \mathrm{H}$ ), 1.39 (d, $J=7.0 \mathrm{~Hz}, 6 \mathrm{H}$ ), 1.20 $(\mathrm{t}, J=7.1 \mathrm{~Hz}, 3 \mathrm{H}) .{ }^{13} \mathrm{C}$ NMR $\left(126 \mathrm{MHz}\right.$, acentone- $\left.d_{6}\right) \delta=176.89,172.05,159.95,159.05$, $158.78,136.24,132.81,131.13,130.97,130.03$, 129.19, 128.98, 127.72, 115.55, 115.52, $110.69,70.05,60.94,60.05,40.67,27.47,21.10,14.50 . \mathrm{MS}\left(\mathrm{ESI}^{+}\right): \mathrm{m} / z 576.16\left([\mathrm{M}+\mathrm{Na}]^{+}\right)$.

Ethyl 2-(4-((2-chloro-4-((3-(2,6-dichlorophenyl)-5-isopropylisoxazol-4-

yl)methoxy)benzyl)oxy)phenyl)acetate (104):

Preparation according to general procedure F using (2-chloro-4-((3-(2,6-dichlorophenyl)-5isopropylisoxazol-4-yl)methoxy)phenyl)methanol $(95,0.32 \mathrm{~g}, 0.75 \mathrm{mmol}, 1.0$ equiv.), ethyl 2(4-hydroxyphenyl)acetate (68, $0.14 \mathrm{~g}, 0.75 \mathrm{mmol}, 1.0$ equiv.), triphenylphosphine $(0.19 \mathrm{~g}, 0.75$ mmol, 1.0 equiv.) and diisopropyl azodicarboxylate $(0.14 \mathrm{~mL}, 0.75 \mathrm{mmol}, 1.0$ equiv.). The product was purified by column chromatography using hexane/EtOAc (10:1) to obtain 104 as a yellow oil $(0.28 \mathrm{~g}, 64 \%) .{ }^{1} \mathrm{H} \mathrm{NMR}\left(500 \mathrm{MHz}, \mathrm{CDCl}_{3}\right) \delta=7.42-7.29(\mathrm{~m}, 4 \mathrm{H}), 7.20(\mathrm{~d}, J=8.7$, $2 \mathrm{H}), 6.91(\mathrm{~d}, J=8.7,2 \mathrm{H}), 6.81(\mathrm{~d}, J=2.5,1 \mathrm{H}), 6.68(\mathrm{dd}, J=8.5,2.5,1 \mathrm{H}), 5.04(\mathrm{~s}, 2 \mathrm{H}), 4.71$ (s, 2H), 4.14 (q, $J=7.1,2 \mathrm{H}$ ), $3.55(\mathrm{~s}, 2 \mathrm{H}), 3.34-3.27(\mathrm{~m}, 1 \mathrm{H}), 1.42(\mathrm{~d}, J=7.0,6 \mathrm{H}), 1.25$ (t, $J=7.1,3 \mathrm{H}) .{ }^{13} \mathrm{C}$ NMR $\left(126 \mathrm{MHz}, \mathrm{CDCl}_{3}\right) \delta=176.66,172.04,159.22,158.55,157.78,135.93$, $133.75,131.45,130.61,130.47,130.26,128.28,127.47,126.89,115.82,115.07,113.84$, $\left.109.12,67.05,60.96,59.79,40.67,27.27,20.95,14.34 . \mathrm{MS}(\mathrm{ESI})^{+}\right): m / z 582.05\left([\mathrm{M}+\mathrm{Na}]^{+}\right)$.

4-((3-(2,6-Dichlorophenyl)-5-isopropylisoxazol-4-yl)methoxy)benzaldehyde (107):

Preparation according to general procedure $F$ using (3-(2,6-dichlorophenyl)-5isopropylisoxazol-4-yl)methanol (94, $0.28 \mathrm{~g}, 1.0 \mathrm{mmol}, 1.0$ equiv.), 4-hydroxybenzaldehyde (105, $0.12 \mathrm{~g}, 1.0 \mathrm{mmol}, 1.0$ equiv.), triphenylphosphine (0.26 g, $1.0 \mathrm{mmol}, 1.0$ equiv.) and diisopropyl azodicarboxylate $(0.2 \mathrm{~mL}, 1.0 \mathrm{mmol}, 1.0$ equiv.). The product was purified by column chromatography using hexane/EtOAc (5:1) to obtain 107 as a yellow oil $(0.28 \mathrm{~g}, 72 \%)$. ${ }^{1} \mathrm{H}$ NMR $\left(500 \mathrm{MHz}, \mathrm{CDCl}_{3}\right) \delta=9.86(\mathrm{~s}, 1 \mathrm{H}), 7.77(\mathrm{~d}, J=8.7,2 \mathrm{H}), 7.42-7.38(\mathrm{~m}, 2 \mathrm{H}), 7.34-$ 
$7.30(\mathrm{~m}, 1 \mathrm{H}), 6.87(\mathrm{~d}, J=8.7,2 \mathrm{H}), 4.81(\mathrm{~s}, 2 \mathrm{H}), 3.33$ (hept, $J=7.0,1 \mathrm{H}), 1.43(\mathrm{~d}, J=7.0,6 \mathrm{H})$. ${ }^{13} \mathrm{C}$ NMR $\left(126 \mathrm{MHz}, \mathrm{CDCl}_{3}\right) \delta=190.82,176.73,163.22,159.15,135.95,132.04,131.51$, 130.49, 128.31, 127.83, 114.99, 108.85, 59.70, 27.30, 20.95. MS (ESI $\left.{ }^{+}\right): m / z 412.03\left(\left[\mathrm{M}+\mathrm{Na}^{+}\right)\right.$.

Ethyl 2-(4-((4-((3-(2,6-dichlorophenyl)-5-isopropylisoxazol-4-

yl)methoxy)benzyl)amino)phenyl)acetate (110):

4-((3-(2,6-dichlorophenyl)-5-isopropylisoxazol-4-yl)methoxy)benzaldehyde (107, $78 \mathrm{mg}, 0.2$ mmol, 1.0 equiv.), ethyl 2-(4-aminophenyl)acetate (109, $36 \mathrm{mg}, 0.2 \mathrm{mmol}, 1.0$ equiv.) and diethyl 1,4-dihydro-2,6-dimethylpyridine-3,5-dicarboxylate (Hantzsch ester, $0.15 \mathrm{~g}, 0.6 \mathrm{mmol}$, 3.0 equiv.) were dissolved in toluene $(20 \mathrm{~mL})$, molecular sieves $(5 \AA, 1 \mathrm{~g})$ were added, and the reaction mixture was stirred at $70{ }^{\circ} \mathrm{C}$ for $24 \mathrm{~h}$. Aqueous hydrochloric acid $(20 \mathrm{~mL}, 10 \%)$ was then added and the product was extracted with ethyl acetate $(3 \times 30 \mathrm{~mL})$. The combined organic layers were dried over $\mathrm{MgSO}_{4}$ and the solvents were evaporated in vacuo. The product was purified by column chromatography using hexane/EtOAc (5:1) to obtain $\mathbf{1 1 0}$ as a yellow oil (67 mg, 61\%). ${ }^{1} \mathrm{H}$ NMR (500 MHz, $\left.\mathrm{CDCl}_{3}\right) \delta=7.43-7.28(\mathrm{~m}, 7 \mathrm{H}), 6.87(\mathrm{~d}, \mathrm{~J}=8.7,2 \mathrm{H}), 6.61$ (d, J=8.7, 2H), $4.81(\mathrm{~s}, 2 \mathrm{H}), 4.41(\mathrm{~s}, 2 \mathrm{H}), 4.15-4.12(\mathrm{~m}, 2 \mathrm{H}), 3.62(\mathrm{~s}, 2 \mathrm{H}), 3.15-3.07$ (m, $1 \mathrm{H}), 1.28-1.24(\mathrm{~m}, 9 \mathrm{H}) .{ }^{13} \mathrm{C}$ NMR $\left(126 \mathrm{MHz} \mathrm{CDCl}_{3}\right) \delta=176.73,176.43,159.11,158.20$, $149.81,135.95,132.04,131.51,131.38,130.45,128.30,128.25,124.95,114.98,114.89$, $108.84,61.21,59.50,46.00,40.97,29.85,20.95,14.30 . \mathrm{MS}\left(\mathrm{ESI}^{+}\right): \mathrm{m} / z 553.07\left([\mathrm{M}+\mathrm{H}]^{+}\right)$.

Ethyl 2-(4-((4-((3-(2,6-dichlorophenyl)-5-isopropylisoxazol-4-yl)methoxy)benzyl)amino)-2methylphenyl)acetate (111):

4-((3-(2,6-dichlorophenyl)-5-isopropylisoxazol-4-yl)methoxy)benzaldehyde (107, $0.15 \mathrm{~g}, 0.38$ mmol, 1.0 equiv.), ethyl 2-(4-amino-2-methylphenyl)acetate $(74,73 \mathrm{mg}, 0.38 \mathrm{mmol}, 1.0$ equiv.) and diethyl 1,4-dihydro-2,6-dimethylpyridine-3,5-dicarboxylate (Hantzsch ester, $0.29 \mathrm{~g}, 1.14$ mmol, 3.00 equiv.) were dissolved in toluene $(20 \mathrm{~mL})$, molecular sieves $(5 \AA, 2 \mathrm{~g})$ were added, and the reaction mixture was stirred at $70{ }^{\circ} \mathrm{C}$ for $24 \mathrm{~h}$. Aqueous hydrochloric acid $(20 \mathrm{~mL}, 10$ $\%)$ was then added and the product was extracted with ethyl acetate ( $3 \times 30 \mathrm{~mL})$. The combined organic layers were dried over $\mathrm{MgSO}_{4}$ and the solvents were evaporated in vacuo. The product was purified by column chromatography using hexane/EtOAc (5:1) to obtain 111 as a yellow oil $(0.11 \mathrm{~g}, 50 \%)$. ${ }^{1} \mathrm{H}$ NMR $\left(500 \mathrm{MHz}, \mathrm{CDCl}_{3}\right) \delta=7.40-7.37(\mathrm{~m}, 2 \mathrm{H}), 7.32-7.29$ $(\mathrm{m}, 1 \mathrm{H}), 7.20(\mathrm{~d}, J=8.6 \mathrm{~Hz}, 2 \mathrm{H}), 6.99(\mathrm{~d}, J=8.2 \mathrm{~Hz}, 1 \mathrm{H}), 6.73(\mathrm{~d}, J=8.6 \mathrm{~Hz}, 2 \mathrm{H}), 6.53-6.44$ $(\mathrm{m}, 2 \mathrm{H}), 4.71(\mathrm{~s}, 2 \mathrm{H}), 4.20(\mathrm{~s}, 2 \mathrm{H}), 3.50(\mathrm{~s}, 2 \mathrm{H}), 4.12$ (q, J=7.1, 2H), 3.32 (hept, $J=7.1 \mathrm{~Hz}$, $1 \mathrm{H}), 2.22(\mathrm{~s}, 3 \mathrm{H}), 1.41(\mathrm{~d}, J=7.0 \mathrm{~Hz}, 6 \mathrm{H}), 1.24(\mathrm{t}, J=7.1 \mathrm{~Hz}, 3 \mathrm{H}) \cdot{ }^{13} \mathrm{C}$ NMR $\left(126 \mathrm{MHz}, \mathrm{CDCl}_{3}\right)$ $\delta=176.48,172.02,159.24,157.88,138.12,135.95,132.03,131.51,131.35,131.21,131.13$, $130.47,129.59,128.62,128.30,128.23,128.03,115.03,109.51,60.83,59.52,38.64,27.22$, 20.92, 19.96, 14.35. MS (ESI $\left.{ }^{+}\right): m / z 567.29\left([\mathrm{M}+\mathrm{H}]^{+}\right)$. 


\section{Computational Methods}

General. Calculations were conducted in Molecular Operating Environment (MOE, version 2018.0101, Chemical Computing Group Inc. Montreal, QC, Canada) using default settings for each tool/function unless stated otherwise. Amber10:EHT was used as default force field for all calculations.

Flexible alignment. The lead structure 5 (cyan), FXR agonist GW4064 (3, yellow) and PPARס agonist 4 (orange) were prepared using MOE Wash tool: Protonation state dominant at $\mathrm{pH}$ 7; Coordinates Rebuild 3D; Preserved Existing Chirality. Flexible alignment of these three compounds was performed using default settings from MOE Flexible Alignment tool. The topranked alignment is shown.

Docking was performed using X-ray structures of FXR ligand binding domain (PDB code $3 \mathrm{DCT}^{1}$ ) in complex with GW4064 and PPAR 8 ligand binding domain (PDB code 3D5F) in complex with L165,041. Protonation state of the complexes was adjusted using the MOE QuickPrep tool. Redocking of the crystallized ligands resulted in a binding pose with RMSD 0.1178 relative to the crystallized binding mode for GW4064 and RMSD 0.2051 for L165,041 respectively. The compounds were prepared using MOE Wash tool: Protonation state dominant at $\mathrm{pH}$ 7; Coordinates Rebuild 3D; Preserved Existing Chirality. Docking was performed using following settings from the MOE Dock tool: Receptor: Receptor + Solvent; Site: Ligand Atoms; Placement: Triangle Matcher; Score: London dG; Poses: 100; Refinement: Rigid receptor; Refinement Score: GBVIWSA dG; Poses: 10. The highest ranked reasonable binding-mode was used. 


\section{Supplementary References}

(1) Akwabi-Ameyaw, A.; Bass, J. Y.; Caldwell, R. D.; Caravella, J. a.; Chen, L.; Creech, K. L.; Deaton, D. N.; Jones, S. a.; Kaldor, I.; Liu, Y.; et al. Conformationally Constrained Farnesoid X Receptor (FXR) Agonists: Naphthoic Acid-Based Analogs of GW 4064. Bioorganic Med. Chem. Lett. 2008, 18 (15), 4339-4343.

https://doi.org/10.1016/j.bmcl.2008.06.073. 